\title{
Recurrent preeclampsia : prediction, risk counseling and methodological challenges
}

Citation for published version (APA):

Sep, S. J. S. (2010). Recurrent preeclampsia : prediction, risk counseling and methodological challenges. [Doctoral Thesis, Maastricht University]. Datawyse / Universitaire Pers Maastricht. https://doi.org/10.26481/dis.20100408ss

Document status and date:

Published: 01/01/2010

DOI:

$10.26481 /$ dis.20100408ss

Document Version:

Publisher's PDF, also known as Version of record

\section{Please check the document version of this publication:}

- A submitted manuscript is the version of the article upon submission and before peer-review. There can be important differences between the submitted version and the official published version of record.

People interested in the research are advised to contact the author for the final version of the publication, or visit the DOI to the publisher's website.

- The final author version and the galley proof are versions of the publication after peer review.

- The final published version features the final layout of the paper including the volume, issue and page numbers.

Link to publication

\footnotetext{
General rights rights.

- You may freely distribute the URL identifying the publication in the public portal. please follow below link for the End User Agreement:

www.umlib.nl/taverne-license

Take down policy

If you believe that this document breaches copyright please contact us at:

repository@maastrichtuniversity.nl

providing details and we will investigate your claim.
}

Copyright and moral rights for the publications made accessible in the public portal are retained by the authors and/or other copyright owners and it is a condition of accessing publications that users recognise and abide by the legal requirements associated with these

- Users may download and print one copy of any publication from the public portal for the purpose of private study or research.

- You may not further distribute the material or use it for any profit-making activity or commercial gain

If the publication is distributed under the terms of Article $25 \mathrm{fa}$ of the Dutch Copyright Act, indicated by the "Taverne" license above, 


\section{Recurrent preeclampsia}

\section{Prediction, risk counseling and}

\section{methodological challenges}


Vormgeving binnenwerk:

Simone Sep, met ondersteuning van Datawyse, Universitaire Pers Maastricht.

Fotografie:

Cor Sep

Afbeelding:

"Esperanza" door Antonio Sobrino Sampedro \& Mercedes Cano Redondo (beeldenpark 'Een Zee van Staal', Wijk aan Zee).

Vormgeving omslag:

Gilbert Sep

Druk:

Datawyse, Universitaire Pers Maastricht

De uitgave van dit proefschrift werd mede mogelijk gemaakt door:

Grouwels Vastgoed BV te Maastricht

ISBN 9789052789293

Copyright@ 2010, SJS Sep, Maastricht 


\section{Recurrent preeclampsia Prediction, risk counseling and methodological challenges}

\section{PROEFSCHRIFT}

ter verkrijging van de graad van doctor aan de Universiteit Maastricht, op gezag van de Rector Magnificus, Prof. Mr. G.P.M.F. Mols volgens het besluit van het College van Decanen, in het openbaar te verdedigen op 8 april 2010 om 10.00 uur

$$
\text { door }
$$

Simone Johanna Sophia Sep

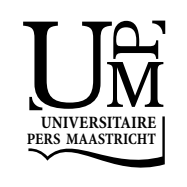




\section{Promotores}

Prof. dr. M.H. Prins

Prof. dr. J.G. Nijhuis

\section{Copromotores}

Dr. L.J.M. Smits

Dr. L.L.H. Peeters

\section{Beoordelingscommissie}

Prof. dr. H. ten Cate (voorzitter)

Prof. dr. G.J. Bonsel (Erasmus MC Rotterdam)

Prof. dr. H.W. Bruinse (UMC Utrecht)

Prof. dr. ir. C.P. van Schayck

Dr. H.C.J. Scheepers 
"The trouble is, if you don't risk anything, you risk even more."

Aan mijn beide oma's 



\section{Contents}

Chapter 1 General Introduction

Part I - Preconception prediction of and counseling for recurrent preeclampsia

Chapter 2 Prediction tests for recurrent hypertensive disease in pregnancy, a systematic review

Chapter 3 Simple prepregnant prediction rule for recurrent early-onset hypertensive disease in pregnancy

Chapter 4 Counseling for recurrent preeclampsia, does obesity matter? 55

Chapter 5 Clinical differences between early-onset HELLP syndrome and early-onset preeclampsia during pregnancy and at least six months postpartum

Chapter 6 Electrocardiographic findings in women with a recent history of preeclampsia with or without the HELLP-syndrome Part II - Early-pregnancy adaptation

Chapter 7 Early-pregnancy adaptation of the maternal lipid profile in recurrent preeclampsia

Chapter 8 Early cardiac adaptation to pregnancy in women with recurrent preeclampsia

\section{Part III - Methodological challenges in predicting} reproductive outcomes

Chapter 9 Collider bias in recurrence risk research: example of obesity and recurrence of preeclampsia

Chapter 10 How long do preconception risk prediction models hold?

Influence of selective fertility on model performance

Chapter 11 General Discussion

Samenvatting

Dankwoord 

CHAPTER 1

General Introduction 


\section{General Introduction}

Human pregnancy involves a complex, highly choreographed sequence of molecular processes. These processes include interactions between the hormonally stimulated endometrium and the developing blastocyst, implantation, a period of placental and fetal development, and a terminal pathway composed of activation of the decidual cells and fetal membranes, myometrial contractility, and cervical ripening. ${ }^{1,2}$ Although the hormonal milieu, metabolic changes, and placental microenvironment are programmed in a compatible manner, pregnancy remains an immunological and hormonal paradox. ${ }^{3}$ Perturbed pre-existing maternal health or altered local environment during the course of pregnancy can lead to pregnancy complications such as preeclampsia.

Preeclampsia occurs in approximately 5 to 8 percent of all pregnancies and is an important cause of maternal and fetal morbidity and mortality worldwide. ${ }^{4}$ The placenta is a prerequisite for its development, as it always dissolves after placental delivery. The syndrome becomes clinically manifest with the development of newonset hypertension, defined as blood pressure of $>140 / 90 \mathrm{~mm} \mathrm{Hg}$ on at least two occasions, 4- 6 weeks apart after 20 weeks gestation, along with proteinuria, defined as excretion of $300 \mathrm{mg}$ of protein or more every $24 \mathrm{~h}^{5}$

A pregnancy-related syndrome linked to preeclampsia is that of hemolysis, elevated liver enzyme levels, and a low platelet count (HELLP). The HELLP syndrome develops in 2 to 12 percent of women with preeclampsia or eclampsia, but can also occur without proteinuria and/or hypertension. ${ }^{6,7}$ Although it is a distinct clinical entity with different risk factors as compared to preeclampsia, many consider it a severe variant of the latter. Actually, their clinical features and symptoms often overlap in clinical practice. ${ }^{6,8}$

Research on preeclampsia was sporadic until about 20 years ago. Since then, both basic and translational research concerning preeclampsia have increased exponentially and, as a result, we now have an abundance of information supporting several plausible hypotheses about its causes, including the contribution of oxidative stress, inflammation, immunologic and circulatory maladaptation, as well as associated humoral, mineral, or metabolic abnormalities. ${ }^{9}$

\section{Pathophysiology of preeclampsia}

The Two Stage Model of the pathophysiology of preeclampsia proposes that a poorly perfused placenta (Stage 1) produces factor(s) triggering the clinical manifestations (Stage 2). ${ }^{10,11}$ Different pathways, fetal and maternal, can lead to the endstage of the disorder. On the one hand, shallow invasion of endovascular and interstitial trophoblast at the maternal-fetal interface has proven to result in failure to 
remodel the maternal spiral arteries. ${ }^{12}$ The spiral arteries do not undergo appropriate remodeling and remain narrow. This is referred to as the fetal pathway in the development of preeclampsia. On the other hand, the maternal pathway is related to thrombosis and atherosis of the spiral arteries, both in conjunction with failed spiral artery remodeling and inadequate compensatory adjustments. ${ }^{13-15}$ In this scenario the spiral arteries may have undergone conversion, but blockage results in deficient utero-placental blood flow. 'Mixed' pathways may be possible as well. In any case, the clinically most prominent features of the disorder seem to originate in the dysfunctional decidua. The end-stage of the placental disorder of preeclampsia is a maternal syndrome defined in terms of disturbances developing in the cardiovascular and renal functions (new-onset hypertension and proteinuria resolving postpartum). The proteinuria is associated with a specific endothelial renal lesion (glomerular endotheliosis), ${ }^{16}$ and there is overwhelming evidence in support of the concept that the hypertension is secondary to diffuse endothelial dysfunction.17 However, the stress response is wider: there are associated changes such as the acute-phase and metabolic responses triggered by systemic inflammation. ${ }^{18}$

Although we know much about the two stages, their linkage in the pathophysiologic model is less clear. It is evident that although reduced placental perfusion seems a prerequisite for preeclampsia to develop, it is clearly not sufficient. As a matter of fact, not all mothers with growth-restricted infants have preeclampsia and vice versa. Some conditions that predispose to preeclampsia (obesity and insulin resistance among othes) are even associated with large infants. In contrast, isolated fetal growth-restriction and preterm delivery appears to be preceded by abnormal implantation. ${ }^{19-21}$ Reduced uteroplacental perfusion thus interacts with maternal constitutional factors, genetic, behavioral and environmental, to result in preeclampsia. $^{22}$

\section{Recurrent preeclampsia, a target for counseling and prediction}

Preeclampsia is considered a disease of nulliparous women, as it is twice as common in primigravidas as in multiparous women. ${ }^{5}$ However, it is well-established that women with a previous pregnancy complicated by preeclampsia are at increased risk of developing the disorder in the next pregnancy. For severely preeclamptic primigravidas, recurrence rates in the next pregnancy are high, reaching up to $50 \%$ in some studies.

Because the disorder is heterogeneous, the pathogenesis may differ in women with diverse risk factors. ${ }^{23}$ For example, in nulliparae the pathogenesis of preeclampsia may differ from that in formerly affected women, and preexisting vascular disease, diabetes, or multiple pregnancies may affect the patholophysiologic pathway. In 
line with this, the risk of recurrent preeclampsia varies depending on underlying mechanism and previous pregnancy outcome.

Preconception counseling and care represents an ideal opportunity to evaluate current or past medical or obstetric complications, thereby minimizing the risk of recurrence in the next gestation. ${ }^{24,25}$ With regard to recurrent preeclampsia, counseling may address issues related to prediction and prevention of recurrence risk, the need for frequent prenatal visits and close fetal surveillance, diagnostic tests to identify underlying predisposing factors, and potential impact on future health. The first step in the management of women with a history of preeclampsia is thus to conduct a detailed evaluation of potential risk factors for preeclampsia prior to a next pregnancy, which may provide clues about the risk of recurrence in a next pregnancy. $^{23}$

The ability to predict or prevent preeclampsia or the development of therapy that safely prolongs gestation would be an important achievement in prenatal care. It could offer clinicians the possibility to identify subclinical preeclampsia early in pregnancy and to provide more tailored care. Underappreciated is the strain that preeclampsia places upon health care resources. It increases the need for artificial preterm birth and neonatal intensive care and predisposes the infants to health problems later in life. Considerable evidence suggests that premature delivery increases the incidence of cardiovascular and metabolic health problems later in life, which themselves create enormous economic health burdens. ${ }^{26}$

Most of the available prediction tests for recurrent preeclampsia are based on a single variable, with disappointing prediction capacity. Preeclampsia is a heterogeneous condition, probably involving several separate pathophysiologic pathways. Therefore, it may be more appropriate to explore combinations of tests performed before and/or during the next pregnancy. ${ }^{23}$

\section{Outline of this thesis}

The aim of this thesis was to address issues regarding prediction of and counseling for recurrent preeclampsia and related methodological challenges. The thesis consists of three parts.

\section{Part I - Preconception prediction of and counseling for recurrent preeclampsia}

Chapter 2 summarizes reported evidence on the performance and clinical usefulness of prediction tests for recurrent hypertensive disease in pregnancy. Although some of the tests have promising predictive potential, their applicability is hampered by statistical imprecision and clinical drawbacks. Therefore, in Chapter $\mathbf{3}$, 
the predictive performance of a new preconception multivariable prediction model for early-onset recurrent preeclampsia and/or HELLP syndrome is evaluated.

In counseling for recurrent preeclampsia, reduction of risk factors often is one of the main objectives. In obese formerly preeclamptic women, this may involve attempts to strive for weight loss. However, it is still unclear whether obesity is really an independent risk factor for recurrent preeclampsia. Chapter $\mathbf{4}$ addresses this question.

HELLP syndrome is often considered a severe form of preeclampsia with overlapping symptoms. However, dissimilarities regarding risk factors have emerged as well. Hypothetically, the pathogeneses of these two syndromes may differ more than currently assumed. Chapter $\mathbf{5}$ gives this hypothesis a more solid scientific basis by evaluating differences in clinical and laboratory variables between former patients who had HELLP syndrome with or without preeclampsia and former patients who had preeclampsia without HELLP.

Chapter 6 determines the value of the electrocardiogram to detect premature or clustering of cardiovascular disease in women with a recent history of preeclampsia, in order to estimate both the prevalence of electrocardiographic abnormalities and their association with recurrent preeclampsia in the next pregnancy.

\section{Part II - Early-pregnancy adaptation}

Although in many cases the pathogenesis of preeclampsia seems to begin early in pregnancy, the disorder does not become clinically manifest before the 20th week. In addition to preconception prediction and counseling, this leaves room for identifying early in the next pregnancy, formerly preeclamptic women at increased risk of developing recurrent disease later on. To this end, in Chapter 7, formerly preeclamptic women with recurrent preeclampsia are compared with their counterparts who do not develop recurrent preeclampsia with respect to the adaptation of the lipid profile to pregnancy. Chapter $\mathbf{8}$ has the same objective but then with respect to the cardiac adaptation to pregnancy.

\section{Part III - Methodological challenges in predicting reproductive outcomes}

Studies on recurrent abnormal pregnancy outcome are becoming increasingly important for the development of evidence-based guidelines in clinical management. However, such studies may be subject to a relatively unknown type of bias, the socalled "collider bias". Collider bias may lead to seriously distorted, even inverted association estimates, as is further discussed and illustrated in Chapter 9.

Chapter $\mathbf{1 0}$ describes another methodological phenomenon, which is specific for preconception prediction models for adverse pregnancy outcome and is caused by 
selective fertility. Selective fertility may affect predictive accuracy when the latter is evaluated after application of the prediction model.

Chapter 11 discusses the main findings described in this thesis. The general discussion provides recommendations for further development and improvement of prediction strategies for recurrent preeclampsia and clinical implications of these strategies. Finally, the conclusions of this thesis are summarized. 


\section{References}

1. Matzuk MM, Burns $\mathrm{KH}$, Viveiros MM, Eppig JJ. Intercellular communication in the mammalian ovary: oocytes carry the conversation. Science 2002;296(5576):2178-80.

2. Paria BC, Reese J, Das SK, Dey SK. Deciphering the cross-talk of implantation: advances and challenges. Science 2002;296(5576):2185-8.

3. Lightner A, Schust DJ, Chen YB, Barrier BF. The fetal allograft revisited: does the study of an ancient invertebrate species shed light on the role of natural killer cells at the maternal-fetal interface? Clin Dev Immunol 2008;2008:631920.

4. Khan KS, Wojdyla D, Say L, Gulmezoglu AM, Van Look PF. WHO analysis of causes of maternal death: a systematic review. The Lancet 2006;367(9516):1066-1074.

5. Report of the National High Blood Pressure Education Program. Working group report on high blood pressure in pregnancy. Am J Obstet Gynecol 2000;183:S1-S22.

6. Barton JR, Sibai BM. Diagnosis and management of hemolysis, elevated liver enzymes, and low platelets syndrome. Clinics in perinatology 2004;31(4):807-833.

7. Baxter JK, Weinstein L. HELLP syndrome: the state of the art. Obstet Gynecol Surv 2004;59(12):838-45.

8. Hay JE. Liver disease in pregnancy. Hepatology 2008;47(3):1067-1076.

9. Davidson NM, Parry EH. Peri-partum cardiac failure. Q J Med 1978;47(188):431-61.

10. Goldman-Wohl DS, Yagel S. Examination of distinct fetal and maternal molecular pathways suggests a mechanism for the development of preeclampsia. J Reprod Immunol 2007;76(1-2):54-60.

11. Roberts JM, Hubel CA. The two stage model of preeclampsia: variations on the theme. Placenta 2009;30 Suppl A:S32-7.

12. Pijnenborg R, Vercruysse L, Hanssens $M$. The uterine spiral arteries in human pregnancy: facts and controversies. Placenta 2006;27(9-10):939-58.

13. Maarek-Charbit M, Corone P. Eisenmenger's syndrome and pregnancy. Arch Mal Coeur Vaiss 1986;79(5):733-40.

14. Saarela T, Jaaskelainen J, Tenhola S, Voutilainen R, Heinonen S. Preeclampsia and androgen receptor gene CAG repeat length: results from both children and women. J Assist Reprod Genet 2005;22(7-8):269-75.

15. Pijnenborg R, Anthony J, Davey DA, Rees A, Tiltman A, Vercruysse L, et al. Placental bed spiral arteries in the hypertensive disorders of pregnancy. Br J Obstet Gynaecol 1991;98(7):648-55.

16. Gaber LW, Spargo BH, Lindheimer MD. Renal pathology in pre-eclampsia. Baillière's Clinical Obstetrics and Gynaecology 1994;8(2):443-468.

17. Roberts JM, Taylor RN, Musci TJ, Rodgers GM, Hubel CA, McLaughlin MK. Preeclampsia: an endothelial cell disorder. Am J Obstet Gynecol 1989;161(5):1200-4.

18. Redman CWG, Sargent IL. Placental Stress and Pre-eclampsia: A Revised View. Placenta 2009;30(Supplement 1):3842.

19. Arias F, Rodriquez L, Rayne SC, Kraus FT. Maternal placental vasculopathy and infection: two distinct subgroups among patients with preterm labor and preterm ruptured membranes. Am J Obstet Gynecol 1993;168(2):585-91.

20. Srinivas SK, Edlow AG, Neff PM, Sammel MD, Andrela CM, Elovitz MA. Rethinking IUGR in preeclampsia: dependent or independent of maternal hypertension? J Perinatol 2009;29(10):680-4.

21. Khong TY, De Wolf F, Robertson WB, Brosens I. Inadequate maternal vascular response to placentation in pregnancies complicated by pre-eclampsia and by small-for-gestational age infants. $\mathrm{Br} J$ Obstet Gynaecol 1986;93(10):1049-59.

22. Roberts JM. Preeclampsia: what we know and what we do not know. Semin Perinatol 2000;24(1):24-8.

23. Barton JR, Sibai BM. Prediction and prevention of recurrent preeclampsia. Obstet Gynecol 2008;112(2):359-72.

24. Dildy GA, 3rd, Belfort MA, Smulian JC. Preeclampsia recurrence and prevention. Semin Perinatol 2007;31(3):13541.

25. Witlin AG. Counseling for women with preeclampsia or eclampsia. Semin Perinatol 1999;23(1):91-8.

26. Lindheimer MD, Umans JG. Explaining and Predicting Preeclampsia. N Engl J Med 2006;355(10):1056-58. 



\section{Part I}

\section{Preconception prediction of and counseling for}

recurrent preeclampsia 



\section{CHAPTER 2}

\section{Prediction tests for}

\section{recurrent hypertensive}

disease in pregnancy,

\section{a systematic review}

Simone Sep, Luc Smits, Martin Prins, Louis Peeters

Hypertension in Pregnancy 2010; in press. 


\section{Abstract}

Objective: to summarize reported evidence on the performance and clinical usefulness of prediction tests for recurrent hypertensive disease in pregnancy.

Methods: A literature search was conducted in MEDLINE/PubMed and EMBASE. Test characteristics were extracted for relevant reports.

Results: Thirty-three of 4,311 articles found met the inclusion criteria. Twenty-four potential predictors were identified. Pre-pregnant plasma volume, uterine-artery blood flow velocity profiles, and combined longitudinal patterns of in-pregnancy laboratory variables had reasonable predictive capacity, but also some practical shortcomings. Confidence intervals were often wide.

Conclusions: Although evidence points to promising predictive accuracy of some tests, immediate applicability is hampered by statistical imprecision and clinical drawbacks. 


\section{Introduction}

Hypertensive disorders in pregnancy are a major cause of maternal mortality worldwide, accounting for approximately $16 \%$ of maternal deaths in Western countries, $9 \%$ in Africa and Asia and over $25 \%$ in Latin America and the Caribbean. ${ }^{1}$ Hypertensive disorders complicate $6 \%$ to $8 \%$ of all pregnancies, and contribute considerably to stillbirth risk and neonatal morbidity and mortality. ${ }^{2}$ Clinical symptoms are preceded by a long subclinical phase, which may even go back to the time of implantation. Neither the trigger nor the cascade of patho-physiologic events afterwards is well understood. ${ }^{2}$ Hypertensive disorders typically occur in the first pregnancy. Pregnant women with uneventful previous pregnancies seldom develop hypertensive disorders. By contrast, women with a history of hypertensive pregnancy disorders are at increased risk for recurrent disease.

The ability to predict the risk of recurrent hypertensive disease in pregnancy would have several advantages. On the one hand, it could offer clinicians the possibility to identify women who require closer surveillance and permit early referral for their treatment as soon as signs or symptoms occur. On the other hand, it would enable the identification of low-risk women who then could be reassured and offered the appropriate regular low-risk care.

Numerous tests have been proposed for the prediction of hypertensive disorders of pregnancy. Most of these tests focus on nulliparous women. ${ }^{3}$ Parous women with a history of hypertensive disorders constitute a patient group far less studied for this purpose. These women, though, are often traumatized by their past experience and anxious for possible recurrent disease in their next pregnancy. ${ }^{4}$ The primary objective of this systematic review was to summarize reported evidence on the performance and clinical usefulness of clinical, biophysical, and biochemical tests for the prediction of recurrent pregnancy-related hypertensive disorders. To our knowledge, this is the first systematic review on this topic.

\section{Methods}

A literature search was conducted in MEDLINE/PubMed and EmBase to identify studies on predictors of the recurrence risk of hypertensive disease in pregnancy. The search was performed in December 2007 and we checked for new articles in May 2008. No limits were set to the years to be covered by the search. Languages were restricted to Dutch, English, French, German, Spanish, Portuguese, and Italian. We used keywords related to hypertensive disorders in pregnancy, recurrent disease, and prediction tests or risk factors (references are made to the online version of the report for the detailed search strategy). Case reports were excluded. Reports of clinical intervention trials were also excluded because these typically do not pro- 
vide any useful information on the prognostic value of patient characteristics (other than the intervention studied). The search results of all search strategies were combined using Endnote version 7.

Titles and abstracts were judged on eligibility by one of the investigators (SS). Potentially relevant reports were retrieved for more detailed evaluation. In case of abstract only publications the authors were contacted for more details. All primary studies evaluating risk factors for and/or predictors of recurrent hypertensive disease in pregnancy were initially included. Any setting was considered eligible. Studies including women who had had pregnancy-induced hypertension, (pre)eclampsia, or the hemolysis, elevated liver enzymes and low platelets (HELLP) syndrome in a previous pregnancy and who established an ongoing ( $>16$ weeks gestation) subsequent pregnancy were considered for inclusion. Case-control studies were excluded because they overestimate predictive test characteristics and do not allow estimation of the screening effectiveness in the general population. ${ }^{5}$ The outcome measures included were recurrence of the following maternal hypertensive pregnancy complications: pregnancy-induced hypertension, (pre)eclampsia or the HELLP syndrome. A distinction was made between early-onset and late-onset disease as defined by the authors. As maternal hypertensive disease is associated with poor placentation, associated with impaired fetal growth, we also included the outcomes growth restriction (birth weight below a cut-off percentile) and low birth weight (birth weight below an absolute threshold). References of retrieved articles and relevant previously published reviews were hand-searched to identify additional studies.

Data were extracted by one reviewer (SS) using a standardized data extraction form. A second reviewer (LS) was consulted in case of doubt. Besides study characteristics that were extracted, the incidences of recurrent hypertensive disease with $95 \%$ confidence intervals were calculated if not reported. Cross tables were constructed to calculate predictive sensitivity and specificity and diagnostic odds ratios with corresponding $95 \%$ confidence intervals. If one or more cells of the cross table did not contain any observation, 0.5 was added to the cells to improve the precision of the predictive accuracy measures. ${ }^{6}$ If the information necessary to construct a $2 \times 2$ table was lacking, the authors were contacted and kindly requested to provide raw data. Results were extracted for all thresholds reported. For studies that resulted in multiple publications, the data of the article reporting the largest sample size were used. We considered pooling predictive sensitivity and specificity statistically, but as explained in the discussion section, calculating summary estimates was contra-indicated.

The assessment of the methodological quality of each study was conducted by one of the investigators (SS). The assessment was based on criteria derived from a quality checklist developed for diagnostic studies (QUADAS). ${ }^{7}$ In adapting this tool, we used an existing protocol for systematic reviews of test accuracy in the prediction of 
preeclampsia. ${ }^{8}$ We assessed study quality by evaluating 1 . patient selection, 2 . inclusion/exclusion criteria, 3. strategy of data collection, 4 . the use of generally accepted definitions for hypertensive disease in pregnancy, 5. verification bias, 6 . pregnancy outcome and test outcome being independent, 7. timing of testing, 8. testing procedure, 9. blinding of test results, 10. procedure of the final diagnose, 11. presentation of inconclusive and/or odd test results, and finally, 12. handling of withdrawals. Quality scores were not used as weights or exclusion criteria, but rather as a subject of discussion.

\section{Results}

Of the 4311 articles identified by the electronic search, 36 studies met the inclusion criteria. Additionally, 34 potentially relevant reports were retrieved from the reference lists, of which two also met the inclusion criteria.

Spaanderman et al. evaluated the same predictors on the same, but updated, cohort in two articles. ${ }^{9,}{ }^{10}$ We considered these results as one study and included the most recent report only. Moreover, the cohort reported on by Heath et al. ${ }^{11}$ was part of the cohort studied by Caritis et al., ${ }^{12}$ the cohort of Fatini et al. ${ }^{13}$ overlapped the cohort evaluated by Mello et al., ${ }^{14}$ and, finally, Trogstad and coworkers reported on the same cohort in two articles. ${ }^{15,16}$ As different prediction tests were evaluated in these six studies, we considered the reports to be independent. In spite of having contacted the authors, we were unable to construct $2 \times 2$ tables for four of the articles selected: Dukler et al. $(2001)^{17}$, Fatini et al. (2006) $)^{13}$, Caritis et al. $(1998)^{12}$, and Van Rijn et al. (2006) ${ }^{18}$. It follows that we were able to evaluate the predictive capacity of tests reported in 33 studies.

Table 1 summarizes characteristics of all studies included in the systematic review. Sample sizes ranged from 23 to 20,285 women. One study reported on a population with a history of pregnancy induced hypertension, 23 studies on populations with a history of preeclampsia and/or eclampsia, and 3 studies on populations with a history of the HELLP syndrome. The study populations in 6 studies consisted of women with mixed obstetric history. The earliest and most recent study appeared in 1973 and in 2007, respectively. The incidence rates of recurrent disease ranged from $16 \%$ to $57 \%$ for pregnancy-induced hypertension, from none to $31 \%$ for preeclampsia and from $3 \%$ to $7 \%$ for HELLP syndrome. The risk of recurrent eclampsia was $4 \%$ and $16 \%$, respectively, in two studies (table 1 ). The prediction tests could be subdivided into three categories: 1 . tests based on anthropometric, demographic and behavior related data; 2 . tests based on obstetric history; and 3. tests related to vascular resistance, endothelial, clotting and immune functions, or uterine blood flow. 
Table 1: Study characteristics for individual studies on predicting recurrent hypertensive disease.

\begin{tabular}{|c|c|c|c|c|c|c|}
\hline $\begin{array}{l}\text { First author } \\
\text { (year) }\end{array}$ & Country & $\mathrm{N}$ & $\begin{array}{l}\text { Obstetric } \\
\text { history }\end{array}$ & Prediction test(s) & $\begin{array}{l}\text { Outcome } \\
\text { subsequent } \\
\text { pregnancy } \\
(95 \%-\mathrm{Cl})\end{array}$ & Population \\
\hline $\begin{array}{l}\text { Aardema } \\
(2000)^{28}\end{array}$ & $\begin{array}{l}\text { The Nether- } \\
\text { lands }\end{array}$ & 87 & $\begin{array}{l}\text { PIH/PE } \\
\text { HELLP }\end{array}$ & $\begin{array}{l}\text { Intra-uterine } \\
\text { demise in previ- } \\
\text { ous pregnancy, } \\
\text { Doppler ultra- } \\
\text { sound screening }\end{array}$ & $\begin{array}{l}\text { PIH/PE: } \\
33 \%(23- \\
43 \%)\end{array}$ & $\begin{array}{l}\text { IN: history of } \\
\text { hypertensive } \\
\text { disorders in } \\
\text { previous } \\
\text { pregnancy, no } \\
\text { current pa- } \\
\text { thology, single- } \\
\text { ton pregnancy }\end{array}$ \\
\hline $\begin{array}{l}\text { Aardenburg } \\
(2003)^{41}\end{array}$ & $\begin{array}{l}\text { The Nether- } \\
\text { lands }\end{array}$ & 83 & $\begin{array}{l}\text { Early- } \\
\text { onset } \\
\text { PE/HELLP }\end{array}$ & $\begin{array}{l}\text { Plasma volume } \\
\text { (at least } 6 \\
\text { months after } \\
\text { i.p.) }\end{array}$ & $\begin{array}{l}\text { PE/HELLP: } \\
25 \%(16- \\
35 \%)\end{array}$ & $\begin{array}{l}\text { IN: history of } \\
\text { early onset } \\
\text { PE/HELLP (<34 } \\
\text { wks) }\end{array}$ \\
\hline $\begin{array}{l}\text { Adelusi } \\
(1986)^{37}\end{array}$ & Nigeria & 64 & $\mathrm{E}$ & $\begin{array}{l}\text { Diastolic blood } \\
\text { pressure (at } \\
\text { booking) }\end{array}$ & $\begin{array}{l}\text { E: } 16 \%(7- \\
25 \%) \\
B W< \\
2000 \mathrm{~g}: 6 \% \\
(0-12 \%)\end{array}$ & $\begin{array}{l}\text { IN: previous } \\
\text { pregnancy } \\
\text { complicated by } \\
\text { eclampsia }\end{array}$ \\
\hline $\begin{array}{l}\text { Basso } \\
(2001)^{21}\end{array}$ & Denmark & 8401 & PE & $\begin{array}{l}\text { Change of } \\
\text { partner, preg- } \\
\text { nancy interval }\end{array}$ & $\begin{array}{l}\text { PE: } 16 \% \\
(15-27 \%)\end{array}$ & $\begin{array}{l}\text { IN: all women } \\
\text { hospitalised } \\
\text { with eclamp- } \\
\text { sia/PE in } \\
\text { Denmark } \\
\text { between } 1980 \\
\text { and } 1994 \text { who } \\
\text { had subse- } \\
\text { quently given } \\
\text { birth } \\
\text { EX: multiple } \\
\text { births, gesta- } \\
\text { tional age } \leq 27 \\
\text { wks, non- } \\
\text { Danish citizens, } \\
\text { pairs where } \\
\text { children had } \\
\text { been given in } \\
\text { adoption. }\end{array}$ \\
\hline $\begin{array}{l}\text { Branch } \\
(2001)^{42}\end{array}$ & USA & 317 & PE & $\begin{array}{l}\text { Antiphospholipid } \\
\text { and anticardi- } \\
\text { olipin antibodies } \\
\text { (13-26 wks of } \\
\text { t.p.) }\end{array}$ & $\begin{array}{l}\text { PE: 20\% } \\
(15-24 \%) \\
\text { FGR: 6\% (3- } \\
8 \%)\end{array}$ & $\begin{array}{l}\text { IN: women } \\
\text { with PE in a } \\
\text { previous } \\
\text { pregnancy who } \\
\text { were being } \\
\text { followed-up in } \\
\text { a treatment }\end{array}$ \\
\hline
\end{tabular}


Table 1 continued

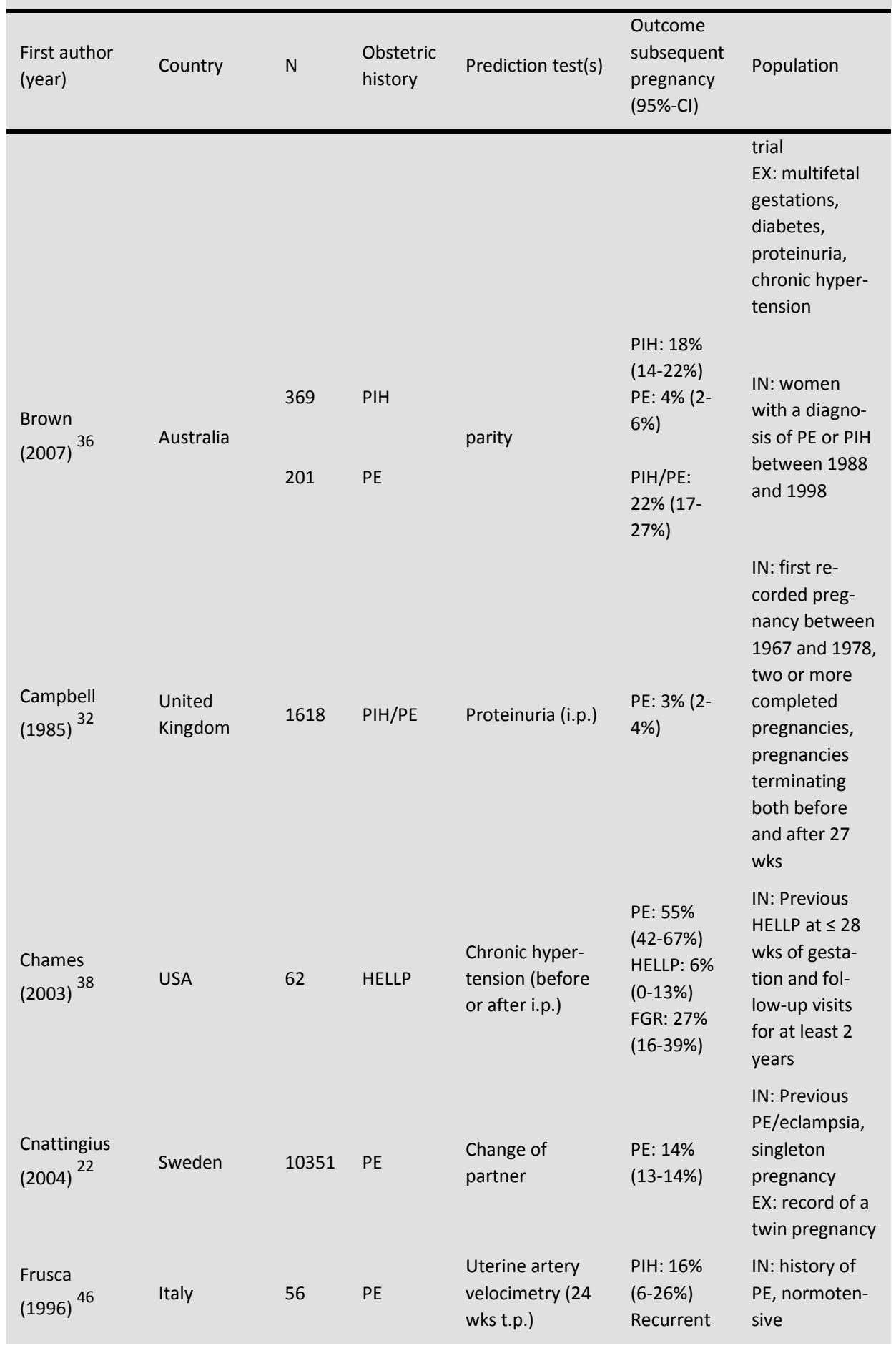


Table 1 continued.

\begin{tabular}{|c|c|c|c|c|c|c|}
\hline $\begin{array}{l}\text { First author } \\
\text { (year) }\end{array}$ & Country & $\mathrm{N}$ & $\begin{array}{l}\text { Obstetric } \\
\text { history }\end{array}$ & Prediction test(s) & $\begin{array}{l}\text { Outcome } \\
\text { subsequent } \\
\text { pregnancy } \\
(95 \%-\mathrm{Cl})\end{array}$ & Population \\
\hline & & & & & $\begin{array}{l}\text { PE: } 5 \%(0- \\
11 \%) \\
\text { FGR: } 23 \% \\
(12-34 \%)\end{array}$ & \\
\hline $\begin{array}{l}\text { Gudnasson } \\
(2004)^{34}\end{array}$ & Sweden & 139 & PE & $\begin{array}{l}\text { Uterine artery } \\
\text { Doppler (i.p.), } \\
\text { parity }\end{array}$ & $\begin{array}{l}\text { PE: } 31 \% \\
(23-39 \%)\end{array}$ & $\begin{array}{l}\text { IN: previous } \\
\text { PE, pregnancy } \\
\text { evaluated by } \\
\text { Doppler }\end{array}$ \\
\hline $\begin{array}{l}\text { Hargood } \\
(1991)^{33}\end{array}$ & Australia & 140 & $\mathrm{PIH} / \mathrm{PE}$ & $\begin{array}{l}\text { Proteinuria in } \\
\text { previous preg- } \\
\text { nancy }\end{array}$ & $\begin{array}{l}\text { PIH: } 45 \% \\
\text { (37-53\%) } \\
\text { PE: } 2 \%(0- \\
5 \%)\end{array}$ & $\begin{array}{l}\text { IN: nulliparous, } \\
\text { normotensive } \\
\text { women, no } \\
\text { history of } \\
\text { hypertension } \\
\text { or renal dis- } \\
\text { ease, subse- } \\
\text { quent preg- } \\
\text { nancy }\end{array}$ \\
\hline $\begin{array}{l}\text { Hauth } \\
(1998)^{11}\end{array}$ & USA & 259 & PE & $\begin{array}{l}\text { Thromboxane B2 } \\
\text { reduction ( } 24-28 \\
\text { wks and/or } 34- \\
34 \text { wks of t.p.) }\end{array}$ & $\begin{array}{l}\text { PE: } 19 \% \\
(15-24 \%)\end{array}$ & $\begin{array}{l}\text { IN: PE in a } \\
\text { previous } \\
\text { pregnancy who } \\
\text { participated in } \\
\text { a treatment } \\
\text { trial }\end{array}$ \\
\hline $\begin{array}{l}\text { Hjartardottir } \\
(2004){ }^{25}\end{array}$ & Iceland & $\begin{array}{l}468 \\
146\end{array}$ & $\begin{array}{l}\text { PIH } \\
\text { PE }\end{array}$ & $\begin{array}{l}\text { Change of } \\
\text { partner }\end{array}$ & $\begin{array}{l}\text { PIH/PE: } \\
66 \%(62- \\
71 \%) \\
\text { PIH/PE: } \\
56 \%(48- \\
64 \%)\end{array}$ & $\begin{array}{l}\text { IN: de-novo } \\
\text { hypertension } \\
\text { during previ- } \\
\text { ous pregnancy, } \\
2 \text { pregnancies, } \\
\text { family history } \\
\text { of PIH/PE } \\
\text { EX: chronic } \\
\text { hypertension }\end{array}$ \\
\hline $\begin{array}{l}\text { Hjartardottir } \\
(2006){ }^{19}\end{array}$ & Iceland & $\begin{array}{l}511 \\
151\end{array}$ & $\begin{array}{l}\text { PIH } \\
\text { PE }\end{array}$ & $\begin{array}{l}\text { Overweight } \\
\text { (before i. p.), } \\
\text { weight gain } \\
\text { (between preg- } \\
\text { nancies), onset } \\
\text { of hypertension } \\
\text { (i.p.) }\end{array}$ & $\begin{array}{l}\text { PIH: } 47 \% \\
\text { (42-51\%) } \\
\text { PE: 7\% (5- } \\
10 \%) \\
\text { PIH: } 34 \% \\
(27-42 \%) \\
\text { PE: } 13 \% \text { (8- } \\
19 \%)\end{array}$ & $\begin{array}{l}\text { IN: } \geq 2 \text { single- } \\
\text { ton births, } \\
\text { hypertensive } \\
\text { disease in the } \\
\text { first pregnancy } \\
\text { EX: hyperten- } \\
\text { sion due to } \\
\text { renal or vascu- } \\
\text { lar diseases }\end{array}$ \\
\hline
\end{tabular}


Table 1 continued.

\begin{tabular}{|c|c|c|c|c|c|c|}
\hline $\begin{array}{l}\text { First author } \\
\text { (year) }\end{array}$ & Country & $\mathrm{N}$ & $\begin{array}{l}\text { Obstetric } \\
\text { history }\end{array}$ & Prediction test(s) & $\begin{array}{l}\text { Outcome } \\
\text { subsequent } \\
\text { pregnancy } \\
(95 \%-\mathrm{Cl})\end{array}$ & Population \\
\hline $\begin{array}{l}\mathrm{Li} \\
(2000)^{23}\end{array}$ & USA & 2833 & PE & $\begin{array}{l}\text { Change of } \\
\text { partner }\end{array}$ & $\begin{array}{l}\text { PE: } 9 \%(8- \\
10 \%)\end{array}$ & $\begin{array}{l}\text { IN: two con- } \\
\text { secutive single- } \\
\text { ton births, PE } \\
\text { in the first } \\
\text { pregnancy }\end{array}$ \\
\hline $\begin{array}{l}\text { Lie } \\
(1998)^{24}\end{array}$ & Norway & 12869 & PE & $\begin{array}{l}\text { Change of } \\
\text { partner }\end{array}$ & $\begin{array}{l}\text { PE: } 13 \% \\
(13-14 \%)\end{array}$ & $\begin{array}{l}\text { IN: more than } \\
16 \text { wks of } \\
\text { completed } \\
\text { gestation, } \\
\text { complicated by } \\
\text { PE, subsequent } \\
\text { pregnancy }\end{array}$ \\
\hline $\begin{array}{l}\text { López-Llera } \\
\text { (1974) }^{27}\end{array}$ & Mexcio & 110 & $E$ & $\begin{array}{l}\text { Onset of } \\
\text { eclampsia (i.p.) }\end{array}$ & $\begin{array}{l}\text { PE: } 35 \% \\
(27-24 \%)\end{array}$ & $\begin{array}{l}\text { IN: subsequent } \\
\text { pregnancy } \\
\text { after eclampsia } \\
\text { with convul- } \\
\text { sions }\end{array}$ \\
\hline $\begin{array}{l}\text { Makkonen } \\
(2000)^{20}\end{array}$ & Finland & 144 & PE & $\begin{array}{l}\text { Age, BMI (before } \\
\text { t.p.), pregnancy } \\
\text { interval, intra- } \\
\text { uterine death } \\
\text { (before t.p.) }\end{array}$ & $\begin{array}{l}\text { PE: } 15 \%(9- \\
20 \%)\end{array}$ & $\begin{array}{l}\text { IN: singleton } \\
\text { birth beyond } \\
24 \text { wks, primi- } \\
\text { parous, second } \\
\text { delivery } \\
\text { EX: structural } \\
\text { or chromoso- } \\
\text { mal abnormali- } \\
\text { ties }\end{array}$ \\
\hline $\begin{array}{l}\text { Mello } \\
(2001)\end{array}$ & Italy & 187 & PE & $\begin{array}{l}\text { Logit model: } \\
\text { parity, age, } \\
\text { number of } \\
\text { abortions, urea, } \\
\text { creatinine, total } \\
\text { proteins uric } \\
\text { acid hematocrit } \\
\text { (longitudinal } \\
\text { pattern 9-20 wks } \\
\text { of t.p.) }\end{array}$ & $\begin{array}{l}\text { PE: } 25 \% \\
(18-31 \%)\end{array}$ & $\begin{array}{l}\text { IN: Pregnant } \\
\text { women with a } \\
\text { history of PE, } \\
\text { whites, nor- } \\
\text { motensive, } \\
\text { absence of } \\
\text { proteinuria, } \\
\text { absenece of } \\
\text { chronic renal } \\
\text { and major } \\
\text { systemic } \\
\text { diseases, body } \\
\text { mass index < } \\
26\end{array}$ \\
\hline Mello & Italy & 106 & PE & $\begin{array}{l}\text { ACE I/D poly- } \\
\text { morphism }\end{array}$ & $\begin{array}{l}\text { PE: } 16 \% \text { (9- } \\
23 \%)\end{array}$ & $\begin{array}{l}\text { IN: history of } \\
\text { PE }\end{array}$ \\
\hline
\end{tabular}


Table 1 continued.

\begin{tabular}{|c|c|c|c|c|c|c|}
\hline $\begin{array}{l}\text { First author } \\
\text { (year) }\end{array}$ & Country & $\mathrm{N}$ & $\begin{array}{l}\text { Obstetric } \\
\text { history }\end{array}$ & Prediction test(s) & $\begin{array}{l}\text { Outcome } \\
\text { subsequent } \\
\text { pregnancy } \\
(95 \%-\mathrm{Cl})\end{array}$ & Population \\
\hline$(2003)^{14}$ & & & & & $\begin{array}{l}\text { FGR: } 29 \% \\
(21-38 \%)\end{array}$ & $\begin{array}{l}\text { EX: kidney } \\
\text { disease, car- } \\
\text { diovascular } \\
\text { pathology, pre- } \\
\text { existing diabe- } \\
\text { tes, thrombo- } \\
\text { philic abnor- } \\
\text { maltities }\end{array}$ \\
\hline $\begin{array}{l}\text { Morris } \\
(1998)^{45}\end{array}$ & Australia & 50 & PE & $\begin{array}{l}\text { Uterine artery } \\
\text { waveform (18th } \\
\text { wk of t.p.) }\end{array}$ & $\begin{array}{l}\text { PE: } 26 \%(8- \\
44 \%)\end{array}$ & $\begin{array}{l}\text { IN: pregnant } \\
\text { women with } \\
\text { second trimes- } \\
\text { ter PE in a } \\
\text { previous } \\
\text { pregnancy }\end{array}$ \\
\hline $\begin{array}{l}\text { Patterson } \\
(1986)^{29}\end{array}$ & USA & 539 & $\mathrm{PIH}$ & FGR (i.p.) & $\begin{array}{l}\text { PIH: } 17 \% \\
(14-21 \%) \\
\text { FGR: } 12 \% \\
(9-15 \%)\end{array}$ & $\begin{array}{l}\text { IN: Hispanic } \\
\text { surname, two } \\
\text { singleton live } \\
\text { born infants } \\
\text { without } \\
\text { anomalies of } \geq \\
26 \text { wks' gesta- } \\
\text { tional age }\end{array}$ \\
\hline $\begin{array}{l}\text { Rasmussen } \\
(2000)^{30}\end{array}$ & Norway & 12489 & PE & $\begin{array}{l}\text { Birth weight, } \\
\text { birth weight } \\
\text { centile (i.p.) }\end{array}$ & $\begin{array}{l}\text { PE: } 14 \% \\
(13-14 \%)\end{array}$ & $\begin{array}{l}\text { IN: gestational } \\
\text { age } \geq 16 \text { wks } \\
\text { EX: only one } \\
\text { pregnancy } \\
\text { between } 1967 \\
\text { and 1992, first } \\
\text { delivery before } \\
1967, \text { no } \\
\text { information } \\
\text { about last day } \\
\text { of last men- } \\
\text { strual period }\end{array}$ \\
\hline & & & & & $\begin{array}{l}E: 4 \%(1- \\
7 \%)\end{array}$ & $\begin{array}{l}\text { IN: pregnancies } \\
\text { delivered }\end{array}$ \\
\hline $\begin{array}{l}\text { Sibai } \\
(1992)^{35}\end{array}$ & USA & 182 & $E$ & Parity & $\begin{array}{l}\text { PE: } 44 \% \\
(37-51 \%) \\
\text { FGR: } 12 \% \\
(7-17 \%)\end{array}$ & $\begin{array}{l}\text { beyond first } \\
\text { trimester, } \\
\text { previous } \\
\text { eclampsia }\end{array}$ \\
\hline $\begin{array}{l}\text { Sibai } \\
(1995)^{39}\end{array}$ & USA & 152 & HELLP & $\begin{array}{l}\text { Chronic hyper- } \\
\text { tension }\end{array}$ & $\begin{array}{l}\text { HELLP: } 3 \% \\
(0-6 \%) \\
\text { PE: } 16 \%\end{array}$ & $\begin{array}{l}\text { IN: first preg- } \\
\text { nancy compli- } \\
\text { cated by }\end{array}$ \\
\hline
\end{tabular}


Table 1 continued.

\begin{tabular}{|c|c|c|c|c|c|c|}
\hline $\begin{array}{l}\text { First author } \\
\text { (year) }\end{array}$ & Country & $\mathrm{N}$ & $\begin{array}{l}\text { Obstetric } \\
\text { history }\end{array}$ & Prediction test(s) & $\begin{array}{l}\text { Outcome } \\
\text { subsequent } \\
\text { pregnancy } \\
(95 \%-\mathrm{Cl})\end{array}$ & Population \\
\hline & & & & & $\begin{array}{l}(11-22 \%) \\
\text { FGR: } 15 \% \\
(9-21 \%)\end{array}$ & $\begin{array}{l}\text { HELLP, preg- } \\
\text { nancies be- } \\
\text { yond first } \\
\text { trimester }\end{array}$ \\
\hline $\begin{array}{l}\text { Simon } \\
(1988)\end{array}$ & France & 41 & $\mathrm{PIH} / \mathrm{PE}$ & HLA DR4 & $\begin{array}{l}\text { PIH/PE: } \\
56 \%(41- \\
71 \%)\end{array}$ & $\begin{array}{l}\text { IN: PIH or PE in } \\
\text { the previous } \\
\text { pregnancy }\end{array}$ \\
\hline $\begin{array}{l}\text { Spaanderman } \\
(2005)^{51}\end{array}$ & $\begin{array}{l}\text { The Nether- } \\
\text { lands }\end{array}$ & 31 & PE & $\begin{array}{l}\text { Central hemo- } \\
\text { dynamic, vascu- } \\
\text { lar, and clotting } \\
\text { function }\end{array}$ & $\begin{array}{l}\text { FGR: } 26 \% \\
(10-41 \%)\end{array}$ & $\begin{array}{l}\text { IN: formerly } \\
\text { preeclamptic, } \\
\text { nondiabetic } \\
\text { women, preg- } \\
\text { nancy occur- } \\
\text { ring within one } \\
\text { year after the } \\
\text { prepregnant } \\
\text { measurements, } \\
\text { only ongoing } \\
\text { singleton } \\
\text { pregnancies } \\
\text { (>16 wks) in } \\
\text { women with- } \\
\text { out preexisting } \\
\text { hypertension }\end{array}$ \\
\hline $\begin{array}{l}\text { Spaanderman } \\
(2005)^{10}\end{array}$ & $\begin{array}{l}\text { The Nether- } \\
\text { lands }\end{array}$ & 47 & PE & Plasma volume & $\begin{array}{l}\text { PIH: } 51 \% \\
(37-65 \%) \\
\text { PE: } 26 \% \\
(13-38 \%)\end{array}$ & $\begin{array}{l}\text { IN: Formerly } \\
\text { preeclamptic, } \\
\text { nondiabetic, } \\
\text { normotensive, } \\
\text { thrombophlic } \\
\text { women, ongo- } \\
\text { ing (> } 16 \text { wks) } \\
\text { singleton } \\
\text { pregnancy } \\
\text { within one } \\
\text { year }\end{array}$ \\
\hline $\begin{array}{l}\text { Sullivan } \\
{(1994)^{31}}^{31}\end{array}$ & USA & 122 & HELLP & $\begin{array}{l}\text { Class I HELLP (< } \\
50,000 \text { plate- } \\
\text { lets } / \mu \mathrm{L})\end{array}$ & $\begin{array}{l}\text { HELLP: } 27 \% \\
(20-34 \%)\end{array}$ & $\begin{array}{l}\text { IN: Previous } \\
\text { HELLP, et least } \\
2 \text { year follow- } \\
\text { up, subsequent } \\
\text { pregnancy }\end{array}$ \\
\hline $\begin{array}{l}\text { Trogstad } \\
(2001)^{15}\end{array}$ & Norway & 19970 & PE & $\begin{array}{l}\text { Change of } \\
\text { partner }\end{array}$ & $\begin{array}{l}\text { PE: } 14 \% \\
(14-15 \%)\end{array}$ & $\begin{array}{l}\text { IN:both single- } \\
\text { ton pregnan- } \\
\text { cies with } \\
\text { deliveries after }\end{array}$ \\
\hline
\end{tabular}


Table 1 continued.

\begin{tabular}{|c|c|c|c|c|c|c|}
\hline $\begin{array}{l}\text { First author } \\
\text { (year) }\end{array}$ & Country & $\mathrm{N}$ & $\begin{array}{l}\text { Obstetric } \\
\text { history }\end{array}$ & Prediction test(s) & $\begin{array}{l}\text { Outcome } \\
\text { subsequent } \\
\text { pregnancy } \\
(95 \%-\mathrm{Cl})\end{array}$ & Population \\
\hline $\begin{array}{l}\text { Trogstad } \\
(2004)^{16}\end{array}$ & Norway & 20285 & PE & Twin & $\begin{array}{l}\text { PE: } 14 \% \\
(13-14 \%)\end{array}$ & $\begin{array}{l}16 \text { wks of } \\
\text { gestation } \\
\text { IN: first and } \\
\text { second deliv- } \\
\text { ery between } \\
1967 \text { and } 1998 \text {, } \\
\text { PE in the first } \\
\text { pregnancy } \\
\text { EX: three or } \\
\text { more fetuses in } \\
\text { the first preg- } \\
\text { nancy and two } \\
\text { or more fe- } \\
\text { tuses in the } \\
\text { second preg- } \\
\text { nancy }\end{array}$ \\
\hline $\begin{array}{l}\text { Zhang } \\
(2001)(26)\end{array}$ & USA & 321 & $\mathrm{PIH} / \mathrm{PE}$ & $\begin{array}{l}\text { Onset of gesta- } \\
\text { tional hyperten- } \\
\text { sion (i.p.) }\end{array}$ & $\begin{array}{l}\mathrm{PIH} / \mathrm{PE}: \\
24 \%(20- \\
29 \%)\end{array}$ & $\begin{array}{l}\text { IN: singleton } \\
\text { first and sec- } \\
\text { ond pregnancy, } \\
\text { registered } \\
\text { before } 25 \\
\text { weeks of } \\
\text { gestation, with } \\
\text { at least three } \\
\text { prenatal visits, } \\
\text { infants born } \\
\text { after } 25 \text { weeks }\end{array}$ \\
\hline
\end{tabular}

PIH: pregnancy-induced hypertension; PE: preeclampsia; HELLP: hemolysis, elevated liver enzymes and low platelets syndrome; FGR: fetal growth restriction; BW: birth weight; IN: inclusion criteria; EX: exclusion criteria; i.p.: index pregnancy; t.p.: target pregnancy.

\section{Tests based on anthropometric, demographic and behavior related data}

Seven studies evaluated the effect of anthropometric, demographic or behavior related variables on the risk of recurrent hypertensive disease in pregnancy. Two studies investigated maternal overweigh, ${ }^{19,20}$ of which one also investigated maternal weight gain ${ }^{19}$ and one also investigated maternal age. ${ }^{20}$ Change of partner was evaluated in six studies. ${ }^{15,21-25}$ All tests mentioned had very low predictive sensitivities (between $3 \%$ and $4 \%$ ) along with moderate to high predictive specificities (between 63 and 97\%) (table 2). The sensitivity of change of partner as a predictor for recurrent $\mathrm{PIH}$ /preeclampsia in women, who had a history of $\mathrm{PIH} /$ preeclampsia 
combined with a family history (mother/sister) of hypertensive disease in pregnancy was $18-24 \%$ (table 2). ${ }^{25}$

\section{Tests based on the obstetric history}

Predictive accuracy of tests based on obstetric history information was assessed in 14 studies. Gestational age at the time of diagnosis in the previous pregnancy was evaluated in three studies. ${ }^{19,26,27}$ Three studies evaluated birth weight percentile of the previous child as a predictor, ${ }^{28-30}$ of which one also evaluated absolute birth weight. $^{30}$ Two studies evaluated previous intra-uterine demise. ${ }^{20,28}$ One study focused on previous twin pregnancy as a predictor for recurrent disease. ${ }^{16}$ The predictive capacity of severity of previous disease was investigated in four studies. ${ }^{28,31-33}$ Three studies reported on multiparity. ${ }^{34-36}$ Severity in these studies was expressed as HELLP syndrome complicating pregnancy-induced hypertension or preeclampsia, very low platelet count in HELLP syndrome, and the degree of proteinuria in preeclampsia. One study evaluated the effect of a short pregnancy interval on recurrence risk, and three studies the effect of parity on the recurrence risk. The predictive sensitivity of most of the factors mentioned was lower than $50 \%$ (table 2). Exceptions were gestational age at diagnosis predicting recurrent preeclampsia (Se: 75\% [95\%-Cl: 55-89\%], Sp: 42\% [95\%-Cl: 65-77\%]), ${ }^{19}$ very low platelet count in HELLP predicting class I HELLP syndrome (Se: $56 \%$ [95\%-Cl: 23-85\%], Sp: 87\% [95\%-Cl: $80-$ $92 \%]$ ), ${ }^{31}$ and multiparity as predictor for preeclampsia after previous $\mathrm{PIH}$ (Se: $73 \%$ [44-92\%], Sp: 88\% [84-91\%]) (table 2). ${ }^{36}$

Tests related to vascular resistance, endothelial, clotting and immune functions, or uterine blood flow

Predictive capacity of tests related to placental perfusion and vascular resistance was investigated in 14 studies. Predictors evaluated were: high diastolic blood pressure at booking (>90 mmHg), ${ }^{37}$ chronic hypertension, ${ }^{38,39}$ low pre-pregnant plasma volume, ${ }^{40,41}$ declining circulating thromboxane B2 levels in pregnancy, ${ }^{11}$ circulating level of anticardiolipin antibodies, ${ }^{42}$ angiotensine converting enzyme (ACE) I/D polymorphism, ${ }^{14}$ human leukocyte antigen (HLA) DR4, ${ }^{43}$ and Doppler ultrasonogrophy of the uterine arteries. ${ }^{28,34,44-46}$ Overall, predictive sensitivity of chronic hypertension, serum thromboxane B2 alterations, anticardiolipin antibodies, and HLA DR4 antigen was low (<50\%) (table 2). Better test characteristics were obtained for plasma volume (Se: $83 \%$ (95\%-Cl: $51-97 \%)$ and $\mathrm{Sp}$ : 100\% (95\%-Cl: $90-100 \%)$ for recurrent preeclampsia), ${ }^{10}$ and some uterine artery blood flow velocity parameters (table 2). 
Table 2: Prediction tests found in the literature with (ranges of) predictive sensitivity and specificity (95\%-confidence interval), summary table.

\begin{tabular}{|c|c|c|c|c|c|}
\hline Prediction test & $\begin{array}{l}\text { \% Test } \\
\text { positive }\end{array}$ & $\begin{array}{l}\text { Sensitivity } \\
(\%)\end{array}$ & $\begin{array}{l}\text { Specificity } \\
\text { (\%) }\end{array}$ & $\begin{array}{l}\text { Obstetric } \\
\text { history }\end{array}$ & Outcome \\
\hline Maternal overweight (BMI $\geq 25$ ) & 25 & $29(23-35)$ & $77(72-82)$ & $\mathrm{PIH}$ & $\mathrm{PIH}$ \\
\hline \multirow[t]{2}{*}{$(19,20)$} & 19 & $19(11-32)$ & $74(65-81)$ & $\mathrm{PE}$ & $\mathrm{PIH}$ \\
\hline & $19-32$ & $29-33(14-57)$ & $68-77(59-83)$ & $\mathrm{PE}$ & PE \\
\hline Weight gain (> $2 \mathrm{~kg} \mathrm{~m}-2$ ) & 33 & $36(30-43)$ & $69(63-74)$ & $\mathrm{PIH}$ & $\mathrm{PIH}$ \\
\hline \multirow[t]{2}{*}{ (19) } & 28 & $26(16-39)$ & $63(54-72)$ & $\mathrm{PE}$ & $\mathrm{PIH}$ \\
\hline & 28 & $43(25-63)$ & $69(61-76)$ & $\mathrm{PE}$ & PE \\
\hline Maternal age (> 35 years) $(20)$ & 8 & $5(0-26)$ & $91(84-95)$ & $\mathrm{PE}$ & PE \\
\hline \multirow[t]{3}{*}{ Change of partner $(15,21-25)$} & 18 & $18(13-22)$ & $82(75-87)$ & $\mathrm{PIH}$ & $\mathrm{PIH} / \mathrm{PE}$ \\
\hline & 26 & $24(15-35)$ & $72(59-82)$ & $\mathrm{PE}$ & $\mathrm{PIH} / \mathrm{PE}$ \\
\hline & $3-9$ & $3-8(2-10)$ & $91-97(90-97)$ & $\mathrm{PE}$ & PE \\
\hline Gestational age at diagnosis $(<$ & 48 & $48(41-54)$ & $52(46-58)$ & $\mathrm{PIH}$ & $\mathrm{PIH}$ \\
\hline \multirow[t]{3}{*}{34 wks) $(19,26,27)$} & 34 & $51(40-63)$ & $72(65-77)$ & $\mathrm{PIH} / \mathrm{PE}$ & $\mathrm{PIH} / \mathrm{PE}$ \\
\hline & 60 & $75(55-89)$ & $42(35-50)$ & $\mathrm{PE}$ & PE \\
\hline & 29 & $39(24-55)$ & $76(64-85)$ & $\mathrm{E}$ & PE \\
\hline Birth weight percentile & 17 & $20(13-30)$ & $84(80-87)$ & $\mathrm{PIH}$ & $\mathrm{PIH}$ \\
\hline \multirow[t]{3}{*}{$(\leq /<\mathrm{p} 10)(28-30)$} & 17 & $30(19-43)$ & $85(81-88)$ & $\mathrm{PIH}$ & FGR \\
\hline & 6 & $10(3-28)$ & 97 (87-99) & $\mathrm{PIH} / \mathrm{PE}$ & $\mathrm{PIH} / \mathrm{PE}$ \\
\hline & 24 & $32(30-43)$ & $77(76-78)$ & $\mathrm{PE}$ & PE \\
\hline \multirow[t]{2}{*}{ Intra-uterine demise $(20,28)$} & 6 & $19(6-43)$ & $96(90-98)$ & $\mathrm{PIH} / \mathrm{PE}$ & $\mathrm{PIH} / \mathrm{PE}$ \\
\hline & 17 & $16(6-35)$ & $83(71-91)$ & $\mathrm{PE}$ & $\mathrm{PE}$ \\
\hline Twin pregnancy (16) & 2 & $1(0-1)$ & $98(98-98)$ & $\mathrm{PE}$ & PE \\
\hline $\begin{array}{l}\text { HELLP as a complication of } \\
\text { PIH/PE (28) }\end{array}$ & 16 & $21(9-40)$ & $87(75-94)$ & $\mathrm{PIH} / \mathrm{PE}$ & $\mathrm{PIH} / \mathrm{PE}$ \\
\hline \multirow[t]{4}{*}{ Class I HELLP (31) } & 16 & $16(9-27)$ & $85(75-91)$ & HELLP & PE/HELLP \\
\hline & 16 & $25(14-41)$ & $88(80-93)$ & HELLP & HELLP \\
\hline & 16 & $56(23-85)$ & $87(80-92)$ & HELLP & Class I \\
\hline & & & & & HELLP \\
\hline \multirow[t]{2}{*}{ Proteinuria ( $\geq 0.5 \mathrm{~g} / 24 \mathrm{~h}$ ) (33) } & 14 & $16(8-28)$ & $88(79-94)$ & $\mathrm{PIH} / \mathrm{PE}$ & $\mathrm{PIH}$ \\
\hline & 14 & $33(2-87)$ & $87(80-92)$ & $\mathrm{PIH} / \mathrm{PE}$ & PE \\
\hline Proteinuria (>0.25 g/24h) (32) & 17 & $44(29-58)$ & $84(82-86)$ & $\mathrm{PE}$ & PE \\
\hline $\begin{array}{l}\text { Pregnancy interval } \leq 12 \text { months } \\
\text { (20) }\end{array}$ & 16 & $19(6-43)$ & 85 (77-99) & $\mathrm{PE}$ & PE \\
\hline \multirow[t]{5}{*}{ Multiparity (34-36) } & 14 & $26(18-36)$ & $89(85-93)$ & $\mathrm{PIH}$ & $\mathrm{PIH}$ \\
\hline & 14 & $73(44-92)$ & $88(84-91)$ & $\mathrm{PIH}$ & PE \\
\hline & 20 & $28(16-44)$ & $83(74-90)$ & $\mathrm{PE}$ & PE \\
\hline & 13 & $8(4-16)$ & $83(74-90)$ & $\mathrm{E}$ & $\mathrm{PE} / \mathrm{E}$ \\
\hline & 13 & $0(0-44)$ & $87(81-91)$ & $E$ & $\mathrm{E}$ \\
\hline
\end{tabular}


Table 2 continued

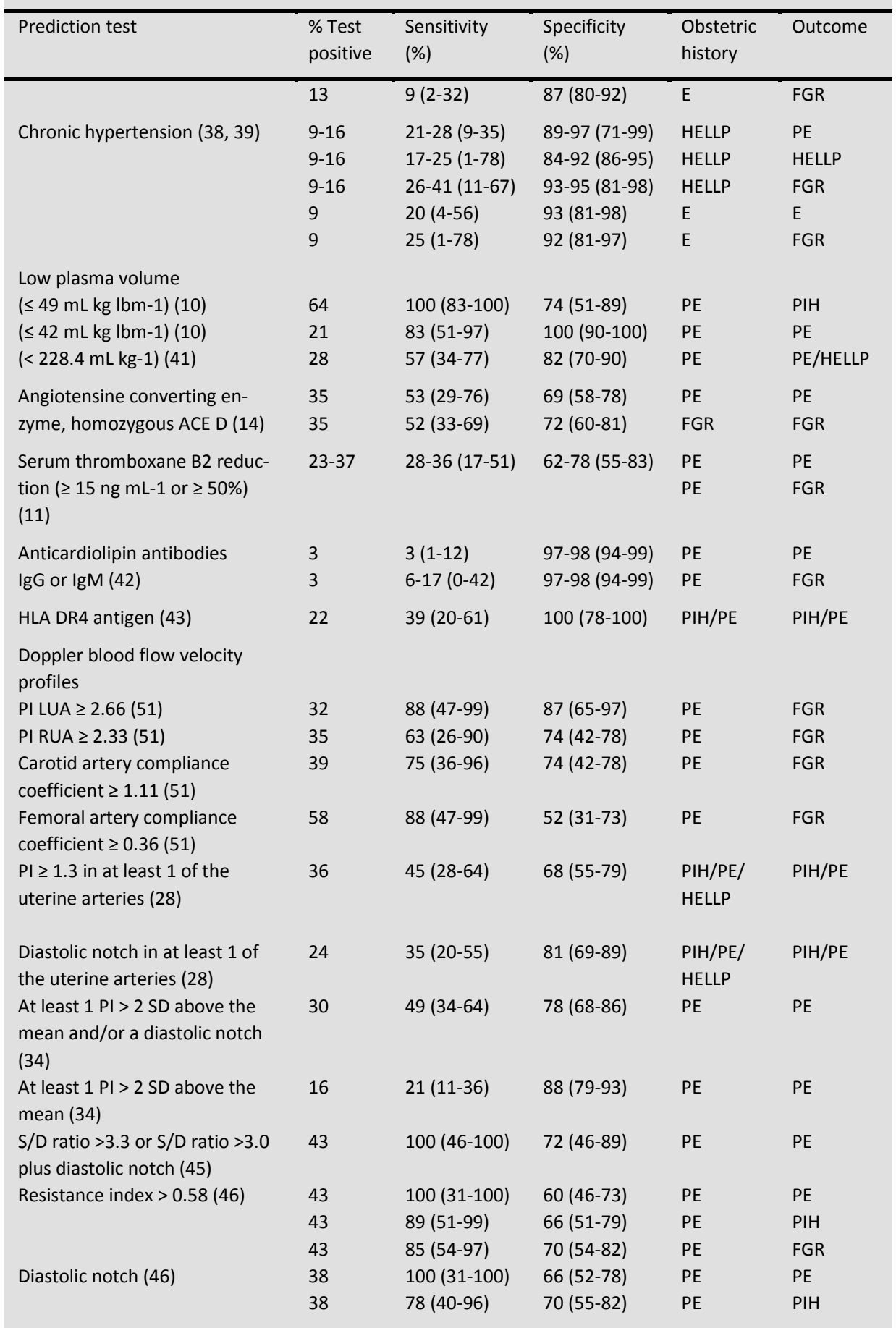


Table 2 continued

\begin{tabular}{llllll}
\hline Prediction test & $\begin{array}{l}\text { \% Test } \\
\text { positive }\end{array}$ & $\begin{array}{l}\text { Sensitivity } \\
(\%)\end{array}$ & $\begin{array}{l}\text { Specificity } \\
(\%)\end{array}$ & $\begin{array}{l}\text { Obstetric } \\
\text { history }\end{array}$ & Outcome \\
\hline & 38 & $85(54-97)$ & $77(61-88)$ & PE & FGR \\
Resistance index $>0.58$ and & 14 & $33(2-87)$ & $87(74-94)$ & PE & PE \\
diastolic notch (46) & 14 & $22(4-60)$ & $87(74-95)$ & PE & PIH \\
& 14 & $46(20-74)$ & $95(83-99)$ & PE & FGR \\
Multivariable model including & 28 & 79 & 89 & PE & PE \\
longitudinal in-pregnancy & & & & & \\
patterns (47) & & & & & \\
\end{tabular}

$\mathrm{PIH}$ : pregnancy-induced hypertension; PE: preeclampsia; E: eclampsia; HELLP: hemolysis, elevated liver enzymes and low platelets syndrome; FGR: fetal growth restriction. When a range is presented for predictive sensitivity or specificity, the confidence interval reported refers to the lowest lower-bound and highest upper-bound of the original 95\%-confidence intervals.

We identified one study that combined the longitudinal patterns of several variables (parity, age, number of abortions, urea, creatinine, total proteins, uric acid, and hematocrit) during the first half of the target pregnancy (from 8 to 20 weeks amenorrhea) in formerly preeclamptic women. ${ }^{47}$ The authors compared the observed value of each marker with an individual 'theoretical physiological pattern'. The match or mismatch to this pattern was included in a logistic regression analysis with recurrent preeclampsia later in pregnancy as dependent variable. After an internal validation procedure, the predictive sensitivity of the model was $79 \%$ (95\%$\mathrm{Cl}: 64-89 \%)$ and the predictive specificity was $89 \%$ (95\%-Cl: $82-93 \%)$.

None of the studies included in this review fulfilled all 12 methodological criteria stated. Ten studies met 9,10 , or 11 criteria, 16 studies scored positive on 7 or 8 criteria, whereas seven studies fulfilled 6 criteria or less. The results of the methodological quality assessment are summarized in figure 1.

\section{Discussion}

We identified few single predictors in the literature that proved to predict the risk of recurrent hypertensive disease in pregnancy with both high predictive sensitivity and predictive specificity. Only 3 types of prediction tests had both sensitivity and specificity values that were significantly higher than 50\%, including: 1) low plasma volume predicting $\mathrm{PIH}$ or preeclampsia in women with previous preeclampsia, ${ }^{10}{ }^{2}$ ) high resistance index $(>0.58)$ and the presence of early diastolic notch in the uterine arteries at 24 weeks amenorrhea predicting PIH and FGR after previous preeclamp$\mathrm{sia}^{46}$ and, finally, 3) the multivariable model including longitudinal in-pregnancy patterns by Mello et al. predicting recurrent preeclampsia (table 2 ). ${ }^{47}$ Although the 
predictive capacities of these predictors proved to be reasonable, some aspects hamper their clinical relevance and/or generalisability. Low plasma volume, for instance, was evaluated in a highly specific study population of formerly preeclamptic women with at least one abnormality in clotting function. A study on plasma volume evaluated in a different population of former preeclamptics revealed less promising results (table 2). ${ }^{41}$ Moreover, the method of assessment used (iodine 125-albumin indicator dilution) is expensive and requires the intravenous administration of radioactive material. Less expensive non-radioactive indicators to measure plasma volume, such as dextran-70, require the same invasive procedure while predictive performance still has to be evaluated.

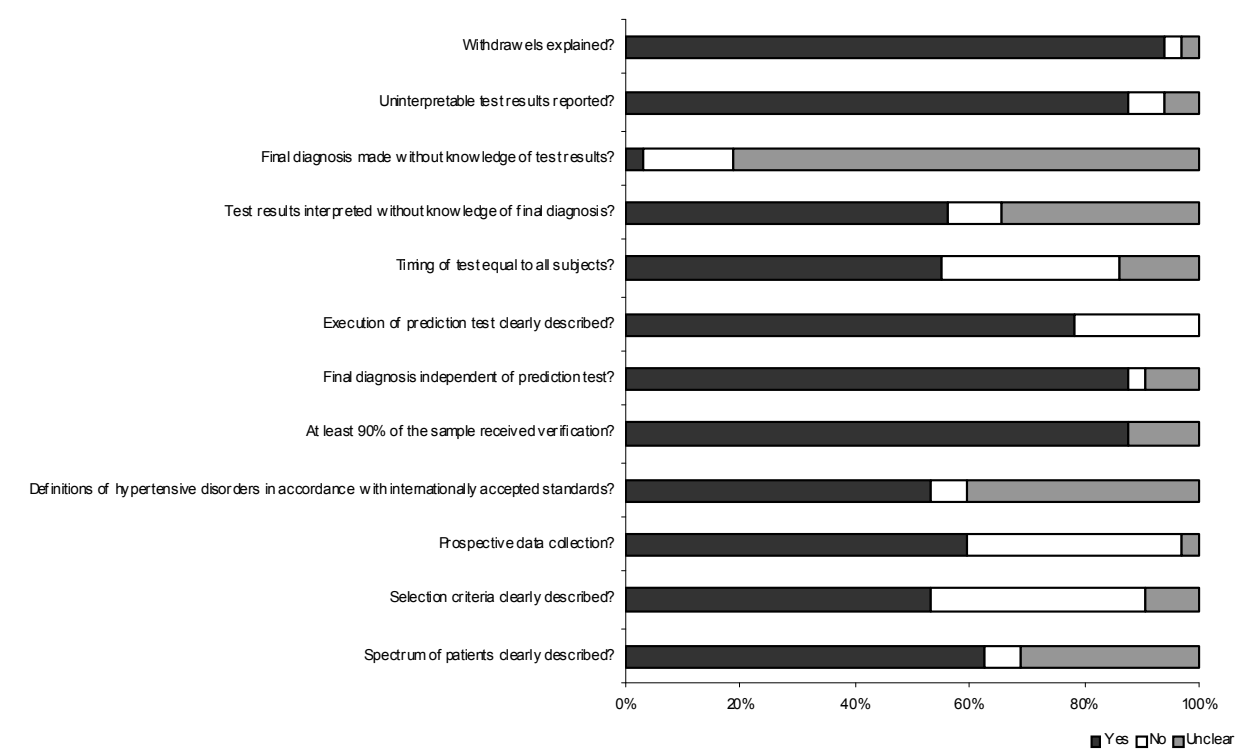

Figure 1: Summary of quality assessment.

In the report on uterine artery velocimetry by Frusca et al. ${ }^{46}$ a clear description of the population characteristics was lacking, as well as a clear definition of the disorders studied. Furthermore, the investigators failed to specify that the Doppler measurements were independent of the final diagnoses. A possible clinical drawback of the blood flow velocimetry tests is that the result will follow until well in the target pregnancy (24 weeks of gestational age), ${ }^{46}$ which could be a disadvantage of Mello's logit model as well (20 weeks of gestational age). ${ }^{47}$

Besides the predictors mentioned, other variables with reasonable predictive capacity (point estimates of sensitivity and specificity $>50 \%$ ) were: gestational age at diagnosis (<34 weeks) during the previous predicting recurrent $\mathrm{PIH} /$ preeclampsia, $^{26}$ previous HELLP with very low platelet count $(\leq 50,000 / \mu \mathrm{L})$ predicting class I HELLP 
syndrome, ${ }^{31}$ multiparity predicting preeclampsia after previous $\mathrm{PIH}{ }^{36}$ and homozygous ACE D genotype predicting recurrent preeclampsia and FGR (table 2). ${ }^{14}$ However, these predictors all had imprecise estimates of predictive sensitivity being, except for multiparity, about $50 \%$ (table 2). Noteworthy, very high specificity (100\%, 95\%-Cl: 78-100), but disappointing sensitivity (39\% (95\%-Cl: $20-61 \%)$ was found for the presence of HLA DR4 antigen predicting recurrent $\mathrm{PIH} /$ preeclampsia. $^{43}$ Since hypertensive disorders in pregnancy are heterogeneous conditions, probably involving several separate pathophysiologic pathways, it is not surprising that predicting the recurrence of these disorders based on a single variable has been disappointing. While some hypertensive disorders are probably best detected by uterine artery Doppler, other forms may be better detected using abnormal levels of circulating markers for endothelial stress. Therefore, it may be more appropriate to explore combinations of tests of different categories. In an attempt to do so, Mello and others combined the longitudinal patterns of several variables during the first half of pregnancy in a logistic regression model to predict recurrent preeclampsia. The characteristics of this prediction model are promising, but as mentioned earlier the usability of the model is somewhat limited because of its late application ( $>20$ weeks) and need for repeated measurements in the target pregnancy. Regrettably, the cut-off value of the predictive probability used was not described in the report. Different clinical manifestations of hypertensive disease of pregnancy are related to different pathological pathways. The risk for developing preeclampsia varies depending on the underlying mechanism and the outcome in a previous pregnancy. ${ }^{48}$ Increasing clinical homogeneity of the study population could facilitate the selection of relevant predictors. Therefore, in addition to combining single predictors, future prediction studies should include women with similar types of hypertensive disease in their previous pregnancy, e.g. late- or early-onset disease.

The quality of reporting of all studies included in this review was often suboptimal. Only ten studies fulfilled $75 \%$ or more of the quality criteria stated. Seven reports met only half of the criteria or less. However, not all studies included in this review were prediction studies, making some quality criteria less appropriate. Nevertheless, complete and accurate reporting is needed to enable readers to assess the potential for bias in the study and to evaluate the generalisability of the results. Although not completely applicable to predictive studies, tools for the quality assessment of studies of diagnostic accuracy, like QUADAS, ${ }^{7}$ can serve as helpful guidelines in writing a report on prediction tests. Moreover, researchers have developed a statement to improve the quality of reporting of studies of diagnostic accuracy, the STARD statement.

We believe that it is unlikely that publication bias has affected the overall conclusions of this review. (Small) studies with non-significant or 'negative' results may have had a lower probability of being published or being cited by others than studies with positive findings. As we did not identify strong evidence for the existence 
of clinically useful prediction tools, adding more negative studies would not have changed the picture. Exclusion of reports in other languages then those mentioned in the methods section might have had the same effect. After our systematic literature search, Sibai et al. ${ }^{49}$ published an article on inhibin A, soluble fms-like tyrosine kinase-1 (sFlt-1), and the ratio of sFlt-1 to placenta growth factor measured before 16 weeks of gestational age as predictors for early-onset preeclampsia $(<27$ weeks of gestational age). However, the study population consisted of both women with previous preeclampsia, chronic hypertension, or both.

As can be concluded from tables 1 and 2, wide variety existed in the obstetric history of the women in the study populations, both prediction tests and thresholds that were evaluated, and the outcomes studied. Predictive sensitivity and specificity are less responsive to variations in a priori probabilities compared to predictive values. We feel that the comparability of predictive performances of the tests would have been affected when we would have used predictive values in stead of sensitivity and specificity. Furthermore, statistically pooling test characteristics was hampered by the same problem of variety. Therefore, we preferred to present prediction data more as an overview of available evidence than as summary estimates of test characteristics. To our knowledge, this is the first systematic review on this topic. Barton and Sibai $(2008)^{48}$ provided an update on recently published reports on methods to identify women at risk for recurrent preeclampsia. In this non-systematic appraisal, neither test characteristics nor precision of point estimates were evaluated.

In summary, an extensive review of the literature resulted in only a small number of predictors with potential to identify women destined to develop recurrent hypertensive disease, i.e. with both satisfying predictive sensitivity and specificity (prepregnant low plasma volume, in-pregnancy uterine-artery Doppler flow velocity profiles, and a multivariable model including the longitudinal patterns of several variables during the first half of pregnancy). Their clinical usefulness and/or generalisibility were limited however. To increase worldwide applicability of prediction tests in clinical practice, predictors should be easily obtainable. Future research on prediction tests for recurrent hypertensive disease in pregnancy should focus on a combination of parameters in homogenous study populations. The first attempts to combine potentially relevant variables have shown potential. 


\section{References}

1. Khan KS, Wojdyla D, Say L, Gulmezoglu AM, Van Look PF. WHO analysis of causes of maternal death: a systematic review. The Lancet 2006;367(9516):1066-1074.

2. Report of the National High Blood Pressure Education Program. Working group report on high blood pressure in pregnancy. Am J Obstet Gynecol 2000;183:S1-S22.

3. Conde-Agudelo A, Villar J, Lindheimer M. World Health Organization systematic review of screening tests for preeclampsia. Obstet Gynecol 2004;104(6):1367-91.

4. Engelhard IM, van Rij M, Boullart I, Ekhart TH, Spaanderman ME, van den Hout MA, et al. Posttraumatic stress disorder after pre-eclampsia: an exploratory study. Gen Hosp Psychiatry 2002;24(4):260-4.

5. Lijmer JG, Mol BW, Heisterkamp S, Bonsel GJ, Prins MH, van der Meulen JH, et al. Empirical evidence of designrelated bias in studies of diagnostic tests. JAMA 1999;282(11):1061-6.

6. Deville WL, Buntinx F, Bouter LM, Montori VM, de Vet HC, van der Windt DA, et al. Conducting systematic reviews of diagnostic studies: didactic guidelines. BMC Med Res Methodol 2002;2:9.

7. Whiting P, Rutjes A, Reitsma J, Bossuyt P, Kleijnen J. The development of QUADAS: a tool for the quality assessment of studies of diagnostic accuracy included in systematic reviews. BMC Med Res Methodol 2003;3(1):25.

8. Cnossen JS, van der Post JA, Mol BW, Khan KS, Meads CA, ter Riet G. Prediction of pre-eclampsia: a protocol for systematic reviews of test accuracy. BMC Pregnancy Childbirth 2006;6:29.

9. Spaanderman ME, Aardenburg R, Ekhart TH, van Eyndhoven HW, van der Heijden OW, van Eyck J, et al. Nonpregnant circulatory volume status predicts subsequent pregnancy outcome in normotensive thrombophilic formerly preeclamptic women. Eur J Obstet Gynecol Reprod Biol 2001;95(2):218-21.

10. Spaanderman MEA, Aardenburg R, Ekhart THA, van Eyndhoven HWF, de Leeuw PW, Peeters LLH. Pre-pregnant prediction of recurrent preeclampsia in normotensive thrombophilic formerly preeclamptic women receiving prophylactic antithrombotic medication. J Society Gynecol Investigation 2005;12(2):112-117.

11. Hauth J, Sibai B, Caritis S, VanDorsten P, Lindheimer M, Klebanoff $M$, et al. Maternal serum thromboxane B2 concentrations do not predict improved outcomes in high-risk pregnancies in a low-dose aspirin trial. American Journal of Obstetrics and Gynecology 1998;179(5):1193-1199.

12. Caritis S, Sibai B, Hauth J, Lindheimer M, VanDorsten $P$, Klebanoff $M$, et al. Predictors of pre-eclampsia in women at high risk. American Journal of Obstetrics and Gynecology 1998;179(4):946-951.

13. Fatini C, Sticchi E, Gensini F, Genuardi M, Tondi F, Gensini F, et al. Endothelial nitric oxide synthase gene influences the risk of pre-eclampsia, the recurrence of negative pregnancy events, and the maternal-fetal flow. J Hypertens 2006;24(9):1823-9.

14. Mello G, Parretti E, Gensini F, Sticchi E, Mecacci F, Scarselli G, et al. Maternal-fetal flow, negative events, and preeclampsia: role of ACE I/D polymorphism. Hypertension 2003;41(4):932-7.

15. Trogstad LI, Eskild A, Magnus P, Samuelsen SO, Nesheim BI. Changing paternity and time since last pregnancy; the impact on pre-eclampsia risk. A study of 547238 women with and without previous pre-eclampsia. Int J Epidemiol 2001;30(6):1317-22.

16. Trogstad L, Skrondal A, Stoltenberg C, Magnus P, Nesheim Bl, Eskild A. Recurrence risk of preeclampsia in twin and singleton pregnancies. Am J Med Genet A 2004;126(1):41-5.

17. Dukler D, Porath A, Bashiri A, Erez O, Mazor M. Remote prognosis of primiparous women with preeclampsia. Eur J Obstet Gynecol Reprod Biol 2001;96(1):69-74.

18. van Rijn $B B$, Hoeks $L B$, Bots ML, Franx A, Bruinse HW. Outcomes of subsequent pregnancy after first pregnancy with early-onset preeclampsia. Am J Obstet Gynecol 2006;195(3):723-8.

19. Hjartardottir S, Leifsson BG, Geirsson RT, Steinthorsdottir V. Recurrence of hypertensive disorder in second pregnancy. Am J Obstet Gynecol 2006;194(4):916-20.

20. Makkonen N, Heinonen S, Kirkinen P. Obstetric prognosis in second pregnancy after preeclampsia in first pregnancy. Hypertens Pregnancy 2000;19(2):173-81.

21. Basso O, Christensen K, Olsen J. Higher risk of pre-eclampsia after change of partner. An effect of longer interpregnancy intervals? Epidemiology 2001;12(6):624-9.

22. Cnattingius $S$, Reilly $M$, Pawitan $Y$, Lichtenstein P. Maternal and fetal genetic factors account for most of familial aggregation of preeclampsia: a population-based Swedish cohort study. Am J Med Genet A 2004;130(4):365-71.

23. Li DK, Wi S. Changing paternity and the risk of preeclampsia/eclampsia in the subsequent pregnancy. Am J Epidemiol 2000;151(1):57-62.

24. Lie RT, Rasmussen S, Brunborg H, Gjessing HK, Lie-Nielsen E, Irgens LM. Fetal and maternal contributions to risk of pre-eclampsia: population based study. BMJ 1998;316(7141):1343-7.

25. Hjartardottir S, Leifsson BG, Geirsson RT, Steinthorsdottir V. Paternity change and the recurrence risk in familial hypertensive disorder in pregnancy. Hypertens Pregnancy 2004;23(2):219-25.

26. Zhang J, Troendle JF, Levine RJ. Risks of hypertensive disorders in the second pregnancy. Paediatr Perinat Epidemiol 2001;15(3):226-31. 
27. Lopez-Llera M, Hernandez Horta JL. Pregnancy after eclampsia. Am J Obstet Gynecol 1974;119(2):193-8.

28. Aardema MW, Lander M, Oosterhof H, De Wolf BT, Aarnoudse JG. Doppler ultrasound screening predicts recurrence of poor pregnancy outcome in subsequent pregnancies, but not the recurrence of PIH or preeclampsia. Hypertens Pregnancy 2000;19(3):281-8.

29. Patterson RM, Gibbs CE, Wood RC. Birth weight percentile and perinatal outcome: recurrence of intrauterine growth retardation. Obstet Gynecol 1986;68(4):464-8.

30. Rasmussen S, Irgens LM, Albrechtsen S, Dalaker K. Predicting preeclampsia in the second pregnancy from low birth weight in the first pregnancy. Obstet gynecol 2000;96(5 Pt 1):696-700.

31. Sullivan CA, Magann EF, Perry KG, Jr., Roberts WE, Blake PG, Martin JN, Jr. The recurrence risk of the syndrome of hemolysis, elevated liver enzymes, and low platelets (HELLP) in subsequent gestations. Am J Obstet Gynecol 1994;171(4):940-3.

32. Campbell DM, MacGillivray I, Carr-Hill R. Pre-eclampsia in second pregnancy. Br J Obstet Gynaecol 1985;92(2):13140.

33. Hargood JL, Brown MA. Pregnancy-induced hypertension: recurrence rate in second pregnancies. Med J Aust 1991;154(6):376-7.

34. Gudnasson HM, Dubiel M, Gudmundsson S. Preeclampsia--abnormal uterine artery Doppler is related to recurrence of symptoms during the next pregnancy. J Perinat Med 2004;32(5):400-3.

35. Sibai BM, Sarinoglu C, Mercer BM. Eclampsia. VII. Pregnancy outcome after eclampsia and long-term prognosis. Am J Obstet Gynecol 1992;166(6 Pt 1):1757-61; discussion 1761-3.

36. Brown M, Mackenzie C, Dunsmuir W, Roberts L, Ikin K, Matthews J, et al. Can we predict recurrence of preeclampsia or gestational hypertension? BJOG 2007.

37. Adelusi B, Ojengbede OA. Reproductive performance after eclampsia. Int J Gynaecol Obstet 1986;24(3):183-9.

38. Chames MC, Haddad B, Barton JR, Livingston JC, Sibai BM. Subsequent pregnancy outcome in women with a history of HELLP syndrome at < or $=28$ weeks of gestation. Am J Obstet Gynecol 2003;188(6):1504-7; discussion 1507-8.

39. Sibai BM, Ramadan MK, Chari RS, Friedman SA. Pregnancies complicated by HELLP syndrome (hemolysis, elevated liver enzymes, and low platelets): subsequent pregnancy outcome and long-term prognosis. Am J Obstet Gynecol 1995;172(1 Pt 1):125-9.

40. Spaanderman ME, Aardenburg R, Ekhart TH, van Eyndhoven HW, de Leeuw PW, Peeters LL. Pre-pregnant prediction of recurrent preeclampsia in normotensive thrombophilic formerly preeclamptic women receiving prophylactic antithrombotic medication. J Soc Gynecol Investig 2005;12(2):112-7.

41. Aardenburg R, Spaanderman ME, Ekhart TH, van Eijndhoven HW, van der Heijden OW, Peeters LL. Low plasma volume following pregnancy complicated by pre-eclampsia predisposes for hypertensive disease in a next pregnancy. BJOG 2003;110(11):1001-6.

42. Branch DW, Porter TF, Rittenhouse L, Caritis S, Sibai B, Hogg B, et al. Antiphospholipid antibodies in women at risk for preeclampsia. Am J Obstet Gynecol 2001;184(5):825-32; discussion 832-4.

43. Simon P, Fauchet R, Pilorge M, Calvez C, Le Fiblec B, Cam G, et al. Association of HLA DR4 with the risk of recurrence of pregnancy hypertension. Kidney Int Suppl 1988;25:S125-8.

44. Spaanderman MEA, Willekes C, Hoeks APG, Ekhart THA, Aardenburg R, Courtar DA, et al. Maternal nonpregnant vascular function correlates with subsequent fetal growth. American Journal of Obstetrics and Gynecology 2005;192(2):504-512.

45. Morris J, Fay R, Ellwood D. Abnormal Uterine Artery Waveforms in the Second Trimester Are Associated with Adverse Pregnancy Outcome in High Risk Women. J Matern Fetal Investig 1998;8(2):82-4.

46. Frusca T, Soregaroli M, Danti L, Guandalini F, Lojacono A, Scalvi L, et al. Uterine artery velocimetry as a screening test in patients with previous preeclampsia. Italian Journal of Gynaecology and Obstetrics 1996;8(3):94-98.

47. Mello G, Parretti E, Cioni R, Lagozio C, Mealli F, Pratesi M. Individual longitudinal patterns in biochemical and hematological markers for the early prediction of pre-eclampsia. J Matern Fetal Neonat Med 2002;11(2):93-9.

48. Barton JR, Sibai BM. Prediction and prevention of recurrent preeclampsia. Obstet Gynecol 2008;112(2):359-72.

49. Sibai BM, Koch MA, Freire S, Pinto e Silva JL, Rudge MV, Martins-Costa S, et al. Serum inhibin A and angiogenic factor levels in pregnancies with previous preeclampsia and/or chronic hypertension: are they useful markers for prediction of subsequent preeclampsia? Am J Obstet Gynecol 2008;199(3):268 e1-9.

50. Mello G, Parretti E, Ognibene A, Mecacci F, Cioni R, Scarselli G, et al. Prediction of the development of pregnancyinduced hypertensive disorders in high-risk pregnant women by artificial neural networks. Clinical chemistry and laboratory medicine CCLM FESCC 2001;39(9):801-5.

51. Spaanderman ME, Willekes C, Hoeks AP, Ekhart TH, Aardenburg R, Courtar DA, et al. Maternal nonpregnant vascular function correlates with subsequent fetal growth. Am J Obstet Gynecol 2005;192(2):504-12. 



\section{CHAPTER 3}

\section{Simple prepregnant}

prediction rule for recurrent early-onset hypertensive disease in pregnancy

Simone Sep, Luc Smits, Martin Prins, Marc Spaanderman, Louis Peeters

Reproductive Sciences 2009; 16(1):80-7 


\section{Abstract}

Objective: We aimed to develop a clinically useful prediction rule for early-onset recurrent preeclampsia or HELLP syndrome that is easy to apply.

Methods: Women with previous early-onset preeclampsia and/or HELLP syndrome, enrolled between 1996 and 2007, and a subsequent ongoing pregnancy were included. Pre-pregnant cardiovascular, metabolic, renal and clotting parameters were evaluated as potential predictors for recurrent disease by logistic regression analysis.

Results: Early-onset preeclampsia and/or HELLP syndrome recurred in 16 (9\%) of 186 next pregnancies. The prediction model included HDL-cholesterol ( $\mathrm{mmol} \mathrm{L}-1$ ) and $24 \mathrm{~h}$ urinary total protein excretion ( $\mathrm{mg} \mathrm{mmol}-1$ creatinine). The Receiver Operating Characteristic area was 0.77 (95\%-Cl: $0.68-0.87)$. Predictive sensitivity and specificity were $94 \%(69-99 \%)$ and $53 \%(45-60 \%)$, respectively. Near $50 \%$ of the women could be classified as having $<1 \%$ risk of recurrent early-onset disease.

Conclusion: The prediction rule identified, with clinically relevant predictive capacity, those women at very low risk for recurrent early-onset disease. 


\section{Introduction}

The pregnancy-induced hypertensive disorders, preeclampsia (PE) and the syndrome of Hemolysis, Elevated Liver enzymes and Low Platelets (HELLP), affect 2-7\% of all pregnancies in nulliparous women. ${ }^{1}$ Although the aetiology is only partly understood, there is general agreement that the placenta plays a central role in the pathogenesis and that dysfunctional endothelium triggers the typical clinical symptoms. In most nulliparous women the disease develops near term with limited unfavourable impact on pregnancy outcome. ${ }^{1}$ However, approximately $10 \%$ of the cases have early-onset disease severe enough to require early pregnancy termination, which is related to serious maternal and/or foetal sequels. ${ }^{1}$

Despite marked improvements in perinatal care in recent decades, the incidence of hypertensive complications of pregnancy has not decreased. Prevention has focused on early identification of women at increased risk. ${ }^{2}$ Although this approach does not prevent the development of hypertensive pregnancy complications, it enables adaptation of intensity of follow-up to the expected probability of recurrent disease.

In the last two decades, various screening methods have been considered with respect to their ability to identify women at risk for hypertensive pregnancy complications. Most studies were aimed at assessing the predictive performance of a single parameter, in nulliparous women. ${ }^{3}$ Parous women with a history of hypertensive complications constitute a patient group far less studied for this purpose. In these women, the recurrence rate has been reported to be up to $50 \%,{ }^{4}$ depending on definitions for onset and severity of the disease. Since hypertensive disorders in pregnancy are heterogeneous conditions, probably involving several separate pathophysiologic pathways, it is not surprising that predicting the recurrence of these disorders based on a single variable has been disappointing. It may be more appropriate to explore combinations of variables.

This study was designed to develop a prediction rule evaluating multiple prepregnant potential predictors, instead of using a single factor, to predict recurrent earlyonset preeclampsia and/or HELLP syndrome in the next pregnancy. We aimed to develop a simple tool that could identify all prospective cases of recurrent earlyonset hypertensive disease, and simultaneously designate a considerable fraction of patients as test-negative. To this end, cardiovascular, metabolic, renal, and clotting parameters were combined with demographic variables and obstetric-history information in 186 women with a first pregnancy complicated by early-onset PE/HELLP. 


\section{Methods}

Women with a hypertensive complication during their previous pregnancy (the index pregnancy), who were referred to our tertiary referral centre from June 1996 onwards were screened for eligibility. They were referred for the detection of associated disorders and for counseling prior to a possible future pregnancy. We excluded women who were multiparous, had no previous early-onset preeclampsia or HELLP syndrome (diagnosed before or at 34 weeks and resulting in delivery before or at 37 weeks amenorrhea), and/or no subsequent ongoing (> 20th pregnancy week) singleton pregnancy resulting in delivery before December 2007. The catchment area of the university hospital was the Province of Limburg with 10,00012,000 births per year during the study period, of which approximately half were first births.

Preeclampsia was defined in accordance with the criteria of the International Society for the Study of Hypertension in Pregnancy (ISSHP), ${ }^{5}$ as de novo hypertension (blood pressure $>140 / 90 \mathrm{mmHg}$, occurring after 20 weeks' gestation) accompanied by proteinuria ( $\geq 300 \mathrm{mg}$ in a 24-hour urine sample). Preeclampsia superimposed on chronic hypertension was defined as new-onset proteinuria ( $\geq 300 \mathrm{mg}$ in a 24 -hour urine sample) after 20 weeks' gestation or a sudden increase in proteinuria or blood pressure in women whose hypertension had previously been well controlled. ${ }^{5}$ The HELLP syndrome was defined in accordance with criteria suggested by Sibai et al., as the combination of haemolysis (evidence on peripheral blood smear, serum bilirubin $>20 \mu \mathrm{mol}$.L-1 and serum LDH level > 600 IU.L-1), elevated ( $\geq 70$ IU.L-1) serum aspartate amino-transferase (ASAT) and/or alanine aminotransferase (ALAT) and a low platelet count $\left(<100 \times 109\right.$. L-1). ${ }^{6}$ The initial diagnosis in the index pregnancy was made by the patient's own obstetrician and later verified by an expert (LP) based on the definitions described above. The onset of complications was considered early if the diagnosis had been made before or at 34 weeks amenorrhea and pregnancy duration was shorter than or equal to 37 weeks. A small-for-gestational-age (SGA) infant was defined as a child with a birth weight below the 10th percentile according to the most recent Dutch birth weight reference curves. ${ }^{7}$

The main outcome measure in this study was recurrent early-onset (superimposed) preeclampsia and/or HELLP syndrome. We obtained information on course and outcome of the 'target pregnancy' using a short standardized questionnaire. Where possible this was supplemented with information deduced from correspondence by the patient's own obstetrician. To reduce loss-to-follow-up, non-respondents were contacted by telephone. In the event of change of address, the patient's general practitioner was contacted to obtain new contact details. During the target pregnancy, all women used low-dose aspirin $(80 \mathrm{mg} / \mathrm{dL}$ ) from 12 until 37 weeks.

In order to detect associated disorders and for counseling purposes, a diagnostic work-up has been performed routinely in our tertiary referral centre since 1996, 
The work-up is performed at least six months after the index pregnancy. Most potential predictors evaluated in this study were derived from this post partum evaluation. After an overnight fast, a blood sample was collected to assess the following laboratory variables using standardized techniques: circulating levels of calcium, urea, creatinine, ASAT, ALAT, fasting glucose and insulin, platelet count, haemoglobin, haematocrit, high-sensitivity C-reactive protein (hs-CRP), free thyroxine 4, thyroid stimulating hormone, total cholesterol, high- and low-density lipoproteins and triglycerides. Clotting factors assessed were fibrinogen, antithrombin, proteins $\mathrm{S}$ and C activity, activated protein C resistance, protrombin G20210A and Factor $V$ Leiden mutations. "Thrombophilia" was diagnosed on the basis of 1) being at least heterozygous for the Factor $V$ Leiden or the prothrombin G20210A mutation and/or 2) a detected protein C, S (antigen) and/or antithrombin deficiency, activated protein $\mathrm{C}$ resistance, and/or the presence of lupus anticoagulant. Detectable circulating anticardiolipine antibodies (IgG and IgM) were measured at two occasions with an interval of at least six weeks. A 24-h urine sample, collected on the preceding day, served to determine the excretion of total protein, calcium, micro-albumin and creatinine. Furthermore, the homocysteine metabolism was assessed by performing a methionine loading test. Hyperhomocysteinemia ( $\mathrm{HHC}$ ) was diagnosed on the basis of either the starved or the post-loading homocysteine level being more than $2 \mathrm{SD}$ above the mean of a normal population of middle-aged women ( $>15 \mathrm{mmol} / \mathrm{L}$ and $>55 \mathrm{mmol} / \mathrm{L}$, respectively). 8 Women diagnosed with $\mathrm{HHC}$ were supplemented with folic acid ( $5 \mathrm{mg}$ daily) and vitamin B6 (20 mg daily). We monitored the blood pressure (systolic, diastolic and mean arterial pressure) for 30 minutes in standardized conditions using a semiautomatic oscillometric device. A patient was considered to have chronic hypertension when during these 30 minutes, her median systolic blood pressure was $\geq 140 \mathrm{mmHg}$ and/or her median diastolic blood pressure was $\geq 90 \mathrm{mmHg}$, or when her physician prescribed antihypertensive medication.9 Demographic variables considered as potential predictors were age, body mass index (BMI), overweight, and obesity, which were assessed during the post partum evaluation as well. Obstetric history information included the number of spontaneous abortions, sex and birth weight of the first child, the first child being small-for-gestational-age $(<p 10)$, intra-uterine demise, amenorrhea at the time of diagnosis of preeclampsia or HELLP syndrome, and the occurrence of eclamptic seizures. After the post partum evaluation the women were informed about detected abnormalities and the possible consequences of abnormal findings for course and management of a next pregnancy. In none of the women enrolled in this study, a future pregnancy was discouraged.

We excluded variables with more than $25 \%$ missing values from the pool of candidate predictors. The number of candidate predictors was further reduced by excluding those variables with a p-value above 0.10 in univariate logistic regression analysis on complete cases. Missing values of the remaining variables were imputed. 
Imputation was based on a multivariable single imputation regression procedure. ${ }^{10}$ Collinearity was indicated by a tolerance value below 0.10 (or clearly different from the others). In case of collinearity the variable that was most commonly used in medical practice was preferred. By means of backward logistic regression analysis (based on likelihood ratio tests) we developed a model to predict recurrent earlyonset preeclampsia and/or HELLP syndrome. This analysis begins with a full model and variables are eliminated from the model in an iterative process. For model fitting we used chi-square tests, Hosmer and Lemeshow Goodness-of-Fit tests, and we reported Nagelkerke's R-squares. The prognostic ability of the models to discriminate between women with and those without recurrent early-onset disease was estimated by means of Receiver Operating Characteristics (ROC) analysis. As quantitative indicators of test performance the area under the ROC curve (AUC), predictive sensitivity (Se) and specificity (Sp), predictive values (PV), likelihood ratios (LR), and diagnostic odds ratios at different cut-off points were reported with corresponding $95 \%$ confidence intervals. ${ }^{11}$ To adjust for the often too optimistic estimate of the predicted performance (AUC) in the derivation study, a standard bootstrapping procedure was used. ${ }^{12}$ The regression model was estimated in 200 bootstrap samples. The 200 models derived from the bootstrap procedure were each evaluated in the bootstrap sample and in the original sample. The average difference in AUC between the bootstrap sample and the original sample was determined in order to indicate the optimism in the initially estimated discriminative ability. All analyses were performed using Stata/IC 10.0 for Windows.

\section{Results}

Of the 701 women with a hypertensive complication during their previous pregnancy, 376 women were primiparous and had had early-onset preeclampsia and/or HELLP syndrome. The response rate to the questionnaires concerning the target pregnancy was $96 \%$ after having contacted the non-responders by telephone. Of these women, 186 established a second pregnancy leading to birth before December 2007 (figure 1).

All women were Caucasian. Mean $( \pm S D)$ maternal age was $28.6( \pm 4.4)$ years at first delivery (table 1$)$. Duration of first pregnancy was $31( \pm 3)$ weeks on average and $152(82 \%)$ pregnancies resulted in delivery before 34 weeks of gestational age. Of the infants $118(25 \%)$ were born small for gestational age $(<\mathrm{p} 10)$ and the mean $( \pm$ SD) birth weight was 1318 ( \pm 599$) \mathrm{g}$. Mean maternal BMI was $25( \pm 4) \mathrm{kg} / \mathrm{m}^{2}$, with $13 \%$ of the women being obese $\left(\mathrm{BMI}>30 \mathrm{~kg} / \mathrm{m}^{2}\right)$. In the study population we also encountered the following conditions: chronic hypertension (23\%), HHC (19\%), detectable antiphospholipid antibodies (18\%) and thrombophilia (16\%). The mean interval between the first and second delivery was $3.1( \pm 1.7)$ years. 


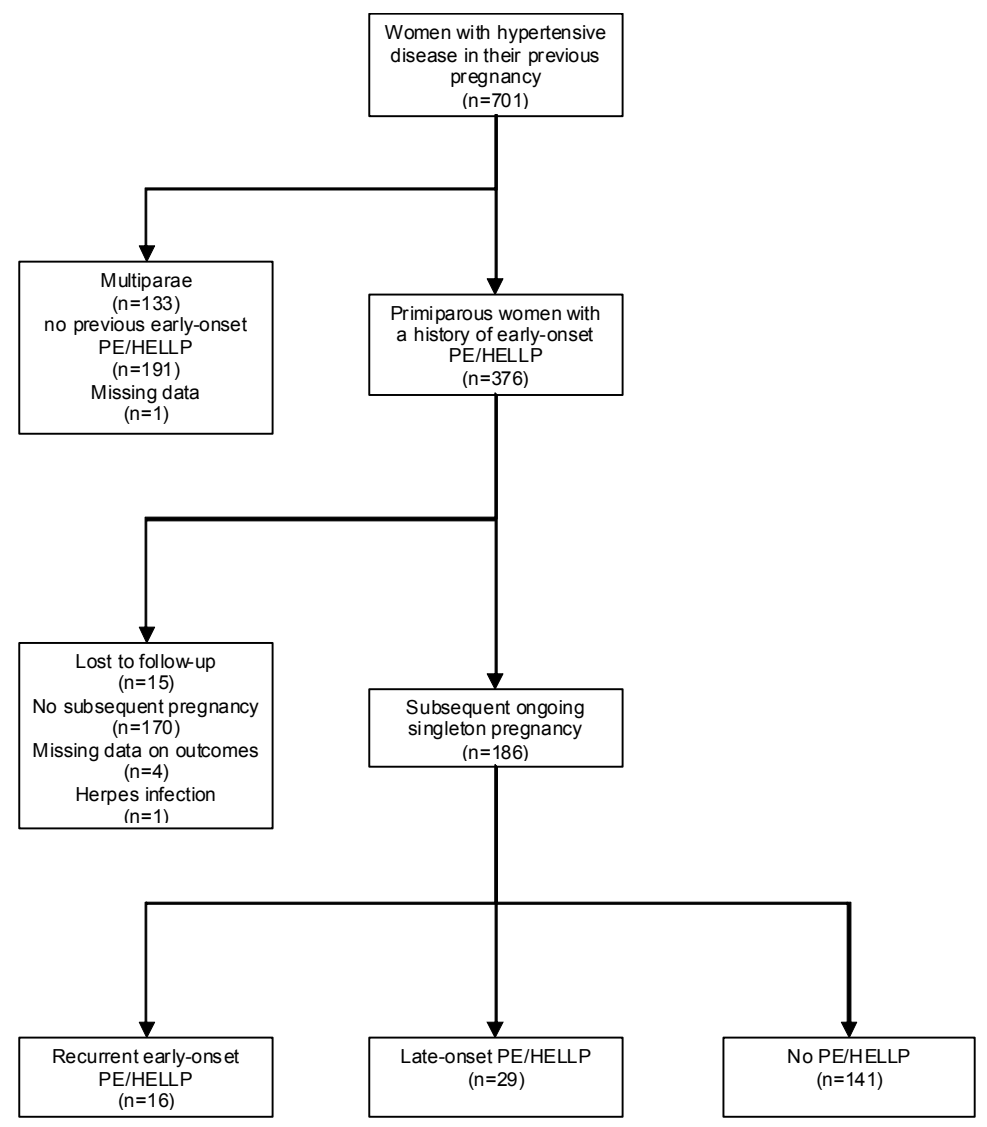

Figure 1: Details on patients selected for the study and their outcome.

In their next pregnancy $16(9 \%)$ women had recurrent early-onset preeclampsia and/or HELLP syndrome, and 29 (16\%) had late-onset disease (table 2). Recurrence was accompanied by the delivery of an SGA infant in 3 (19\%) cases with early-onset disease and in 5 (17\%) cases with late-onset disease. Of the women without recurrent disease 19 (10\% of total N) gave birth to an SGA infant and $50(27 \%)$ had isolated gestational hypertension. Pregnancy was uneventful in 72 women (39\%) (table 2).

The variables that we excluded from statistical analysis because insufficient $(<75 \%)$ data were available were: circulating levels of free thyroxine 4 , thyroid stimulating hormone, activated protein $\mathrm{C}$ resistance, high-sensitivity C-reactive protein (hs-CRP) and prothrombin 20210A mutation. After univariate analysis of the remaining variables the following were selected as candidate predictors for recurrent early-onset preeclampsia and/or HELLP syndrome and were thus included in further analysis: maternal age, circulating level of high-density lipoproteins (HDL), the ratio of HDL to 
low-density lipoproteins (LDL) and 24-h urinary protein excretion (ratio of total protein to creatinine).

Table 1: Clinical characteristics of 186 women and their first pregnancies, which were complicated by early-onset PE/HELLP.

\begin{tabular}{ll}
\hline Age at delivery (years) \pm sd & $28.6 \pm 4.4$ \\
Preeclampsia complicated by HELLP syndrome & $120(65 \%)$ \\
Preeclampsia without HELLP syndrome & $47(25 \%)$ \\
Isolated HELLP syndrome & $22(12 \%)$ \\
Gestational age at delivery (weeks) \pm sd & $31 \pm 3$ \\
Delivery $\leq 34$ weeks of gestational age & $152(82 \%)$ \\
SGA infant (<p10) & $118(25 \%)$ \\
Birth weight $(\mathrm{g}) \pm \mathrm{sd}$ & $1318 \pm 599$ \\
Maternal BMI $(\mathrm{kg} / \mathrm{m} 2)$ & $25 \pm 4$ \\
Obesity (BMI > 30 kg/m2) & $25(13 \%)$ \\
Chronic hypertension & $43(23 \%)$ \\
Hyperhomocysteïnaemia & $35(19 \%)$ \\
Anti-phospholipid antibodies & $18(10 \%)$ \\
Thrombophilia§ & $30(16 \%)$
\end{tabular}

Maternal BMI, obesity, chronic hypertension, hyperhomocysteinemia, anti-phospholipid antibodies and thrombophilia were assessed during the post partum evaluation. ${ }^{\S}$ At least 1 test positive. SGA: small for gestational age (birth weight $<10$ th percentile), BMI: body mass index

Table 2: Hypertensive complications in 186 second pregnancies after previous early-onset PE/HELLP.

\begin{tabular}{|c|c|}
\hline Early-onset PE/HELLP, of which & $16(9 \%)$ \\
\hline - PE and HELLP & $11(79 \%)$ \\
\hline - PE without HELLP & $4(25 \%)$ \\
\hline - HELLP without PE & $1(6 \%)$ \\
\hline - SGA infant $(<p 10)$ & $3(19 \%)$ \\
\hline - Normal birth weight ( $\geq \mathrm{p} 10)$ & $13(81 \%)$ \\
\hline Late-onset PE/HELLP, of which & $29(16 \%)$ \\
\hline - PE and HELLP & $6(21 \%)$ \\
\hline - PE without HELLP & $20(69 \%)$ \\
\hline - HELLP without PE & $3(10 \%)$ \\
\hline - SGA infant $(<p 10)$ & $5(17 \%)$ \\
\hline - Normal birth weight ( $\geq \mathrm{p} 10)$ & $24(83 \%)$ \\
\hline SGA infant $(<\mathrm{p} 10)$, no PE/HELLP & $19(13 \%)$ \\
\hline Isolated gestational hypertension & $50(27 \%)$ \\
\hline Uneventful pregnancy & $72(39 \%)$ \\
\hline
\end{tabular}

Less than $1 \%$ of the required data were imputed because of missing values. Collinearity was indicated between HDL cholesterol and the ratio of HDL to LDL cholesterol. We preferred the level of HDL as a predictor because of simplicity (only one variable had to be assessed) and better predictive performance.

By backward analysis the following model was developed (see also table 3): 
Predicted probability $=1 /[1+\mathrm{e}-(1.37-3.23 * \mathrm{HDL}+0.09 * \mathrm{P} / \mathrm{C})]$

In this equation, HDL represents circulating level of high-density lipoproteins ( $\mathrm{mmol}$ $\mathrm{L}-1$ ) and $\mathrm{P} / \mathrm{C}$ the protein to creatinine ratio in $24-\mathrm{h}$ urine collection (mg protein / mmol creatinine).

Table 3: Logistic regression model with recurrent early-onset PE/HELLP as dependent variable.

\begin{tabular}{|c|c|c|c|c|c|}
\hline Predictor & $\beta$ & SE $\beta$ & Wald's $\chi 2$ & $\mathrm{df}$ & $\mathrm{p}$ \\
\hline Constant & 1.37 & 1.21 & 1.13 & 1 & 0.26 \\
\hline $\mathrm{HDL}\left(\mathrm{mmol} \cdot \mathrm{L}^{-1}\right)$ & -3.23 & 1.05 & -3.07 & 1 & 0.00 \\
\hline $\mathrm{P} / \mathrm{C}$ ratio $(\mathrm{mg} / \mathrm{mmol})$ & 0.09 & 0.04 & 2.19 & 1 & 0.03 \\
\hline Test & & & $x^{2}$ & $\mathrm{df}$ & $\bar{p}$ \\
\hline \multicolumn{6}{|c|}{ Overall model evaluation: } \\
\hline Likelihood ratio test & & & 15.22 & 2 & 0.00 \\
\hline \multicolumn{6}{|l|}{ Goodness-of-fit test: } \\
\hline Hosmer \& Lemeshow & & & 111.6 & 8 & 0.99 \\
\hline
\end{tabular}

The area under the ROC curve was 0.77 ( $95 \% \mathrm{Cl}$ : 0.68-0.87) (fig. 2). The bootstrapping procedure yielded an optimism in the apparent performance of 0.02 , resulting in an internally validated ROC area of 0.75 . Table 4 shows model characteristics with different thresholds for the predicted probability. If the threshold was set to 0.05 , the predictive sensitivity (Se) and specificity (Sp) were 94\% (69-99\%) and 53\% (45$60 \%)$, respectively. Positive and negative likelihood ratios were 1.99 (1.62-2.44) and $0.12(0.02-0.79)$, respectively. The positive predictive value was $16 \%(9-24 \%)$ and 91 (49\%) women would be test negative with a predictive value (PV-) of 99\% (94-99\%).

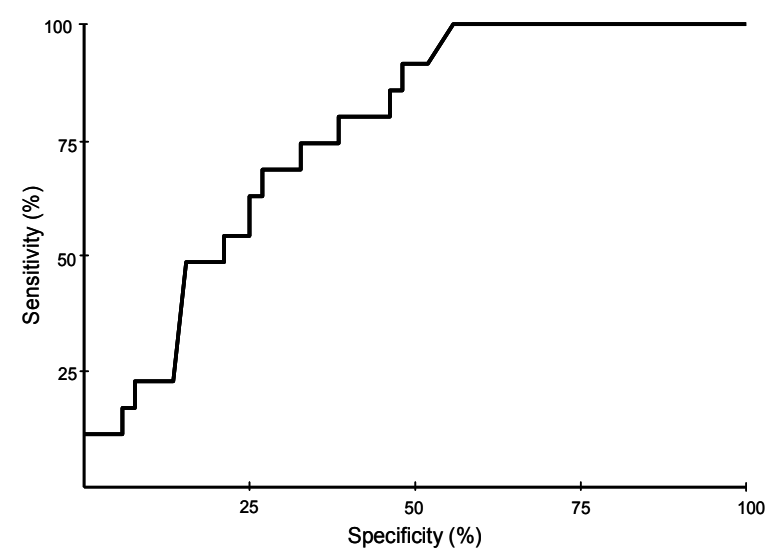

Figure 2: Receiver Operating Characteristics curve for recurrent early-onset preeclampsia/HELLP. 


\section{Discussion}

Women who had hypertensive disease in a previous pregnancy are known to be at increased risk for recurrent disease. In many Western countries this awareness has led to intensified care of pregnant former patients relative to that of their counterparts with a history of uneventful pregnancies only. The objective of this intensified care is secondary prevention. A considerable proportion of previous patients, however, will not develop (severe) recurrent hypertensive disease. Therefore, a prediction test would be of great benefit if it would enable the identification of those women with a low recurrence risk, e.g. a risk comparable to that of "healthy" nulliparae. The care provided to these women may be adjusted to the level of regular low-risk care. This could reduce health care expenses substantially without compromising on quality of care.

From that point of view, a clinically relevant screening tool for recurrent hypertensive disease should be highly sensitive (identifying the cases who will actually develop recurrent disease) with a large proportion of negative test results. Preferably, risk prediction is established before or in early pregnancy.

We developed a simple pre-pregnant prediction rule for recurrent early-onset preeclampsia and/or HELLP syndrome that includes the circulating level of starved HDLcholesterol and the 24-h urinary protein/creatinine ratio. Cut-off values can be varied as for different purposes. With a cut-off value of the predicted probability of 0.05 , almost half $(49 \%)$ of the population of former patients could be classified as being at low risk $(<1 \%)$ for recurrent early-onset disease. Especially early-onset preeclampsia and HELLP syndrome are related to an increased risk of adverse maternal and perinatal outcome. It predisposes to potentially lethal complications, such as eclampsia and placental abruption and is associated with a higher rate of small-for-gestational-age infants. ${ }^{13}$

Table 4: Test characteristics of the prediction rule $(95 \%-\mathrm{Cl})$ at different cut-off points of the predicted probability (P).

\begin{tabular}{lllllllll}
\hline$P \geq$ & Se & Sp & $+P V$ & $-P V$ & LR+ & LR- & DOR $\begin{array}{l}\text { \% neg. } \\
\text { test results }\end{array}$ \\
\hline \multirow{2}{*}{0.04} & 100 & 45 & 15 & 100 & 1.80 & 0.00 & NaN & 41 \\
& $(79-100)$ & $(37-52)$ & $(8-22)$ & $(95-100)$ & $(1.57-2.07)$ & $(0-N a N)$ & & \\
\multirow{2}{*}{0.05} & 94 & 53 & 16 & 99 & 1.99 & 0.12 & 17 & 49 \\
& $(69-99)$ & $(45-60)$ & $(9-24)$ & $(94-99)$ & $(1.62-2.44)$ & $(0.02-0.79)$ & & \\
0.06 & 88 & 55 & 15 & 98 & 1.93 & 0.23 & 10 & 51 \\
& $(61-98)$ & $(46-62)$ & $(8-24)$ & $(92-99)$ & $(1.50-2.47)$ & $(0.06-0.84)$ & & \\
0.07 & 75 & 68 & 18 & 97 & 2.31 & 0.37 & 6 & 64 \\
& $(47-92)$ & $(60-74)$ & $(9-29)$ & $(91-99)$ & $(1.62-3.31)$ & $(0.16-0.86)$ & & \\
\hline
\end{tabular}

Se: sensitivity, Sp: specificity, +PV: positive predictive value, -PV: negative predictive value, +LR: positive likelihood ratio, -LR: negative likelihood ratio, DOR: diagnostic odds ratio 
In accordance with previous reports, our data show that the outcome of a next pregnancy in women with previous early-onset preeclampsia/HELLP is more favourable than that of the prior complicated pregnancy. ${ }^{14}$ Relative to the first pregnancy, mean duration of the next pregnancy was 7.5 weeks longer and mean birth weight $1778 \mathrm{~g}$ higher. The birth weight criterion for referral to the neonatal intensive care unit in the Netherlands is $<1250 \mathrm{~g}$. Of previous pregnancies, $53 \%$ resulted in delivery of an infant with birth weight below this treshold, against only $2 \%$ of the subsequent pregnancies. Nevertheless, preeclampsia and/or the HELLP syndrome recurred in about one-fourth of our study population, in line with previous findings. ${ }^{13}$ Although $75 \%$ of our study population had the HELLP syndrome during their previous pregnancy, the recurrence rate of this syndrome was relatively low (11\%), an observation also reported by others. ${ }^{15}$

Previous attempts have been made to predict the risk of recurrent disease in former preeclamptic or HELLP syndrome patients, often with disappointing test performances. Most of these studies focused on single parameters. Among them, parameters related to uterine artery Doppler blood flow velocity profiles might be promising in the prediction of recurrent preeclampsia. An elevated systolic/diastolic ratio (>3.3 or $>3.0$ combined with a diastolic notch) at 18 weeks of gestational age, ${ }^{16}$ increased resistance index $(>0.58),{ }^{17}$ and the presence of a diastolic notch ${ }^{17}$ at 24 weeks of gestational age each predicted recurrent preeclampsia with a sensitivity of $100 \%$. The specificity was moderate $(72 \%, 60 \%$ and $62 \%$, respectively) and $57 \%$ of the women had negative test results. However, the confidence intervals around the estimated sensitivities were quite large and by the time the prediction results had been obtained the women were already 4-6 months pregnant. The latter limits the possibility of reducing intensity of follow-up during the target pregnancy in testnegative women.

Since hypertensive disorders in pregnancy are heterogeneous conditions, probably involving several separate pathophysiologic pathways, it is not surprising that predicting the recurrence of these disorders based on a single variable has been disappointing. Mello and others ${ }^{18}$ combined the longitudinal patterns of several variables during early pregnancy (until 20 weeks) in a logistic regression model to predict recurrent preeclampsia. The characteristics of this prediction model showed potential (Se and Sp were $79 \%$ and $89 \%$, respectively), but again the usability of the model to reduce intensity of care is limited because of its late application ( $>20$ weeks) and repeated measurements are needed in the target pregnancy.

Obviously, the management of next pregnancies in this study may have ameliorated the outcome, an effect that could limit the applicability of the model to other populations, in which management is different. This effect probably only concerns nonuniformly supported treatments such as low molecular weight heparins (LMWH), which we prescribed to about half of the women with thrombophilia ( $7 \%$ of the population). These women were equally distributed among the two outcome 
groups ( $p=0.721$ ). Moreover, most women in this study started to use multivitamin supplements as per advice before or during the target pregnancy, including the women with hyperhomocysteinemia. Another aspect that could hamper the validity of the model in future applications is the selection of the study population based on the presence of a subsequent pregnancy. If the composition of the study population in terms of clinical characteristics is to change, whether or not caused by tests results of the current prediction rule, this could influence the predictive capacity of the model. Therefore, it is important to update the prediction rule regularly.

Prediction models generally tend to perform better in the patients that provided the input for the model (derivation cohort) than on new patients. However, internal validation by means of bootstrapping techniques showed that over-optimism is limited in the present prediction model. Before introducing the prediction rule in daily practice, it should be evaluated and, if necessary, updated in a new comparable population (external validation). ${ }^{19}$

\section{Acknowledgements}

We thank T Ekhart and I Schreij for the collection and entry of the data. 


\section{References}

1. Sibai B, Dekker G, Kupferminc M. Pre-eclampsia. Lancet 2005;365(9461):785-99.

2. Sibai BM. Diagnosis, prevention, and management of eclampsia. Obstet Gynecol 2005;105(2):402-10.

3. Conde-Agudelo A, Villar J, Lindheimer M. World Health Organization systematic review of screening tests for preeclampsia. Obstet Gynecol 2004;104(6):1367-91.

4. van Pampus MG, Aarnoudse JG. Long-term outcomes after preeclampsia. Clin Obstet Gynecol 2005;48(2):489-94.

5. Brown MA, Lindheimer MD, de Swiet M, Van Assche A, Moutquin JM. The classification and diagnosis of the hypertensive disorders of pregnancy: statement from the International Society for the Study of Hypertension in Pregnancy (ISSHP). Hypertens Pregnancy 2001;20(1):IX-XIV.

6. Sibai BM, Ramadan MK, Usta I, Salama M, Mercer BM, Friedman SA. Maternal morbidity and mortality in 442 pregnancies with hemolysis, elevated liver enzymes, and low platelets (HELLP syndrome). Am J Obstet Gynecol 1993;169(4):1000-6.

7. The Netherlands Perinatal Registry [homepage on the internet]. Bilthoven: NPR-foundation; [cited 2007 September 18]. Available from: http://www.perinatreg.nl/

8. Refsum H, Smith AD, Ueland PM, Nexo E, Clarke R, McPartlin J, et al. Facts and recommendations about total homocysteine determinations: an expert opinion. Clin Chem 2004;50(1):3-32.

9. ACOG Practice Bulletin. Chronic hypertension in pregnancy. ACOG Committee on Practice Bulletins. Obstet Gynecol 2001;98(1):suppl 177-85.

10. Longford N. Missing data and small-area estimation. In. London: Springer; 2005. p. 37-58.

11. Glas AS, Lijmer JG, Prins MH, Bonsel GJ, Bossuyt PMM. The diagnostic odds ratio: a single indicator of test performance. J of Clin Epidemiol 2003;56(11):1129-35.

12. Steyerberg EW, Harrell FE, Borsboom GJJM, Eijkemans MJC, Vergouwe Y, Habbema JDF. Internal validation of predictive models: Efficiency of some procedures for logistic regression analysis. J Clin Epidemiol 2001;54(8):774781.

13. Witlin AG, Saade GR, Mattar F, Sibai BM. Predictors of neonatal outcome in women with severe preeclampsia or eclampsia between 24 and 33 weeks' gestation. Am J Obstet Gynecol 2000;182(3):607-11.

14. van Rijn BB, Hoeks LB, Bots ML, Franx A, Bruinse HW. Outcomes of subsequent pregnancy after first pregnancy with early-onset preeclampsia. Am J Obstet Gynecol 2006;195(3):723-8.

15. Sibai BM, Ramadan MK, Chri RS, Friedman SA. Pregnancies complicated by HELLP syndrome (hemolysis, elevated liver enzymes, and low platelets): Subsequent pregnancy outcome and long-term prognosis. Am J Obstet Gynecol 1995;172(1, Part 1):125-129.

16. Morris J, Fay R, Ellwood D. Abnormal Uterine Artery Waveforms in the Second Trimester Are Associated with Adverse Pregnancy Outcome in High Risk Women. J Matern Fetal Investig 1998;8(2):82-4.

17. Frusca T, Soregaroli M, Danti L, Guandalini F, Lojacono A, Scalvi L, et al. Uterine artery velocimetry as a screening test in patients with previous preeclampsia. Italian Journal of Gynaecology and Obstetrics 1996;8(3):94-98.

18. Mello G, Parretti E, Cioni R, Lagozio C, Mealli F, Pratesi M. Individual longitudinal patterns in biochemical and hematological markers for the early prediction of pre-eclampsia. J Matern Fetal Neonat Med 2002;11(2):93-9.

19. van Houwelingen HC. Validation, calibration, revision and combination of prognostic survival models. Stat Med 2000;19(24):3401-15. 



\section{CHAPTER 4}

\section{Counseling for recurrent}

preeclampsia, does

\section{obesity matter?}

Simone Sep, Silvia Andrietti, Julia Spaan, Luc Smits, Louis Peeters 


\section{Abstract}

Objective: In this study we tested the hypothesis that not obesity, but the associated metabolic abnormalities predispose to recurrent preeclampsia.

Methods: In this observational study, we used hospital data collected between 1996 and 2008 of 196 women with two consecutive pregnancies, the first pregnancy being complicated by early-onset (diagnosis $\leq 34$ weeks, delivery $\leq 37$ weeks) preeclampsia. After this index pregnancy, all women were screened for underlying abnormalities. Using these screening data, we estimated the association between obesity (body mass index $\geq 30 \mathrm{~kg} / \mathrm{m} 2$ ) and recurrent preeclampsia by logistic regression analysis, controlling for potential confounders (maternal age, interpregnancy interval, thrombophilia, plasma volume, creatinine clearance rate) and metabolic syndrome (MetS) related abnormalities defined according to the International Diabetes Federation (triglycerides, HDL-cholesterol, blood pressure, fasting plasma glucose).

Results: Overall, 49 (25\%) women developed recurrent preeclampsia. The odds ratio for recurrent disease in obese $(n=28)$ versus non-obese $(n=168)$ women was 2.5 (95\%-Cl: 0.9-6.4) after adjustment for confounders. However, after additional correction for the presence of the four MetS-constituting parameters, the odds ratio was 1.1 (0.4-3.2). By contrast, the odds ratio in women with two or more criteria of the metabolic syndrome versus none was, independent of obesity, 3.8 (1.410.2).

Conclusion: Our results indicate that metabolic abnormalities rather than obesity predispose to recurrent preeclampsia. Meeting at least two MetS criteria, irrespective the presence of obesity, is associated with an increased risk for recurrent disease. Therefore, in preconceptional counseling of obese women, besides weight reduction the components of the metabolic syndrome deserve at least as much attention. 


\section{Introduction}

Obesity is a widely established risk factor for preeclampsia, ${ }^{1}$ although the mechanisms involved are only partially understood. Obesity is associated with hypertension, chronic inflammation and metabolic abnormalities such as insulin resistance and dyslipidemia. ${ }^{2,3}$ In pregnancy, all these abnormalities may affect placental growth and development. ${ }^{4}$ It is conceivable that these metabolic abnormalities, rather than obesity itself, predispose to preeclampsia.

In clinical practice, obesity is considered an independent risk factor for preeclampsia. Women with a history of preeclampsia are often counseled for recurrent disease prior to their next pregnancy. ${ }^{3}$ One objective in preconceptional counseling is to reduce modifiable risk factors. ${ }^{5}$ In obese former preeclamptics, the latter usually consists of strategies to promote weight loss. However, if the association between obesity and preeclampsia is weaker than the one between underlying metabolic abnormalities and preeclampsia, counseling should focus on improvement of these abnormalities rather than on advocating weight loss solely.

Cardiovascular sequels of preeclampsia have prompted a search for a common mechanism or predisposing factors. A spectrum of metabolic disorders, known as metabolic syndrome (MetS), has been posited as an important connection between preeclampsia and cardiovascular disease in later life. ${ }^{6-11}$ Women with a history of preeclampsia frequently exhibit features of Mets. ${ }^{12,13}$

The aim of this study was to test the hypothesis that metabolic abnormalities rather than obesity itself predispose to recurrent preeclampsia. To this end, we determined the independent contribution of both obesity and MetS components to the recurrence risk of preeclampsia.

\section{Methods}

This is an observational study performed at Maastricht University Medical Centre in the Netherlands. Women with a recent history of preeclampsia are referred to our tertiary referral center for the detection of underlying disorders or abnormalities, and for counseling prior to their next pregnancy. All measurements reported in this study had been obtained as part of the usual care provided to high-risk obstetrical patients. It follows that, although observations had been collected prospectively, the collection of the data was done retrospectively. All hospital data, including those on pregnancy outcome, were collected and entered in a database by a clinical research assistant who was not involved in the statistical analysis. Prior to analysis, data were anonymized. In the Netherlands, ethical approval of a study based on anonymized data originating from clinical care, is not required. 
For the purpose of this study, we screened women who had had early-onset preeclampsia (diagnosed $\leq 34$ weeks pregnancy and resulting in delivery $\leq 37$ weeks), referred from June 1996 onwards, for eligibility $(N=444)$. We excluded women who were multiparous at the time of referral, had no subsequent ongoing ( $>20$ weeks of pregnancy) singleton pregnancy resulting in delivery before December 2008, were lost-to-follow up, or had missing data on metabolic variables leading to failure in defining MetS.

Multiparous $(n=59)$

No subsequent singleton pregnancy $(n=167)$

Lost-to-follow up $(n=15)$

Missing metabolic data $(n=7)$

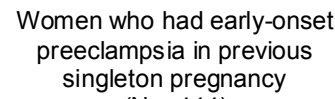

Women who had early-onset preeclampsia in previous singleton pregnancy $(\mathrm{N}=444)$
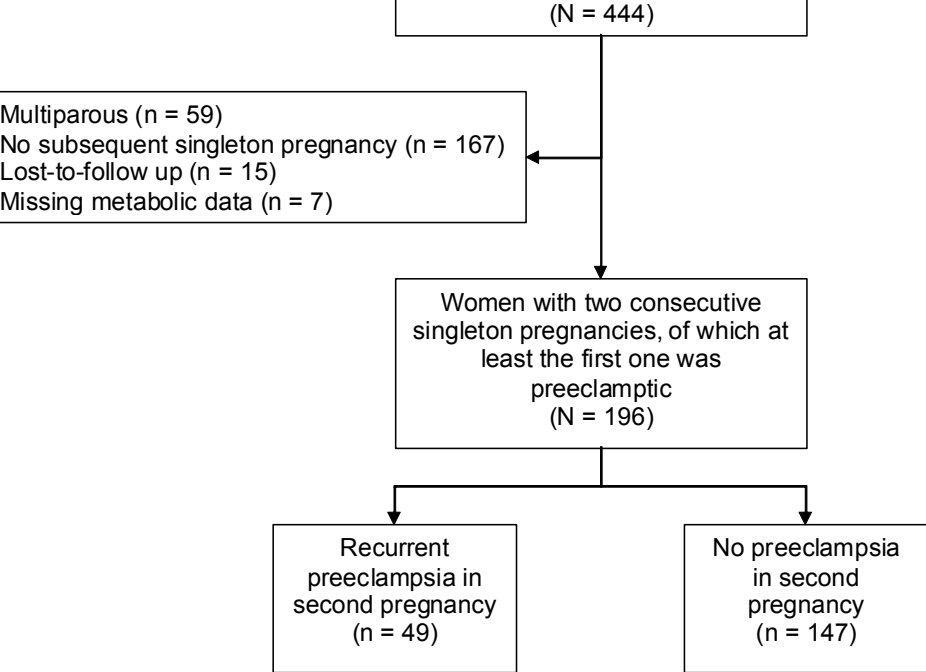

Figure 1: The selection of the study population.

We defined preeclampsia according to the guidelines of the National working group on High Blood Pressure in Pregnancy, as new-onset hypertension (blood pressure > $140 / 90 \mathrm{mmHg}$, occurring after the 20th week of pregnancy) accompanied by proteinuria (> $300 \mathrm{mg} / 24 \mathrm{~h}$ or $>30 \mathrm{mg} / \mathrm{mmol}$ creatinine). ${ }^{12}$ Preeclampsia superimposed on chronic hypertension was defined as new-onset proteinuria after 20 weeks' gestation. Late-onset preeclampsia was defined as preeclampsia diagnosed after 34 weeks pregnancy and/or resulting in delivery after 37 weeks. We used a birthweight below the 10th percentile, based on the most recent Dutch birthweight reference curves, to diagnose fetal growth restriction. Although screening data were collected in our medical center, the location of delivery in the next pregnancy could be in other Dutch hospitals, giving rise to variation in diagnostic methods for preeclampsia. For example, the diagnosis of proteinuria was based on a 24-hours urine collection in some hospitals and on the ratio protein to creatinine in others. In the database available for statistical analysis, women were coded as having had or not hav- 
ing had a next pregnancy complicated by preeclampsia, according to the definition described above. Individual in-pregnancy laboratory values were not supplied.

The screening - at least six months postpartum - also included the measurement of metabolic variables. Serum concentrations of triglycerides (TG), total cholesterol (TC) and HDL-cholesterol (HDL-C) were determined on a Beckman Coulter LX20 PRO Clinical Chemistry analyzer (Beckman Coulter, Fullerton, USA). We calculated lowdensity lipoprotein cholesterol (LDL-C) by the Friedewald equation. ${ }^{13}$ Fasting levels of glucose and insulin were assessed using standard laboratory techniques. Body length and weight were determined in a standardized fashion. We obtained body mass index $(\mathrm{BMI})$ by taking the ratio of weight $(\mathrm{kg})$ and height $(\mathrm{cm})$ squared. We defined (central) obesity as $B M I \geq 30 \mathrm{~kg} / \mathrm{m}^{2}$.

The MetS was defined in accordance with the 'new worldwide definition (2006)' of the International Diabetes Federation, as central obesity with at least two of the following criteria: raised triglycerides ( $\geq 1.7 \mathrm{mmol} / \mathrm{L} ; 150 \mathrm{mg} / \mathrm{dL}$ ) or specific treatment; reduced $\mathrm{HDL}$-cholesterol $(<1.29 \mathrm{mmol} / \mathrm{L} ; 50 \mathrm{mg} / \mathrm{dL})$ or specific treatment; raised blood pressure $(\geq 130 / 85 \mathrm{mmHg}$ ) or specific treatment; and raised fasting plasma glucose (> $5.6 \mathrm{mmol} / \mathrm{L} ; 100 \mathrm{mg} / \mathrm{dL}$ ) or type II diabetes mellitus. ${ }^{14}$

We adjusted the association estimated for a range of maternal conditions and characteristics, including thrombophilia, plasma volume, creatinin clearance rate, maternal age, and inter-pregnancy interval. Within the scope of the thrombophilic screening, all women had been tested for anticardiolipin antibodies (IgG/IgM $>10$ GPL/MPL) and lupus anticoagulant in peripheral blood, as detailed previously. ${ }^{15}$ The fasting circulating level of homocysteine had been assessed and was considered elevated when levels exceeded $15 \mu \mathrm{mol} / \mathrm{L}$. The factor $\mathrm{V}$ Leiden and prothrombin 20210A mutations had been analyzed by routine PCR techniques after extraction of genomic DNA from peripheral leukocytes. Activity of antithrombin (Chromogenix, Molndal, Sweden) and protein C (Behring, Marburg, Germany) had been measured by chromogenic substrate assays, and protein $S$ antigen levels by enzyme-linked immunosorbent assay (ELISA; DAKO, Glostrup, Denmark). We defined deficiency of each of these parameters as an activity level below $65 \%$ of normal. For the statistical analysis, we created a dichotomous thrombophilic variable that was positive when at least one of the following conditions were present: Factor $V$ Leiden mutation, prothrombin 20210A mutation, deficiency of antithrombin AT III, protein C or protein $\mathrm{S}$, increased level of fasting homocystein, or positive tests for anticardiolipin antibodies or lupus anticoagulant. We quantified plasma volume by the indicator dilution technique using $125 \mathrm{I}$ - labeled albumin (125I-HSA) as indicator, as detailed previously. ${ }^{15}$ We measured creatinine both in a 24 -hour urine sample and in the peripheral blood. As an estimate for the glomerular filtration rate, we calculated the volume of blood plasma that is cleared of creatinine per unit time (creatinine clearance rate). 
We used SPSS version 15.0.0 for statistical analysis. In a multiple logistic regression model, we estimated the odds ratio $(\mathrm{OR})$ for recurrent preeclampsia in obese women adjusted for the potential confounders described above. In a second regression model, we further adjusted the OR for the metabolic components of the MetS: HDLcholesterol, triglycerides, mean arterial pressure (calculated as [ $2 \mathrm{x}$ diastolic)+systolic] / 3) and fasting glucose. A third regression model included the presence or absence of the MetS instead of obesity as an independent variable, to estimate its association. Based on the cut-off values defined for the MetS components, we created a variable with three categories: 1) no metabolic criteria fulfilled, 2) one metabolic criterion fulfilled and 3) two or more metabolic criteria fulfilled, irrespective the presence or absence of obesity. We added this variable to a fourth regression model, which additionally included obesity and the confounders described to estimate the association between the presence of these metabolic abnormalities and recurrent preeclampsia, independent of obesity. In this fourth model, we also tested for interaction between BMI and the number of MetS components. We reported ORs with $95 \%$-confidence intervals $(95 \%-\mathrm{Cl})$.

Table 1: Demographic and clinical characteristics of the study population.

\begin{tabular}{|c|c|c|c|}
\hline & $\begin{array}{l}\text { Overall } \\
(N=196)\end{array}$ & $\begin{array}{l}\text { Obese women } \\
(n=28)\end{array}$ & $\begin{array}{l}\text { Non-obese women } \\
(n=168)\end{array}$ \\
\hline Maternal age (y) & $30.0 \pm 3.6$ & $29.6 \pm 3.6$ & $30.1 \pm 3.6$ \\
\hline Body weight (kg) & $71.8 \pm 13.8$ & $94.5 \pm 12.6$ & $68.0 \pm 9.8$ \\
\hline Body length (cm) & $168 \pm 6$ & $167 \pm 7$ & $169 \pm 6$ \\
\hline \multicolumn{4}{|l|}{ Weight class: } \\
\hline Underweight (BMI < 20) & $16(8 \%)$ & - & $16(10 \%)$ \\
\hline Normal weight (BMI 20-25) & $90(46 \%)$ & - & $90(54 \%)$ \\
\hline Overweight (BMI 25-30) & $62(32 \%)$ & - & $62(37 \%)$ \\
\hline Obesity (BMI 30-35) & $18(9 \%)$ & $18(64 \%)$ & - \\
\hline Morbid obesity (BMI > 35) & $10(5 \%)$ & $10(36 \%)$ & - \\
\hline Fasting glucose (mmol/L) & $5.1 \pm 0.5$ & $5.4 \pm 0.4$ & $5.1 \pm 0.5$ \\
\hline Fasting insulin (mmol/L) & $11.9 \pm 6.2$ & $18.9 \pm 7.5$ & $10.8 \pm 5.2$ \\
\hline Total cholesterol (mmol/L) & $4.9 \pm 0.9$ & $5.1 \pm 0.9$ & $4.9 \pm 0.9$ \\
\hline HDL-cholesterol (mmol/L) & $1.37 \pm 0.35$ & $1.13 \pm 0.30$ & $1.41 \pm 0.34$ \\
\hline LDL-cholesterol (mmol/L) & $3.1 \pm 0.8$ & $3.3 \pm 0.7$ & $3.1 \pm 0.8$ \\
\hline Triglyceride (mmol/L) & $1.1 \pm 0.8$ & $1.64 \pm 0.81$ & $0.99 \pm 0.74$ \\
\hline $\begin{array}{l}\text { Systolic blood pressure } \\
\text { (mmHg) }\end{array}$ & $122 \pm 13$ & $126 \pm 15$ & $122 \pm 13$ \\
\hline $\begin{array}{l}\text { Diastolic blood pressure } \\
(\mathrm{mmHg})\end{array}$ & $76 \pm 11$ & $77 \pm 9$ & $75 \pm 12$ \\
\hline Mean arterial pressure $(\mathrm{mmHg})$ & $93 \pm 11$ & $96 \pm 12$ & $93 \pm 11$ \\
\hline Chronic hypertension & $71(36 \%)$ & $12(43 \%)$ & $59(35 \%)$ \\
\hline Plasma volume (mL) & $2376 \pm 376$ & $2680 \pm 385$ & $2311 \pm 346$ \\
\hline$\geq 1$ thrombophilic test positive & $50(26 \%)$ & $7(25 \%)$ & $43(26 \%)$ \\
\hline $\begin{array}{l}\text { Creatinine clearance } \\
\left(\mathrm{mL} / \mathrm{min} / 1.73 \mathrm{~m}^{2}\right)\end{array}$ & $112 \pm 29$ & $108 \pm 31$ & $113 \pm 29$ \\
\hline Inter-pregnancy interval (y) & $2.3(2.1)$ & $2.6(2.4)$ & $2.3(2.0)$ \\
\hline
\end{tabular}

Inter-pregnancy interval reported as median (IQR). 


\section{Results}

From the 444 screened women with a history of early-onset preeclampsia, 196 women were eligible for inclusion, as illustrated in figure 1. Twenty-eight women (14\%) were obese. Table 1 lists demographic and clinical characteristics of the study population. Obese formerly preeclamptic women differed from their non-obese counterparts by higher mean circulating levels of fasting total cholesterol, LDLcholesterol, triglycerides, glucose and insulin along with lower levels of HDL cholesterol. Moreover, their plasma volume was larger and their median inter-pregnancy interval about 3.5 months longer.

Table 2 lists the frequencies of metabolic abnormalities. The MetS was diagnosed in $17(9 \%)$ obese women at least six months postpartum. Four of these women fulfilled all MetS criteria. The presence of $\geq 2$ components of the MetS was positively associated with weight class, as shown in figure 2. Nevertheless, 34 (20\%) nonobese women fulfilled $\geq 2$ metabolic criteria (table 2 ).

Table 2: Metabolic syndrome components in obese and non-obese formerly preeclamptic women.

\begin{tabular}{lll}
\hline & $\begin{array}{l}\text { Obese women } \\
(\mathrm{n}=28)\end{array}$ & $\begin{array}{l}\text { Non-obese women } \\
(\mathrm{n}=168)\end{array}$ \\
\hline Raised triglycerides or specific treatment & $12(43 \%)$ & $15(9 \%)$ \\
Reduced HDL-cholesterol or specific treatment & $20(71 \%)$ & $56(33 \%)$ \\
Raised blood pressure or specific treatment & $12(43 \%)$ & $59(35 \%)$ \\
Raised fasting glucose or type II diabetes mellitus & $11(39 \%)$ & $23(14 \%)$ \\
None of these & & $57(34 \%)$ \\
1 component & $2(7 \%)$ & $77(46 \%)$ \\
2 components & $9(32 \%)$ & $30(18 \%)$ \\
3 components & $9(32 \%)$ & $4(2 \%)$ \\
4 components & $4(14 \%)$ & - \\
\hline
\end{tabular}

raised triglycerides ( $\geq 1.7 \mathrm{mmol} / \mathrm{L} ; 150 \mathrm{mg} / \mathrm{dL}$ ); reduced $\mathrm{HDL}$-cholesterol (<1.29 mmol/L; $50 \mathrm{mg} / \mathrm{dL}$; raised blood pressure ( $\geq 130 / 85 \mathrm{mmHg})$; raised fasting plasma glucose $(>5.6 \mathrm{mmol} / \mathrm{L} ; 100 \mathrm{mg} / \mathrm{dL}$ )

Table 3 summarizes the outcome of the first and the second pregnancy. Overall, 49 (25\%, 95\%-Cl: 19-32\%) women developed preeclampsia in their next pregnancy. The second pregnancy lasted on average 7.5 weeks longer and the infant's birth weight was on average $1.8 \mathrm{~kg}$ higher as compared to the first pregnancy.

Table 4 presents the association estimates of obesity and the MetS with recurrent preeclampsia. The OR of obesity was 2.5 (95\%-Cl: 0.9-6.4), after adjustment for confounding, which was almost similar to the association between the MetS and recurrent preeclampsia (2.4 (95\%-Cl: 0.7-7.7)). Due to listwise deletion, two women, who had not developed recurrent preeclampsia, were excluded from the multivariable analysis. After additional adjustment for the fasting circulating levels of triglycerides, HDL-cholesterol, glucose and the mean arterial pressure, the OR of obesity 
reduced to 1.0 (95\%-Cl: $0.3-3.0)$. By contrast, the presence of two or more metabolic syndrome criteria proved, independent of obesity, to be associated with recurrent preeclampsia (OR = 3.8, 95\%-Cl: 1.4-10.2).

Table 3: Outcome of the first and second pregnancies.

\begin{tabular}{lll}
\hline & First pregnancy & Second pregnancy \\
\hline Early-onset preeclampsia & $100 \%$ & $19(10 \%)$ \\
Late-onset preeclampsia & - & $30(15 \%)$ \\
Gestational hypertension & - & $35(18 \%)$ \\
Pregnancy duration (wks) & $30.9 \pm 3.1$ & $38.4 \pm 2.6$ \\
Infant's birth weight (g) & $1307 \pm 567$ & $3085 \pm 712$ \\
SGA infant (<p10) & $41(21 \%)$ & $42(21 \%)$ \\
IUD & $17(9 \%)$ & $6(3 \%)$ \\
IUD: Intra-uterine demise & & \\
\hline
\end{tabular}

Table 4: Odds ratios (OR) with corresponding 95\%-confidence intervals for recurrent preeclampsia of obesity, the MetS and the presence of two or more metabolic components of the MetS (irrespective the presence or absence of obesity).

\begin{tabular}{|c|c|c|c|c|c|}
\hline & $\mathrm{N}$ & $\begin{array}{l}\text { Recurrent } \\
\text { preeclampsia }\end{array}$ & $\begin{array}{l}\text { OR } \\
\text { unadjusted }\end{array}$ & $\begin{array}{l}\text { OR } \\
\text { adjusted I }\end{array}$ & $\begin{array}{l}\text { OR } \\
\text { adjusted II }\end{array}$ \\
\hline \multicolumn{6}{|l|}{ Obesity } \\
\hline No & & $39(23 \%)$ & 1 & 1 & 1 \\
\hline Yes & & $10(36 \%)$ & $1.8(0.8-4.3)$ & $2.5(0.9-6.4)$ & $1.1(0.4-3.2)^{\dagger}$ \\
\hline \multicolumn{6}{|l|}{ MetS } \\
\hline No & & $43(24 \%)$ & 1 & 1 & - \\
\hline Yes & & $6(35 \%)$ & $1.7(0.6-4.8)$ & $2.4(0.7-7.7)$ & - \\
\hline \multicolumn{6}{|c|}{ MetS components } \\
\hline 0 & & $8(14 \%)$ & 1 & 1 & 1 \\
\hline 1 & & $20(24 \%)$ & $2.0(0.8-4.8)$ & $2.0(0.8-5.0)$ & $1.9(0.8-4.8)^{\ddagger}$ \\
\hline$\geq 2$ & & $21(41 \%)$ & $4.5(1.8-11.3)$ & $4.3(1.6-11.2)$ & $3.8(1.4-10.2)^{\ddagger}$ \\
\hline \multicolumn{6}{|l|}{ Joint effect } \\
\hline Obesity $_{0} \mathrm{MetS}_{0}$ & & $7(12 \%)$ & 1 & 1 & - \\
\hline Obesity $_{0}$ MetS $_{\geq 2}$ & & $15(44 \%)$ & $5.6(2.0-16.0)$ & $4.8(1.6-14.2)$ & - \\
\hline Obesity $_{1}$ MetS $_{\geq 2}$ & & $6(35 \%)$ & 3.9 (1.1-13.9) & $5.7(1.3-24.2)$ & - \\
\hline
\end{tabular}

No statistically significant interaction was detected between obesity and the presence of at least two MetS components on a multiplicative scale $(p=0.14)$. However, relative to non-obese women without metabolic abnormalities, the joint effect of obesity and the presence of two or more MetS components, after adjustment for 
confounders, tended to be stronger (OR $=5.7,95 \%-\mathrm{Cl}: 1.3-24.2)$ than the effect of the presence of two or more components in the absence of obesity (OR $=4.8,95 \%$ $\mathrm{Cl}: 1.6-14.2)$.

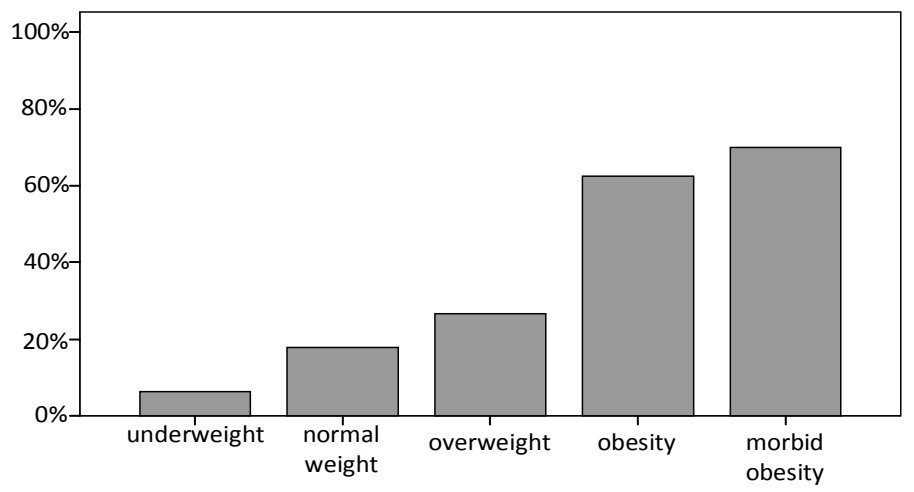

Figure 2: Frequency of the presence of $\geq 2$ metabolic components of the MetS in different weight categories.

\section{Discussion}

Our results provide evidence that obesity related metabolic abnormalities rather than obesity by itself predispose to recurrent preeclampsia. The presence of at least two metabolic components of the MetS correlates strongly with the recurrence of preeclampsia, independent of the presence of obesity.

Because of the absence of data on waist circumference, we defined (central) obesity as $\mathrm{BMI} \geq 30 \mathrm{~kg} / \mathrm{m}^{2}$. The International Diabetes Federation defines obesity as a waist circumference $\geq 80 \mathrm{~cm},{ }^{14}$ with the remark that central obesity can be assumed if the BMI exceeds $30 \mathrm{~kg} / \mathrm{m}^{2}$. Consequently, false positive diagnoses of central obesity are unlikely. Nevertheless, in our population the prevalence of central obesity, and thus its association with recurrent preeclampsia, mmay be slightly underestimated. Furthermore, we calculated the BMI at the time of screening, which was at least six months after the preeclamptic pregnancy. It is possible that obese women tried to lose weight between the post-screening counseling visit and the next pregnancy. Although we did not have data on maternal body weight shortly before the second pregnancy, based upon our experience significant weight loss in the short period between screening and the next pregnancy (median: 10 months, IQR: 7-21 months in obese women) is unlikely. Effective interventions for overweight and obesity are currently unavailable. ${ }^{16}$ 
The pregnancy rate in obese $\left(\mathrm{BMI} \geq 30 \mathrm{~kg} / \mathrm{m}^{2}\right.$ ) primiparous women tended to be lower $(44 \%)$ than in non-obese primiparae $(55 \%)$, which may be due to menstrual dysfunction and anovulation. ${ }^{17}$ However, the frequency of obesity and morbid obesity in the selected population of women with a second pregnancy (table 1 ) was similar as in the total population of screened former primiparous patients $(\mathrm{N}=368$; $11 \%$ and $5 \%$, respectively).

Contrary to expectation, the prevalence of obesity (BMI $\geq 30$ ) in our study population was similar to that in the overall population of Dutch women of reproductive age, being $10 \%$ and $13 \%$ among women aged $20-29$ and $30-39$ years, respectively, in 2001 and having increased slightly since. ${ }^{18,19}$ This might be due to the inclusion of women with a history of early-onset preeclampsia only, with possible different pathophysiological pathways than late-onset preeclampsia. ${ }^{20}$ However, since the risk of recurrence is highest in women with previous early-onset preeclampsia, these women in particular are closely monitored. ${ }^{21}$ When we analyzed early- (as previously defined) and late (diagnosis $\geq 34$ weeks and/or delivery $\geq 37$ weeks) recurrence of preeclampsia separately, the association with obesity was comparable $(\mathrm{OR}=2.3,95 \%-\mathrm{Cl}: 0.6-9.3$, and $\mathrm{OR}=2.7,95 \%-\mathrm{Cl}: 0.8-8.7$, respectively), but the confounding effect of MetS related variables tended to be stronger in the former (OR for obesity $=0.7,95 \%-\mathrm{Cl}: 0.1-3.8$, and 1.4, 95\%-Cl: 0.4-5.1, respectively, after adjustment for triglycerides, $\mathrm{HDL}-\mathrm{C}$, glucose and MAP). Along these lines, the association of the presence of at least two metabolic components of the MetS with early-onset recurrent preeclampsia was stronger ( $O R=7.4,95 \%-\mathrm{Cl}: 1.4-38.5)$ than that with late-onset recurrent preeclampsia (OR $=2.1,95 \%-\mathrm{Cl}: 0.6-6.8)$, independent of obesity. In the perspective of the modest statistical power of these subanalyses, which included 10 and 7 independent variables, respectively, overall recurrent preeclampsia as primary outcome was preferred.

To the best of our knowledge, there is no evidence against obesity being an independent risk factor for preeclampsia, although others have suggested the hypothesis before. ${ }^{22}$ The link between the metabolic syndrome and preeclampsia risk has gained growing attention. ${ }^{23-27} \mathrm{~A}$ metabolic score rather than the traditional definition of metabolic syndrome or individual risk factors alone has been suggested to provide a screening, predictive and eventually a target for intervention. ${ }^{23,26}$ These studies consider increased BMI as an important component and thus risk contributor. Although the presence of metabolic abnormalities is associated with BMI, only $33 \%$ of the women in our study population with two or more metabolic abnormalities were also obese. The contribution of obesity to the preeclampsia risk may be well overrated. Therefore, we would recommend taking note of metabolic abnormalities when counseling for recurrent preeclampsia, regardless the woman's BMI. Other interventions than primary weight loss to manage metabolic disorders and to reduce the risk of recurrent preeclampsia might be both more effective and achievable in the relatively short period of time between two pregnancies. 
In conclusion, our findings indicate that the association between obesity and recurrent preeclampsia is a consequence of its relationship with metabolic abnormalities. In line with the findings of others, the metabolic components clustered in the MetS proved useful to indicate increased recurrence risk. Newsworthy is the observation that the role of obesity in this concept is modest. The presence of al least two metabolic syndrome criteria proved to be associated with recurrent preeclampsia, independent of the presence of obesity.

\section{Acknowledgements}

We thank T Ekhart and I Schreij for the collection and entry of the data. 


\section{References}

1. Walsh SW. Obesity: a risk factor for preeclampsia. Trends Endocrinol Metab 2007;18(10):365-70.

2. Huda SS, Brodie LE, Sattar N. Obesity in pregnancy: prevalence and metabolic consequences. Semin Fetal Neonatal Med 2009.

3. Sep SJ, Smits L, Prins MH, Spaanderman ME, Peeters LL. Simple prepregnant prediction rule for recurrent earlyonset hypertensive disease in pregnancy. Reprod Sci 2009;16(1):80-7.

4. King JC. Maternal obesity, metabolism, and pregnancy outcomes. Annu Rev Nutr 2006;26:271-91.

5. Barton JR, Sibai BM. Prediction and prevention of recurrent preeclampsia. Obstet Gynecol 2008;112(2):359-72.

6. Alberti KG, Zimmet P, Shaw J. Metabolic syndrome--a new world-wide definition. A Consensus Statement from the International Diabetes Federation. Diabet Med 2006;23(5):469-80.

7. Sattar N. Do pregnancy complications and CVD share common antecedents? Atheroscler Suppl 2004;5(2):3-7.

8. Harskamp RE, Zeeman GG. Preeclampsia: at risk for remote cardiovascular disease. Am J Med Sci 2007;334(4):2915.

9. Rodie VA, Freeman DJ, Sattar N, Greer IA. Pre-eclampsia and cardiovascular disease: metabolic syndrome of pregnancy? Atherosclerosis 2004;175(2):189-202.

10. Pouta A, Hartikainen AL, Sovio U, Gissler M, Laitinen J, McCarthy MI, et al. Manifestations of metabolic syndrome after hypertensive pregnancy. Hypertension 2004;43(4):825-31.

11. Brown DW, Dueker N, Jamieson DJ, Cole JW, Wozniak MA, Stern BJ, et al. Preeclampsia and the risk of ischemic stroke among young women: results from the Stroke Prevention in Young Women Study. Stroke 2006;37(4):10559.

12. Forest JC, Girouard J, Masse J, Moutquin JM, Kharfi A, Ness RB, et al. Early occurrence of metabolic syndrome after hypertension in pregnancy. Obstet Gynecol 2005;105(6):1373-80.

13. Report of the National High Blood Pressure Education Program. Working group report on high blood pressure in pregnancy. Am J Obstet Gynecol 2000;183:S1-S22.

14. Friedewald WT, Levy RI, Fredrickson DS. Estimation of the concentration of low-density lipoprotein cholesterol in plasma, without use of the preparative ultracentrifuge. Clin Chem 1972;18(6):499-502.

15. Spaanderman ME, Ekhart TH, van Eyck J, Cheriex EC, de Leeuw PW, Peeters LL. Latent hemodynamic abnormalities in symptom-free women with a history of preeclampsia. Am J Obstet Gynecol 2000;182(1 Pt 1):101-7.

16. Birdsall KM, Vyas S, Khazaezadeh N, Oteng-Ntim E. Maternal obesity: a review of interventions. Int J Clin Pract 2009;63(3):494-507.

17. Rasmussen KM, Kjolhede CL. Maternal obesity: a problem for both mother and child. Obesity (Silver Spring) 2008;16(5):929-31.

18. Schokker DF, Visscher TLS, Nooyens ACJ, Baak MAv, Seidell JC. Prevalence of overweight and obesity in the Netherlands. Obesity Reviews 2007;8(2):101-107.

19. Achterberg P. Met de besten vergelijkbaar? Internationale verschillen in sterfte rond de geboorte. Bilthoven: Report of the National Institute for Public Health and Environment (RIVM); 2005.

20. von Dadelszen P, Magee LA, Roberts JM. Subclassification of preeclampsia. Hypertens Pregnancy 2003;22(2):143-8.

21. Sibai BM. Management of pre-eclampsia remote from term. Eur J Obstet Gynecol Reprod Biol 1991;42 Suppl:S96101

22. Callaway LK, O'Callaghan M, Mclntyre HD. Obesity and the hypertensive disorders of pregnancy. Hypertens Pregnancy 2009;28(4):473-93.

23. Srinivas SK, Sammel MD, Bastek J, Ofori E, Andrela CM, Wolfe ML, et al. Evaluating the association between all components of the metabolic syndrome and pre-eclampsia. J Matern Fetal Neonatal Med 2009;22(6):501-9.

24. Scioscia M, Gumaa K, Rademacher TW. The link between insulin resistance and preeclampsia: new perspectives. Journal of Reproductive Immunology 2009;82(2):100-105.

25. Legro RS. Insulin resistance in women's health: why it matters and how to identify it. Curr Opin Obstet Gynecol 2009;21(4):301-5.

26. Mazar RM, Srinivas SK, Sammel MD, Andrela CM, Elovitz MA. Metabolic score as a novel approach to assessing preeclampsia risk. Am J Obstet Gynecol 2007;197(4):411 e1-5.

27. Scioscia M, Greco P, Selvaggi LE, Rademacher TW. Is there a link between insulin resistance and inflammatory activation in preeclampsia? Med Hypotheses 2009;73(5):813-7. 


\section{CHAPTER 5}

\section{Clinical differences}

\section{between early-onset}

\section{HELLP syndrome and}

\section{early-onset preeclampsia}

\section{during pregnancy}

and at least six months

postpartum

Simone Sep, Jef Verbeek, Gerardus Koek, Luc Smits, Marc paanderman, Louis Peeters

Am J Obstet Gynecol 2010; in press. 


\section{ABSTRACT}

Objective: To evaluate whether clinical and laboratory variables differ between former patients who had HELLP syndrome and former patients who had preeclampsia (PE) without HELLP.

Methods: We compared early-onset HELLP $(n=75)$ with early-onset PE $(n=40)$ with respect to clinical features during the hypertensive complication and to metabolic, hemodynamic, and hemostatic variables determined at least six months postpartum.

Results: HELLP differed from PE by a borderline higher frequency of eclampsia (13\% vs. $3 \%$ ) during the complication, and by a lower prevalence of hypertension (19\% vs. $33 \%$ ), proteinuria ( $2 \%$ vs. $23 \%$ ), thrombophilia ( $6 \%$ vs. $27 \%$ ), obesity ( $9 \%$ vs. $33 \%$ ), hypertriglyceridemia ( $1 \%$ vs. $15 \%$ ), hyperglycemia ( $0 \%$ vs. $11 \%$ ), and elevated levels of fasting homocysteine ( $6 \%$ vs. $21 \%$ ) at least six months postpartum.

Conclusion: Women with HELLP had less signs of abnormalities consistent with the metabolic syndrome and a fourfold lower prevalence of thrombophilia as compared with preeclamptic women without HELLP. 


\section{Introduction}

Although preeclampsia and the syndrome of hemolysis, elevated liver enzymes and low platelets (HELLP) are considered different clinical entities, the two syndromes are strongly related. In both (early-onset) syndromes, abnormal placental growth and development are thought to contribute to the initiation of a cascade of events that eventually leads to the well-known clinical symptoms of either. ${ }^{1,2}$ Together with the overlapping symptoms this has led to a comparable clinical management of both syndromes, consisting of symptomatic treatment followed by timely termination of pregnancy.

However, dissimilarities between preeclampsia and HELLP have also emerged. A recent study showed that the molecular signature of the placenta in early-onset HELLP differs from that in early-onset preeclampsia. ${ }^{3}$ Moreover, certain maternal features known as risk factors for preeclampsia, such as obesity, have not been associated with the HELLP syndrome. ${ }^{4}$ These observations provide support for the view that disentanglement of both syndromes may contribute to improvements in the current clinical management. Particularly in the perspective of the increased risk of recurrent disease in a next pregnancy, in which the main objective is to reduce risk factors before conception, ${ }^{5}$ the identification of possible differences in risk profile between preeclampsia and HELLP seems meaningful. Therefore, our objective was to evaluate clinical dissimilarities between the HELLP syndrome and preeclampsia without HELLP. To this end, we compared pregnancy outcome and the frequency of underlying disorders that had been assessed at least six months postpartum, between women who had their pregnancy complicated by HELLP with those whose pregnancy had been complicated by preeclampsia without HELLP.

\section{Material and Methods}

We reviewed the medical records of women with early-onset HELLP syndrome and those of women with early-onset preeclampsia without any signs of the HELLP syndrome, who were admitted to Maastricht University Medical Center, the Netherlands (between March 11996 and December 31 2007), and who had been offered a set of tests to identify underlying disorders or abnormalities at least six months postpartum. All measurements reported in this prospective observational study were obtained as part of the usual care provided to high-risk obstetrical patients in our tertiary referral center. We anonymised all data prior to statistical analysis. Women with twin pregnancies were excluded from the analysis. We only included women with early-onset disease, defined as diagnosis $\leq 34$ weeks and delivery $\leq 37$ weeks. 
We applied the following diagnostic criteria for the HELLP syndrome: platelet count $\leq 100 \times 10^{9} / \mathrm{L}$, elevated liver enzymes (serum alanine aminotransferase (ALAT) > 70 $\mathrm{U} / \mathrm{L}$ and/or serum aspartate aminotransferase (ASAT) $>70 \mathrm{U} / \mathrm{L}$ ) and hemolysis characterized by serum lactic dehydrogenase $(\mathrm{LDH})$ level over $600 \mathrm{U} / \mathrm{L}$. Preeclampsia was defined as de novo proteinuria ( $>300 \mathrm{mg} / 24 \mathrm{~h}$ or $>30 \mathrm{mg} / \mathrm{mmol}$ creatinine) in a pregnant patient with de novo hypertension (> 140/90 mmHg). ${ }^{6}$ Chronic hypertension was defined as hypertension already present before pregnancy, diagnosed before the 20th week of gestation or not resolving within six months postpartum. ${ }^{6}$ We used new-onset proteinuria as a diagnostic criterion for preeclampsia in these women. ${ }^{6}$ Epileptic seizures in women without history of epilepsy were considered to be eclamptic fits. All women who developed eclampsia, received magnesium sulfate after their seizure to prevent recurrence. An infant was considered small for gestational age (SGA), when his/her birth weight was below the $10^{\text {th }}$ percentile according to the most recent Dutch birth weight reference curves. ${ }^{7}$ Perinatal mortality was defined as infant mortality within 28 days after birth.

We determined the following metabolic variables between 6 and 10 months postpartum: circulating levels of fasting glucose, $\mathrm{HbA}_{\mathrm{C}}$, insulin, total cholesterol, low density lipoprotein cholesterol (LDL-C), high density lipoprotein cholesterol (HDL-C), and triglycerides. We used the criteria stated by the National Cholesterol Education Program (NCEP) to define abnormalities related to the metabolic syndrome: fasting plasma glucose $\geq 5.6 \mathrm{mmol} / \mathrm{L}(101 \mathrm{mg} / \mathrm{dL}), \mathrm{HDL}$ cholesterol $\leq 1.29 \mathrm{mmol} / \mathrm{L}(49.88$ $\mathrm{mg} / \mathrm{dL}$ ) and triglycerides $\geq 1.7 \mathrm{mmol} / \mathrm{L}(150.6 \mathrm{mg} / \mathrm{dL}){ }^{8}$ Hypercholesterolemia was defined as total cholesterol $>6.4 \mathrm{mmol} / \mathrm{L}(247.5 \mathrm{mg} / \mathrm{dL})$ and increased LDL-C was defined as a level $\geq 4.5 \mathrm{mmol} / \mathrm{L}(174.0 \mathrm{mg} / \mathrm{dL})$ according to the laboratory reference values. We considered women hyperinsulinemic when fasting insulin exceeded 10 $\mathrm{mmol} / \mathrm{L}$. We defined obesity as a body mass index $(\mathrm{BMI}) \geq 30 \mathrm{~kg} / \mathrm{m}^{2}$. Furthermore, we determined total protein excretion in a 24-hour urine collection and creatinine clearance (corrected for body surface area) was estimated by the ratio of urinary creatinine concentration to that in peripheral blood.

Echocardiography was performed in the semi-left lateral position by using a cross sectional phased-array Doppler system (Agilent Sonos 5500; Philips Medical System, Eindhoven, the Netherlands). ${ }^{9}$ Aortic flow was measured across the aortic valves from an apical approach. The average area under the aortic velocity curve (aortic velocity integral) of five consecutive ejections was used to calculate stroke volume (SV) and cardiac output (CO). Aortic valve diameter, necessary for the calculation of the aortic area, was measured off-line at the orifice during systole using M-mode. Total peripheral vascular resistance (TPVR) was calculated by dividing mean arterial pressure (MAP) by CO. We obtained blood pressure and heart rate as the median of 11 measurements recorded at 3 minutes intervals under standardized conditions using a semiautomatic oscillometric device (Dinamap Vital Signs Monitor 1846; Critikon, Tampa, Florida, USA). An estimate for global arterial compliance 
$(\mathrm{ml} / \mathrm{mmHg}$ ) was obtained by dividing SV by pulse pressure (systolic minus diastolic blood pressure). ${ }^{10}$

Within the scope of the thrombophilic screening, all women were tested for cardiolipin antibodies (IgG/IgM > $10 \mathrm{GPL} / \mathrm{MPL}$ ) and lupus anticoagulant in peripheral blood, as detailed previously. ${ }^{9}$ We assessed the circulating level of fasting homocysteine and considered it elevated when the level exceeded $15 \mathrm{mmol} / \mathrm{L}$. The factor $\checkmark$ Leiden and prothrombin 20210A mutations were analyzed by routine PCR techniques after extraction of genomic DNA from peripheral leukocytes. Activity of antithrombin (Chromogenix, Mo“Indal, Sweden) and protein C (Behring, Marburg, Germany) was measured by chromogenic substrate assays, and protein $\mathrm{S}$ antigen levels by enzyme-linked immunosorbent assay (ELISA; DAKO, Glostrup, Denmark). We defined deficiency of each of these parameters as an activity level below $65 \%$ of normal.

In both subgroups, the type of management during pregnancy consisted of symptomatic treatment, stabilization of the maternal condition and eventually pregnancy termination when the risks of pregnancy continuation outweighed the benefits for either mother or fetus. As part of the screening protocol, the participants discontinued breastfeeding and the use of oral contraceptives and antihypertensive medication at least 2 weeks prior to the measurements. We used SPSS version 15.0 for statistical analysis. Data distribution was evaluated visually using histograms. Continuous variables were analyzed using independent-samples T-test and MannWhitney- $U$ test, and dichotomous variables using Chi-square and Fisher's exact tests. A p-value $<0.05$ was considered statistically significant.

\section{Results}

In the postpartum screening database we identified 40 formerly preeclamptic and 75 former HELLP patients with complete hospital records. The majority of HELLP patients also had hypertension and proteinuria $(n=70)$. Thirty-seven HELLP patients had class 1 and 38 class 2 HELLP syndrome. All women were Caucasian. Table 1 lists clinical and obstetric characteristics of the women and their infants in the two patient groups. The groups were comparable with respect to maternal age, parity, family history of chronic hypertension, the proportion of women with delivery within 48 hours after diagnosis, gestational age at birth, infants' birth weight, and intrauterine mortality. The prevalence of eclampsia, however, tended to be higher in women with the HELLP syndrome ( $13 \%$ vs. $3 \%, p=0.06)$.

Table 2 lists the postpartum observations with respect to the prevalence of abnormalities associated with the metabolic syndrome. Obesity, hyperglycemia, and elevated circulating levels of both total cholesterol and triglycerides were more common in women with a history of preeclampsia without HELLP as compared to wom- 
en who had had the HELLP syndrome $(p<0.05)$. Moreover, the prevalence of chronic hypertension tended to be higher in formerly preeclamptic women (table 2).

\begin{tabular}{|c|c|c|c|}
\hline & $\begin{array}{l}\text { HELLP } \\
(n=75)\end{array}$ & $\begin{array}{l}\text { PE without HELLP } \\
(n=40)\end{array}$ & $\mathrm{p}$ \\
\hline Maternal age (y) & $29.8 \pm 4.7$ & $29.8 \pm 4.7$ & 0.97 \\
\hline \multicolumn{4}{|l|}{ Family history ( $1^{\text {st }}$ degree) positive for: } \\
\hline Preeclampsia/HELLP & $15(20 \%)$ & $14(35 \%)$ & 0.09 \\
\hline Chronic hypertension & $44(59 \%)$ & $23(58 \%)$ & 0.71 \\
\hline Multiparous (\%) & $8(11 \%)$ & $8(20 \%)$ & 0.17 \\
\hline Interval between diagnosis and delivery $\leq 48 \mathrm{~h}$ & $6(10 \%)$ & $4(12 \%)$ & 0.73 \\
\hline Eclampsia & $10(13 \%)$ & $1(3 \%)$ & 0.06 \\
\hline \multirow{2}{*}{ Infant birth weight (g) } & 1150 & 1280 & 0.33 \\
\hline & $(880-1545)$ & $(810-2100)$ & \\
\hline Gestational age at birth (weeks) & $30.1 \pm 2.6$ & $30.2 \pm 2.7$ & 0.83 \\
\hline IUFD & $7(9 \%)$ & $5(13 \%)$ & 0.59 \\
\hline SGA infant $(<p 10)$ & $15(22 \%)$ & $13(33 \%)$ & 0.19 \\
\hline Extremely preterm birth (<32 wks) & $60(81 \%)$ & $29(74 \%)$ & 0.41 \\
\hline Perinatal mortality & $7(10 \%)$ & $1(3 \%)$ & 0.17 \\
\hline Interval between delivery and measurements & 7.4 & 7.0 & 0.85 \\
\hline (months) & $(6.0-9.6)$ & $(6.2-10.4)$ & \\
\hline
\end{tabular}

Maternal age at infants' birth day. IUFD: Intra-uterine fetal demise. Birth weight and time interval between delivery and measurements are expressed as median (IQR). All cases of perinatal mortality were born $<32$ weeks of gestational age.

Persistent proteinuria ( $>300 \mathrm{mg} / 24 \mathrm{~h}$ ) was detected in only $2 \%$ of women who had the HELLP syndrome, as opposed to $23 \%$ in formerly preeclamptic women ( $p<$ $0.01)$, the odds ratio being 18 (95\%-Cl: $2-152)$ and persisting after adjustment for the in-pregnancy peak values of urinary protein excretion in a logistic regression analysis. The median creatinine clearance tended to be higher in formerly preeclamptic women (111, IQR: $87-137 \mathrm{~mL} / \mathrm{min} / 1.73 \mathrm{~m} 2$ ) as compared to former HELLP patients (106, IQR: $90-122 \mathrm{~mL} / \mathrm{min} / 1.73 \mathrm{~m} 2$ ) as well.

Table 3 lists postpartum data on cardiovascular function. Except for a lower mean heart rate in former HELLP patients as compared to formerly preeclamptics (73 \pm 10 vs. $79 \pm 12 \mathrm{bpm}, \mathrm{p}=0.01$ ), both groups were comparable. Finally, thrombophilic abnormalities are presented in table 4 . Heterozygosity for the factor $V$ Leiden and prothrombin 20210GA mutations were less prevalent in former HELLP patients than in former preeclamptics ( $2 \%$ vs. $13 \%, p=0.04$, and $17 \%$ vs. $3 \% p=0.03$ ). None of the women were homozygous for either mutation. Elevated fasting levels of homocysteine were less common in women who had had HELLP ( $6 \%$ vs. $21 \%, p=0.02$ ). The two groups were comparable with respect to the rates of protein $C, S$, and antithrombin deficiency and of positive tests for antiphospholipid antibodies and lupus anticoagulant. 
Table 2: Metabolic syndrome related abnormalities in women with a recent history of the HELLP syndrome or preeclampsia (PE) without HELLP. Data are expressed as proportion (95\%-confidence interval).

\begin{tabular}{llll}
\hline & $\begin{array}{l}\text { HELLP } \\
(\mathrm{n}=75)\end{array}$ & $\begin{array}{l}\text { PE without HELLP } \\
(\mathrm{n}=40)\end{array}$ & $\mathrm{p}$ \\
\hline Obesity & $9 \%(4-19)$ & $33 \%(19-49)$ & $<0.01$ \\
Hypertension & $19 \%(11-30)$ & $33 \%(19-49)$ & 0.10 \\
Hyperinsulinemia & $52 \%(40-64)$ & $50 \%(33-67)$ & 0.83 \\
Hyperglycemia & $0 \%(0-7)$ & $11 \%(4-26)$ & $<0.01$ \\
High total cholesterol & $10 \%(4-20)$ & $23 \%(12-40)$ & 0.06 \\
High LDL-cholesterol & $13 \%(6-24)$ & $21 \%(10-37)$ & 0.29 \\
Low HDL-cholesterol & $7 \%(3-17)$ & $10 \%(3-25)$ & 0.57 \\
High triglycerides & $1 \%(0-9)$ & $15 \%(6-31)$ & $<0.01$ \\
\hline
\end{tabular}

\section{Comments}

Women with preeclampsia and no HELLP proved to have more often a profile consistent with the metabolic syndrome. Moreover, we observed a fourfold higher prevalence of thrombophilia amongst formerly preeclamptics as compared to those who had had HELLP. Even though neonatal outcome did not differ appreciably between both subgroups, eclampsia tended to be more prevalent in women with the HELLP syndrome.

Table 3: Cardiovascular variables in women with a recent history of the HELLP syndrome or preeclampsia $(\mathrm{PE})$ without HELLP. Data are presented as mean $\pm \mathrm{SE}$.

\begin{tabular}{llll} 
& $\begin{array}{l}\text { HELLP } \\
(\mathrm{n}=75)\end{array}$ & $\begin{array}{l}\text { PE without HELLP } \\
(\mathrm{n}=40)\end{array}$ & $\mathrm{p}$ \\
\hline Stroke volume $(\mathrm{mL})$ & $75 \pm 2$ & $73 \pm 1$ & 0.34 \\
Heart rate $(\mathrm{bpm})$ & $73 \pm 1$ & $79 \pm 2$ & 0.01 \\
Cardiac output $(\mathrm{L} / \mathrm{min})$ & $5.4 \pm 0.1$ & $5.5 \pm 0.1$ & 0.45 \\
TPVR (dynes.s/cm $\left.{ }^{5}\right)$ & $1410 \pm 29$ & $1380 \pm 41$ & 0.53 \\
Arterial compliance $(\mathrm{ml} / \mathrm{mmHg})$ & $1.61 \pm 0.06$ & $1.46 \pm 0.07$ & 0.17 \\
Systolic blood pressure $(\mathrm{mmHg})$ & $121 \pm 1$ & $123 \pm 2$ & 0.41 \\
Diastolic blood pressure $(\mathrm{mmHg})$ & $76 \pm 1$ & $75 \pm 2$ & 0.68 \\
Mean arterial pressure $(\mathrm{mmHg})$ & $93 \pm 1$ & $93 \pm 2$ & 0.82 \\
\hline TPVR: total peripheral vascular resistance & & &
\end{tabular}

We only included women who had been diagnosed before 34 weeks and gave birth before 37 weeks. We expected this selection to contribute to a more homogeneous study population as early- and late-onset preeclampsia/HELLP are probably different disease entities with different risk profile. ${ }^{11}$ However, despite the inclusion of early cases only, differential participation based on disease severity may have led to overrepresentation of HELLP patients in our hospital population. To our opinion, its impact on the study results regarding the comparison of HELLP and preeclampsia is 
negligible, as this did not affect the allocation to either subgroup. Although we performed our diagnostic work-up for maternal abnormalities after the complicated pregnancy, abnormalities such as obesity with the associated metabolic syndrome are likely to be preexistent. Nevertheless, it is understood that preconceptional analysis would have been preferable.

We did not observe significant differences in perinatal outcomes between pregnancies complicated by HELLP and those complicated by preeclampsia without HELLP, an observation in line with others. ${ }^{12-14}$ Nonetheless, we observed a trend to a higher incidence of eclampsia in HELLP relative to preeclampsia, a finding not in line with previous reports. ${ }^{12}$ Although differences between findings may be partly attributable to differences in demography and overall disease severity, the more expectant management in our study to thrive for maximum efficacy of corticosteroids in accelerating fetal lung maturation is expected to have enlarged the window for the development of eclampsia. In HELLP circulating levels of reactive oxygen species have been found higher than in preeclampsia, ${ }^{15}$ which suggests activation of the immune system, raising endothelial stress. A central role for immune system activation also arises from the observation of dose-dependent improvement of laboratory values after corticosteroids, even though clinical outcome is not affected. ${ }^{16-18}$ It follows that a more aggressive management, which includes a lower threshold for the administration of magnesium sulphate, particularly in early-onset HELLP, may lower the risk for eclampsia.

Table 4: Thrombophilic defects in women with a recent history of the HELLP syndrome or preeclampsia (PE) without HELLP. Data are expressed as proportion (95\%-confidence interval).

\begin{tabular}{llll} 
& $\begin{array}{l}\text { HELLP } \\
(\mathrm{n}=75)\end{array}$ & $\begin{array}{l}\text { PE without HELLP } \\
(\mathrm{n}=40)\end{array}$ & $\mathrm{p}$ \\
\hline Protein S deficiency & $4 \%(0-14)$ & $3 \%(0-19)$ & 0.90 \\
Protein C deficiency & $0 \%(0-6)$ & $3 \%(0-15)$ & 0.15 \\
Antithrombin deficiency & $0 \%(0-7)$ & $0 \%(0-12)$ & - \\
Prothrombin 20210GA mutation & $3 \%(0-15)$ & $17 \%(6-40)$ & 0.03 \\
Factor V Leiden mutation & $2 \%(0-10)$ & $13 \%(4-30)$ & 0.04 \\
Any of the above & $6 \%(2-15)$ & $27 \%(14-44)$ & $<0.01$ \\
Elevated levels of homocysteine & $6 \%(2-15)$ & $21 \%(10-37)$ & 0.02 \\
Presence of circulating anticardiolipin & $8 \%(3-18)$ & $9 \%(2-25)$ & 0.79 \\
antibodies IgG and/or IgM & $3 \%(0-6)$ & $0 \%(0-16)$ & 0.17 \\
Lupus anticoagulant & All women detected with factor V Leiden or prothrombin mutation were heterozygous.
\end{tabular}

Women with preeclampsia differ from those with HELLP by the presence of a smaller placenta with more infarcts. ${ }^{19}$ Moreover, contrary to the findings of others, ${ }^{12-14}$ Vinnars and coworkers found a higher incidence of fetal growth restriction in preeclampsia. ${ }^{19}$ Although the authors studied the placentas from early - and late-onset disease combined, the data support the view of a longer subclinical disease period preceding preeclampsia as compared to HELLP. The latter is also in line with our 
observations and those reported by others, ${ }^{3,4,20,21}$ suggesting preexistent maternal abnormalities capable of jeopardizing microvascular functioning, are more common in preeclampsia than in HELLP.

These inferences led us to postulate that preeclampsia differs from HELLP by a more gradual course in early pregnancy due to unfavorable constitutional conditions for placental growth and development. Eventually, intervillous hypoxia results in the placental release of toxic substances pushing the subclinical condition into the wellknown clinical symptomatology. Conversely, an abnormal immune response to the placental allograft with no appreciable negative impact on placental function is thought to characterize the subclinical phase of a HELLP pregnancy. The acute course and appearance of HELLP with episodic exacerbations, suggests that HELLP may resemble a so-called "second hit" or an intermittent Shwartzman-like response. $^{22,23}$ Obviously, the pathogenetic pathways are interrelated, which explains why the clinical presentation of preeclampsia and HELLP are often overlapping.

In summary, the postpartum lower rate of underlying maternal metabolic and thrombophilic abnormalities in HELLP as compared to PE suggests these syndromes to have at least in part a different pathophysiology.

\section{Acknowledgements}

We thank T Ekhart and I Schreij for the collection and entry of the data. 


\section{References}

1. Sibai BM. Diagnosis, prevention, and management of eclampsia. Obstet Gynecol 2005;105(2):402-10.

2. Gilbert JS, Nijland MJ, Knoblich P. Placental ischemia and cardiovascular dysfunction in preeclampsia and beyond: making the connections. Expert Rev Cardiovasc Ther 2008;6(10):1367-77.

3. Buimer M, Keijser R, Jebbink JM, Wehkamp D, van Kampen AH, Boer K, et al. Seven placental transcripts characterize HELLP-syndrome. Placenta 2008;29(5):444-53.

4. Leeners B, Rath W, Kuse S, Irawan C, Imthurn B, Neumaier-Wagner P. BMI: new aspects of a classical risk factor for hypertensive disorders in pregnancy. Clin Sci (Lond) 2006;111(1):81-6.

5. Barton JR, Sibai BM. Prediction and prevention of recurrent preeclampsia. Obstet Gynecol 2008;112(2):359-72.

6. Report of the National High Blood Pressure Education Program. Working group report on high blood pressure in pregnancy. Am J Obstet Gynecol 2000;183:S1-S22.

7. The Netherlands Perinatal Registry [homepage on the internet]. Bilthoven: NPR-foundation; [cited April 2009]. Available from: http://www.perinatreg.nl/.

8. Grundy SM, Cleeman JI, Daniels SR, Donato KA, Eckel RH, Franklin BA, et al. Diagnosis and management of the metabolic syndrome. An American Heart Association/National Heart, Lung, and Blood Institute Scientific Statement. Executive summary. Cardiol Rev 2005;13(6):322-7.

9. Spaanderman ME, Ekhart TH, van Eyck J, Cheriex EC, de Leeuw PW, Peeters LL. Latent hemodynamic abnormalities in symptom-free women with a history of preeclampsia. Am J Obstet Gynecol 2000;182(1 Pt 1):101-7.

10. Fagard RH, Pardaens K, Staessen JA, Thijs L. The pulse pressure-to-stroke index ratio predicts cardiovascular events and death in uncomplicated hypertension. Journal of the American College of Cardiology 2001;38(1):227-231.

11. Noris M, Perico N, Remuzzi G. Mechanisms of disease: Pre-eclampsia. Nat Clin Pract Nephrol 2005;1(2):98-114; quiz 120.

12. Haddad B, Barton JR, Livingston JC, Chahine R, Sibai BM. Risk factors for adverse maternal outcomes among women with HELLP (hemolysis, elevated liver enzymes, and low platelet count) syndrome. Am J Obstet Gynecol 2000;183(2):444-8.

13. Osmanagaoglu MA, Erdogan I, Zengin U, Bozkaya H. Comparison between HELLP syndrome, chronic hypertension, and superimposed preeclampsia on chronic hypertension without HELLP syndrome. J Perinat Med 2004;32(6):4815.

14. Gul A, Cebeci A, Aslan H, Polat I, Ozdemir A, Ceylan Y. Perinatal outcomes in severe preeclampsia-eclampsia with and without HELLP syndrome. Gynecol Obstet Invest 2005;59(2):113-8.

15. Diedrich F, Renner A, Rath W, Kuhn W, Wieland E. Lipid hydroperoxides and free radical scavenging enzyme activities in preeclampsia and HELLP (hemolysis, elevated liver enzymes, and low platelet count) syndrome: no evidence for circulating primary products of lipid peroxidation. Am J Obstet Gynecol 2001;185(1):166-72.

16. van Runnard Heimel PJ, Kavelaars A, Heijnen CJ, Peters WH, Huisjes AJ, Franx A,Bruinse HW. HELLP syndrome is associated with an increased inflammatory response, which may be inhibited by administration of prednisolone. Hypertens Pregnancy. 2008;27(3):253-65.

17. O'Brien JM, Milligan DA, Barton JR.Impact of high-dose corticosteroid therapy for patients with HELLP (hemolysis,elevated liver enzymes, and low platelet count) syndrome. Am J Obstet Gynecol. 2000;183(4):921-4.

18. Matchaba P, Moodley J. Corticosteroids for HELLP syndrome in pregnancy. Cochrane Database Syst Rev. 2004;(1):CD002076.

19. Vinnars MT, Wijnaendts LC, Westgren M, Bolte AC, Papadogiannakis N, Nasiell J. Severe preeclampsia with and without HELLP differ with regard to placental pathology. Hypertension 2008;51(5):1295-9.

20. Martin JN, Jr., May WL, Rinehart BK, Martin RW, Magann EF. Increasing maternal weight: a risk factor for preeclampsia/eclampsia but apparently not for HELLP syndrome. South Med J 2000;93(7):686-91.

21. Kujovich JL. Thrombophilia and pregnancy complications. Am J Obstet Gynecol 2004;191(2):412-24.

22. Sailhamer EA, Li Y, Smith EJ, Shuja F, Shults C, Liu B, et al. Acetylation: a novel method for modulation of the immune response following trauma/hemorrhage and inflammatory second hit in animals and humans. Surgery 2008;144(2):204-16.

23. Brozna JP. Shwartzman reaction. Semin Thromb Hemost 1990;16(4):326-32. 
CHAPTER 6

\section{Electrocardiographic}

findings in women with a recent history of preeclampsia with or

\section{without the HELLP-syndrome}

Philippe Hoogsteder, Simone Sep, Robijn Wagenmakers, Willem Dassen, Anton Gorgels, Louis Peeters 


\section{Abstract}

Objectives: 1. To assess the prevalence of electrocardiographic (ECG) abnormalities shortly after a pregnancy complicated by preeclampsia and/or the syndrome of Hemolysis, Elevated Liver Enzymes and Low Platelets (PE). 2. To compare the ECG dimensions between primiparous formerly early-onset preeclamptics who did, with those who did not develop recurrent PE in their next pregnancy.

Methods: Our study population for the first objective consisted of 658 formerly preeclamptics, whereas the one for our second objective, consisted of the subgroup of primiparae with both a history of early-onset PE (delivery < 34 weeks) and a completed second pregnancy, which had either a normal course $(n=46)$ or became complicated by recurrent PE $(n=33)$.

Results: The ECG of $13(2.0 \%), 2(0.3 \%)$ and $2(0.3 \%)$ former patients $(2.0 \%)$ suggested ischemia, left ventricular hypertrophy and left atrial enlargement, respectively. Primiparae with a history of early-onset PE, who developed recurrent PE in their second pregnancy, differed from their counterparts with an uneventful second pregnancy by a leftward deviation of both the $P$ and the R-axis, of $11^{\circ}(p=0.022)$ and $12^{\circ}(p=0.021)$, respectively with a prolonged QT-interval.

Conclusions: The prevalence of ECG abnormalities in women with a recent history of PE did not differ appreciably from that in a large population of healthy women of comparable age. ECG differences between primiparous formerly early-onset preeclamptics with and without recurrent PE in their next pregnancy may, at least in part, be related to a slightly higher mean blood pressure and/or a higher body mass index (BMI) in the recurrence group, the higher BMI being accompanied by more intraabdominal pressure, which lifts the diaphragm and with it, exaggerates the normal leftward cardiac rotation. 


\section{Introduction}

Pregnancy induces hemodynamic, metabolic and endocrine changes that impact the cardiac function. ${ }^{1}$ Already in the first trimester, cardiac output begins to increase to reach a plateau in the second trimester of $30-40 \%$ above prepregnancy levels. This adaptive change puts extra strain upon the heart, ${ }^{2}$ which responds with cardiac remodeling resembling the so-called "eccentric" hypertrophy observed in athletes, characterized by an increase in the ventricular dimensions and in the left ventricular wall thickness. ${ }^{3,4}$ The latter changes affects the electrocardiogram (ECG) by prolonging the QT interval corrected for the higher heart rate (QT-c), and by a leftward deviation of the QRS and T-axis. ${ }^{5}$ Although the change in the alignment of the intrathoracic organs during pregnancy, which results from lifting of the diaphragm by the higher intra-abdominal pressure, explains most of the change of the electrical heart field ${ }^{6}$ it is likely that the change in cardiac structure and function also contributes to the change of the electrical heart field. ${ }^{7}$

Women with a history of early-onset preeclampsia, eclampsia or the syndrome of Hemolysis, Elevated Liver Enzymes and Low Platelets (HELLP), are at increased risk of developing cardiovascular disease later in life. ${ }^{8}$ These former patients often have pre-existing renal, vascular, metabolic, and immune disorders, ${ }^{9-11}$ which, independent of pregnancy, are also associated with premature cardiovascular disease. ${ }^{8,12}$ It is unknown, whether the higher prevalence of pre-existing disorders in these former patients is accompanied by a higher prevalence of electrocardiographic (ECG) abnormalities.

In this study, we tested the following two hypotheses: 1) The prevalence of clinically relevant ECG abnormalities is higher in formerly preeclamptic women than in agematched women in the general population. 2) Formerly early-onset preeclamptics with recurrent preeclampsia with or without the HELLP-syndrome (PE) in their next pregnancy have different ECG dimensions than their counterparts, who only had PE in their first pregnancy. To this end, we recorded an ECG in 658 formerly preeclamptics at least 6 months after their complicated pregnancy and compared in a subgroup of 79 primiparae with a history of early-onset PE, the ECG dimensions between women, who did and did not develop recurrent PE in their second pregnancy.

\section{Materials and methods}

Since 1996, we have screened in our tertiary referral center, all women with a recent history of PE for underlying maternal abnormalities known to be associated with hypertensive disorders of pregnancy. The screening program includes the recording of an ECG. To warrant adequate postpartum recovery of all relevant func- 
tions, we perform the screening at least six months postpartum. All measurements reported in this observational study are part of the routine care provided to highrisk obstetrical patients in our center, and derived from a database by a clinical research assistant, who was not involved in the statistical analysis. Prior to analysis, data were anonymized. In the Netherlands, ethical approval is not required for research using anonymized data from a database containing data from routine patient care.

To evaluate the prevalence of ECG abnormalities, we included all women with a history of PE $(n=658)$. To compare ECG dimensions between women with recurrent $\mathrm{PE}$ and women with an uneventful next pregnancy, we selected a subgroup of former patients who 1 . were screened before February 2008, 2. were primiparous at the time of screening, 3. had had early-onset (delivery $<34$ weeks) PE in their first pregnancy, and 4. had a subsequent ongoing ( $>20$ weeks) singleton pregnancy ( $n=$ 134), which either had an uneventful course or resulted in recurrent PE. Eventually, we were able to compare the computerized ECGs of 33 women who had developed recurrent $\mathrm{PE}$ in their second pregnancy with 46 former patients with an uneventful second pregnancy. The selection procedure is illustrated in figure 1.

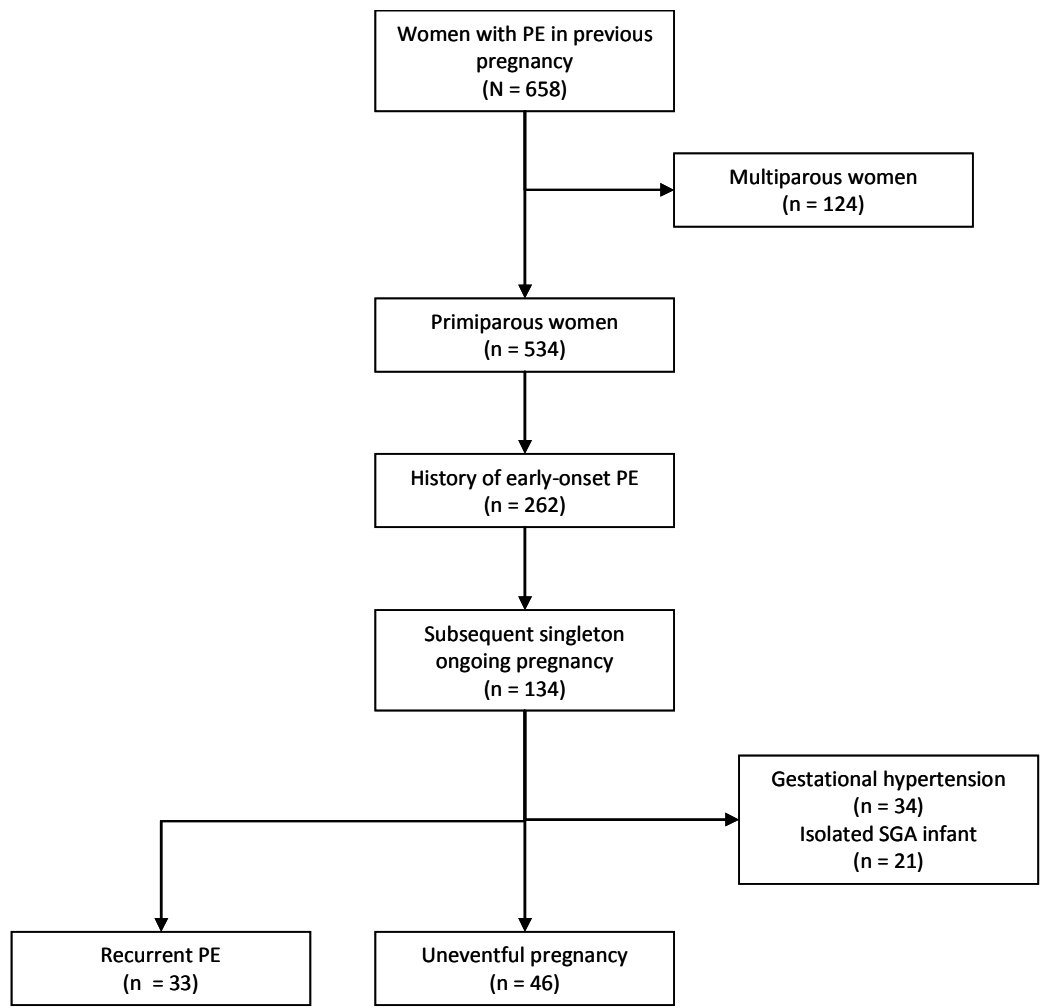

Figure 1: Details on patients selected for the study and their outcome. PE: preeclampsia; SGA: small for gestational age. 
We adhered to the definitions for preeclampsia and HELLP-syndrome used by the International Society for the Study of Hypertension in Pregnancy (ISSHP). ${ }^{13,14}$ Furthermore, we defined the birth of an SGA infant as an infant born with a birth weight below the 10th percentile according to the most recent Dutch birth weight curves. $^{15}$

We recorded the ECG with the subject in supine position, using the 12-lead Marquette MacVu and Marquette 12SL analysis program (GE Marquette, Inc., Milwaukee, Wisconsin) to enable analysis and calculation of standard ECG interval times and the electrical heart axis. Computer-calculated ECG-interval times were expressed in milliseconds ( $\mathrm{ms}$ ), whereas $\mathrm{P}, \mathrm{R}$ and $\mathrm{T}$-wave axis were expressed in degrees $\left({ }^{\circ}\right)$. P-wave axis is considered normal between $0^{\circ}$ and $+75^{\circ}$ and reflects atrial conduction. ${ }^{16}$ The R-wave axis gives information about ventricular conduction and activation with normal values ranging from $-30^{\circ}$ to $+100^{\circ}$. Finally, the T-axis reflects the conduction of ventricular repolarisation. ${ }^{17,18}$ Figure 2 illustrates the orientation of the three cardiac-axis. The QT-c interval describes cardiac depolarization, and excessive prolongation was defined as a QT-c interval over $450 \mathrm{~ms}$, whereas the long QT-syndrome was defined as a QT-c complex $>500 \mathrm{~ms}^{19}$

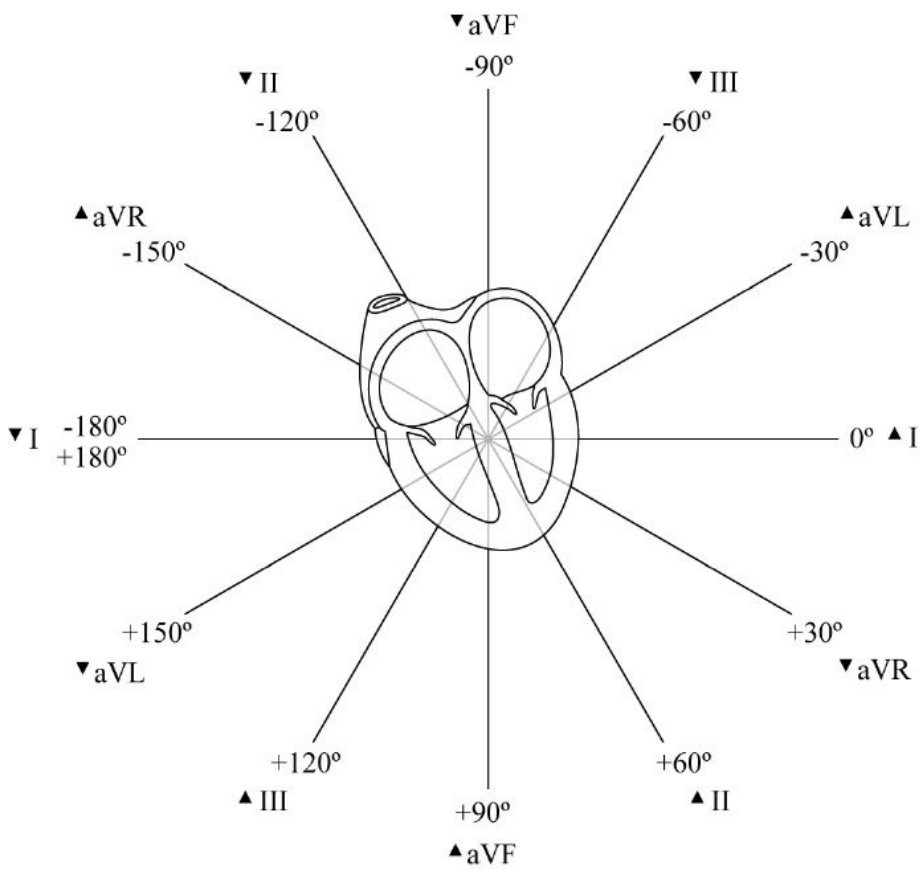

Figure 2: Schematic illustration of the electrocardiographic heart axis. P, R and T-wave axis are derived as a vector of all limb leads.

All ECGs were evaluated and classified by cardiologists not involved in this study. These ECG findings were defined either as normal or as suspect for clinically rele- 
vant cardiac pathology. Left ventricular hypertrophy (LVH) was defined by the Sokolow-Lyon criteria. ${ }^{20}$ We defined left atrial dilatation by a P-wave duration in excess of $0.12 \mathrm{~s}$ in the frontal plane (usually lead II), accompanied by a notched P-wave in the limb leads with an inter-peak duration $>0.04 \mathrm{~s}$, or in case of terminal $\mathrm{P}$ negativity, in lead V1 (i.e., "P-terminal force") with duration > $0.04 \mathrm{~s}$ and depth $>1 \mathrm{~mm} .21$ We used the Minnesota code classification system for ECG findings (code 11-3; code V1-3; IV1-3; code VII1) to consider an ECG to be suspect of myocardial ischemia (ischemic ECG). ${ }^{22,23}$

During the postpartum screening we also recorded blood pressure in standardized conditions using a semiautomatic oscillometric device for 30 minutes (Dinamap Vital Signs Monitor 1846, Critikon, Tampa, FL). A patient was considered to have chronic hypertension, when she was using prescription anti-hypertensive drugs at the time of postpartum screening. Important demographic variables such as age, body mass index (BMI), and the presence of chronic hypertension were registered at the time of postpartum screening. A patient with BMI over $30 \mathrm{~kg} / \mathrm{m}^{2}$ was considered obese. Obstetric history data registered at screening were gender, weight and condition at birth of the infant. Variables with a missing value rate of over $25 \%$ were omitted from further analyses. The results of this postpartum screening enables individualized counseling of former patients for possible consequences of detected abnormalities, for both future pregnancies and general health later in life.

We analyzed the data using SPSS version 16.0 for Windows. For data distribution, we evaluated histograms visually. Non-normally and normally distributed data were analyzed using the Mann-Whitney $U$ test and the independent-samples t-test, respectively. Finally, binomial data were analyzed by Chi-square tests. Data are either presented as mean \pm standard deviation (SD) or as number of patients with corresponding percentage. Differences between groups were considered significant, when the $p$-value was below 0.05 .

\section{Results}

From January 1996 until February 2008, we enrolled 658 women with a recent history of PE in our postpartum screenings program. Women were screened at least 6 months postpartum with a median of 11 months. Table 1 lists the characteristics of our study population and ECG dimensions. Mean age at delivery was $29.7 \pm 4.4$ years. 320 (49\%) women had a history of early-onset preeclampsia with mean gestational age at delivery of $33 \pm 4$ weeks. Of the total study population, 534 (81\%) were primiparous and $182(28 \%)$ gave birth to a SGA infant. Mean maternal BMI was $25.4 \pm 5.2 \mathrm{~kg} / \mathrm{m}^{2}$, with $107(16 \%)$ women being obese. A total of 88 (13\%) women used prescription antihypertensive medication at the time of screening. 
Table 1: Clinical characteristics of 658 women with a first pregnancy complicated by preeclampsia and/or HELLP.

\begin{tabular}{ll}
\hline Index pregnancy & $(\mathrm{n}=658)$ \\
\hline Age at delivery $(\mathrm{y})$ & $29.7 \pm 4.4$ \\
Age at screening $(\mathrm{y})$ & $31.4 \pm 4.1$ \\
Primiparae & $534(81 \%)$ \\
Early-onset PE & $320(49 \%)$ \\
Gestational age at delivery (wks) & $33.0 \pm 4.0$ \\
Birth of an SGA infant & $182(28 \%)$ \\
Chronic hypertension & $88(13 \%)$ \\
Maternal BMI $\left(\mathrm{kg} / \mathrm{m}^{2}\right)$ & $25.4 \pm 5.2$ \\
Obesity $\left(\mathrm{BMI}>30 \mathrm{~kg} / \mathrm{m}^{2}\right)$ & $107(16 \%)$ \\
\hline
\end{tabular}

PE: preeclampsia; SGA: small for gestational age; BMI: body mass index. Pre-existent hypertension, maternal BMI, and obesity were obtained at the time of the postpartum screening. Data are listed as mean \pm SD or $n(\%)$, unless otherwise specified.

Table 2: Electrocardiographic characteristics of 658 women with a first pregnancy complicated by PE.

\begin{tabular}{lll}
\hline Electrocardiographic findings & & $(\mathrm{n}=658)$ \\
\hline Ventricular rate (bpm) & {$[60-100]^{30}$} & $68 \pm 11$ \\
PR interval (ms) & {$[120-200]^{30}$} & $142 \pm 20$ \\
QRS-duration (ms) & {$[<120]^{30}$} & $86 \pm 8$ \\
QT-c interval (ms) & {$[<450]^{30}$} & $404 \pm 15$ \\
P-wave axis (degrees) & {$[0-+75]^{16}$} & $40 \pm 22$ \\
R -wave axis (degrees) & {$[-30-+100]^{17}$} & $50 \pm 25$ \\
T-wave axis (degrees) & {$[+15-+75]^{31}$} & $31 \pm 22$ \\
\hline Electrocardiographic Rhythm & & $(\mathrm{n}=658)$ \\
\hline \multicolumn{1}{c}{ Sinus Rhythm } & $651(98.9)$ \\
Supra Ventricular Rhythm & & $7(1.1 \%)$ \\
\hline Clinically relevant ECG findings & & $(\mathrm{n}=23)$ \\
\hline Ischemic ECG findings & $13(2.0 \%)$ \\
Left Atrial Enlargement & & $2(0.3 \%)$ \\
LVH & & $2(0.3 \%)$ \\
Dextrocardia & $1(0.2 \%)$ \\
Right heart axis & $1(0.2 \%)$ \\
QT-c interval >450ms & $4(0.6 \%)$ \\
\hline
\end{tabular}

LVH: left ventricular hypertrophy, determined by Sokolow-Lyon criteria. Bpm: beats per minute; QT-c: QT-interval corrected for heart rate. [Normal range defined in ms or degrees]. Data are listed as mean \pm SD or $\mathrm{n}(\%)$, unless specified otherwise.

None of the 658 women of the original population had an ECG abnormality requiring immediate consultation or intervention by a cardiologist. In the total group, the ECG was consistent with $\mathrm{LVH}$, left atrial dilatation and myocardial ischemia in 2 $(0.3 \%), 2(0.3 \%)$ and 13 women (2.0\%), respectively. One former patient $(0.15 \%)$ had an ECG indicative for dextrocardia, confirmed by ultrasound. Four (0.6\%) women had excessive prolongation of the QT-c interval exceeding $450 \mathrm{~ms}$, but none 
were diagnosed with the long QT-syndrome. Finally, 1 ECG $(0.15 \%)$ was interpreted as being abnormal because of an extreme rightward deviation of the electrical heart axis. Table 2 lists all clinically relevant ECG abnormalities.

Table 3: Clinical characteristics of primiparous former patients with recurrent disease and uneventful second pregnancies.

\begin{tabular}{llll}
\hline & $\begin{array}{l}\text { Recurrent PE } \\
(\mathrm{n}=33)\end{array}$ & $\begin{array}{l}\text { Uneventful } \\
(\mathrm{n}=46)\end{array}$ & $\mathrm{P}$ \\
\hline Index pregnancy & & & \\
Age at delivery first pregnancy (years) & $28.5 \pm 4.0$ & $28.3 \pm 3.2$ & 0.774 \\
Age at screening (years) & $29.8 \pm 4.1$ & $29.6 \pm 3.2$ & 0.800 \\
Gestational age at delivery (weeks) & $29.8 \pm 2.0$ & $29.3 \pm 2.1$ & 0.293 \\
SGA infant & $4(5 \%)$ & $7(9 \%)$ & 0.813 \\
MAP (mmHg) & $96 \pm 10$ & $90 \pm 10$ & 0.004 \\
Maternal BMI (kg/m ${ }^{2}$ ) & $26.8 \pm 4.4$ & $25.2 \pm 5.3$ & 0.165 \\
Obesity BMI > 30 kg/m ${ }^{2}$ & $9(11 \%)$ & $7(9 \%)$ & 0.186 \\
Pre-existing hypertension & $5(6 \%)$ & $2(3 \%)$ & 0.096 \\
Subsequent pregnancy & & & 0.886 \\
Age at the time of delivery (years) & $31.8 \pm 3.9$ & $31.9 \pm 3.4$ & $<0.001$ \\
Gestational age at delivery (weeks) & $36.3 \pm 3.4$ & $39.1 \pm 1.9$ & $<0.001$ \\
Birth weight (g) & $2496 \pm 912$ & $3357 \pm 486$ & - \\
Birth of an SGA infant & $8(10 \%)$ & - & - \\
Preeclampsia & $33(42 \%)$ & - & - \\
Early-onset PE & $6(8 \%)$ & - & \\
\hline SGA: small for gestational age; MAP: mean arterial pressure; BMI: body mass index; PE: preeclampsia. \\
Pre-existent hypertension, maternal BMI, and obesity at the time of the postpartum screening. Data are \\
listed as mean \pm SD or $\mathrm{n}$ (\%), unless otherwise specified. & &
\end{tabular}

To determine whether primiparous, formerly early-onset preeclamptics, who developed recurrent disease in their second pregnancy, differed from their counterparts with a normal second pregnancy, we performed a subgroup analysis on 79 primiparous women with a history of early-onset disease and a subsequent singleton pregnancy. In their second pregnancy, 33 (42\%) women developed recurrent PE as compared to 46 (58\%) former patients, who had an uneventful second pregnancy. Baseline characteristics of both subgroups summarized in table 3 were comparable, except for a higher MAP in the recurrent subgroup (96 \pm 10 and $90 \pm 10 \mathrm{mmHg}$, resp., $\mathrm{p}=0.004)$. Only 6 women $(7.6 \%)$ developed recurrent early-onset PE in their second pregnancy. The recurrence subgroup differed from the uneventful subgroup by a mean leftward deviation of the P-wave axis $\left(32^{\circ} \pm 23\right.$ and $43 \circ \pm 18$, respectively, $p=0.022$ ), along with a mean leftward deviation of the R-wave axis (470 \pm 24 and $590 \pm 23$, respectively, $p=0.021$ ), and a longer QT-c interval (411 \pm 15 and $404 \pm 12$ $\mathrm{ms}$, respectively, $\mathrm{p}=0.025$ ). Table 4 lists the ECG indices. Other baseline ECG features did not differ appreciably between the two subgroups.

Besides these differences in ECG characteristics, we found the MAP to be higher in the recurrence as compared to the uneventful subgroup (96 \pm 10 and $90 \pm 10$ 
$\mathrm{mmHg}$, resp., $\mathrm{p}=0.004)$. Although the recurrence group tended to have a higher BMI than the uneventful group (26.8 versus $25.2 \mathrm{~kg} / \mathrm{m}^{2}$ ), this difference did not reach statistical significance $(p=0.17)$.

Table 4: Baseline electrocardiographic data of primiparous early-onset preeclamptics with recurrent disease and uneventful second pregnancies.

\begin{tabular}{llll}
\hline & $\begin{array}{l}\text { Recurrent PE } \\
(\mathrm{n}=33)\end{array}$ & $\begin{array}{l}\text { Uneventful } \\
(\mathrm{n}=46)\end{array}$ & $\mathrm{P}$ \\
\hline Heart rate (bpm) & $70 \pm 12$ & $68 \pm 12$ & 0.279 \\
PR interval (ms) & $140 \pm 16$ & $137 \pm 20$ & 0.516 \\
QRS-duration (ms) & $84 \pm 6$ & $85 \pm 8$ & 0.524 \\
QT-c interval (ms) & $411 \pm 15$ & $404 \pm 13$ & 0.025 \\
P-wave axis (degrees) & $32 \pm 23$ & $43 \pm 18$ & 0.022 \\
R-wave axis (degrees) & $47 \pm 24$ & $59 \pm 23$ & 0.021 \\
T-wave axis (degrees) & $29 \pm 19$ & $33 \pm 19$ & 0.315 \\
\hline Bpm: beats per minute; QT-c: QT-interval corrected for heart rate. All variables were assessed at the time \\
of the postpartum screening. Data are listed as mean \pm SD, unless otherwise specified.
\end{tabular}

\section{Discussion}

This study is the first to analyze the prevalence of ECG abnormalities in a large group of 658 formerly preeclamptic women. Of the total study population, 19 (2.9\%) were identified with clinically relevant ECG abnormalities suggestive for LVH $(n=2)$, left atrial dilatation $(n=2)$, dextrocardia $(n=1)$, rightward deviation electrical heart axis $(n=1)$, myocardial ischemia $(n=13)$ and excessive prolongation of the QT-c interval $(n=4)$. We did not have a reference group of women with an uneventful first pregnancy. Nevertheless, the close resemblance between the low prevalence of abnormal ECG findings in our study population and that reported for a large cohort of healthy women of comparable age provides indirect evidence for lack of clustering of abnormal ECGs in women with a recent history of PE. ${ }^{23}$ Apparently, the twice as high risk in formerly preeclamptics to develop cardiovascular morbidity at middle age $8 \mathrm{~s}$ not accompanied by a higher incidence of abnormal ECGs shortly after the complicated pregnancy in spite of the higher incidence of metabolic syndrome, hypertension, renal disease, and autoimmune disorders in this population. ${ }^{8,24,25}$ Apparently, the increased risk of these women to develop premature cardiovascular disorders is not reflected in more abnormal ECGs shortly after PE. Therefore, an ECG obtained during a postpartum screening program in women with a recent history of PE seems superfluous because of its low yield.

In a sub-analysis, we compared the computer-analyzed ECG indices between 33 and 46 primiparae with a recent history of early-onset $\mathrm{PE}$, who did or did not develop recurrent disease in their second pregnancy, respectively. Primiparae who developed recurrent disease in their second pregnancy not only differed from their coun- 
terparts with an uneventful second pregnancy by a significantly leftward deviation of the P-wave and R-wave axis along with a prolonged QT-c interval. They also differed by a higher MAP. Although previous studies indicated reversal of the shifted electrical heart axis and of the prolonged QT-c to prepregnant values immediately post partum, ${ }^{5}$ to the best of our knowledge there are no previous studies comparing the ECG between women with recurrent hypertensive disease and women with an uncomplicated pregnancy. The leftward shift of the electrical heart axis in the subgroup of women with recurrent PE appears to be a confounder of the trend towards a higher BMI in this subgroup. Conversely, the relative leftward shift may also be related to a higher cardiac afterload secondary to the higher MAP in that subgroup as compared to the subgroup with a normal second pregnancy. ${ }^{26}$ Previous reports support the concept that leftward deviation of the electrical and anatomical heart axis vary as a function of left ventricular mass. The latter is expected to be higher in the recurrence subgroup with the higher MAP. ${ }^{27}$ After adjustment for MAP, BMI and the presence or absence of pre-existent hypertension by multiple linear regression analysis, the inter-subgroup differences in electrical $P$ and $R$-axis persisted $(p<0.05)$, indicating that other still unknown factors are involved.

A prolonged QT-c interval in the recurrence subgroup relative to the uneventful subgroup reflects delayed depolarization and provides indirect evidence for a different left ventricular structure. ${ }^{28,29}$ The difference may also result from a combination of a higher left ventricular mass, a higher MAP and a higher BMI. However, in contrast to the persisting difference in electrical $P$ and $R$-axis in the recurrence subgroup, after adjustment for MAP, BMI and pre-existent hypertension, the QT-c interval did not differ anymore between the 2 subgroups ( $p=0.197$ ).

In summary, the prevalence of abnormal ECGs in women with a recent history of PE is similar to that reported for women of comparable age in the general population. Therefore, the value of the ECG to identify formerly preeclamptic women at risk for premature cardiovascular disease is negligible. Differences in the electrical heart axis and in QT-c between former patients that do and those that do not develop recurrent disease in their second pregnancy appear to result predominantly from differences in blood pressure, with possibly some contribution of differences in cardiac structure.

\section{Acknowledgements}

We thank T Ekhart and I Schreij for the collection and entry of the data. 


\section{References}

1. Elkayam U G.N., Hemodynamics and cardiac function during normal pregnancy and the puerperium. Cardiac problems in pregnancy. 1990. 5-24.

2. Abbas A.E., Lester S.J., Connolly H., Pregnancy and the cardiovascular system. Int J Cardiol, 2005. 98(2): p. 179-89.

3. Campos O., Doppler Echocardiography During Pregnancy: Physiological and Abnormal Findings. Echocardiography, 1996. 13(2): p. 135-146.

4. Simmons L.A., Gillin A.G., Jeremy R.W., Structural and functional changes in left ventricle during normotensive and preeclamptic pregnancy. Am J Physiol Heart Circ Physiol, 2002. 283(4): p. H1627-33.

5. Carruth J.E., Mivis S.B., Brogan D.R., Wenger N.K., The electrocardiogram in normal pregnancy. Am Heart J, 1981. 102(6 Pt 1): p. 1075-8.

6. Lechmanova M., Parizek A., Halaska M., Slavicek J., Kittnar O., Changes of the electrical heart field and hemodynamic parameters in the 34th to 40th weeks of pregnancy and after delivery. Arch Gynecol Obstet, 2002. 266(3): $p$ 145-51.

7. Yuan L., Duan Y., Cao T., Echocardiographic study of cardiac morphological and functional changes before and after parturition in pregnancy-induced hypertension. Echocardiography, 2006. 23(3): p. 177-82.

8. Bellamy L., Casas J.P., Hingorani A.D., Williams D.J., Pre-eclampsia and risk of cardiovascular disease and cancer in later life: systematic review and meta-analysis. BMJ, 2007. 335(7627): p. 974.

9. Spaanderman M.E., Ekhart T.H., van Eyck J., Cheriex E.C., de Leeuw P.W., Peeters L.L., Latent hemodynamic abnormalities in symptom-free women with a history of preeclampsia. Am J Obstet Gynecol, 2000. 182(1 Pt 1): p. 101-7.

10. Dekker G.A., de Vries J.I., Doelitzsch P.M., Huijgens P.C., von Blomberg B.M., Jakobs C., et al., Underlying disorders associated with severe early-onset preeclampsia. Am J Obstet Gynecol, 1995. 173(4): p. 1042-8.

11. Aardenburg R., Spaanderman M.E., Ekhart T.H., van Eijndhoven H.W., van der Heijden O.W., Peeters L.L., Low plasma volume following pregnancy complicated by pre-eclampsia predisposes for hypertensive disease in a next pregnancy. BJOG, 2003. 110(11): p. 1001-6.

12. Barden A.E., Beilin L.J., Ritchie J., Walters B.N., Michael C., Does a predisposition to the metabolic syndrome sensitize women to develop pre-eclampsia? J Hypertens, 1999. 17(9): p. 1307-15.

13. Brown M.A., Lindheimer M.D., de Swiet M., Van Assche A., Moutquin J.M., The classification and diagnosis of the hypertensive disorders of pregnancy: statement from the International Society for the Study of Hypertension in Pregnancy (ISSHP). Hypertens Pregnancy, 2001. 20(1): p. IX-XIV.

14. Report of the National High Blood Pressure Education Program Working Group on High Blood Pressure in Pregnancy. Am J Obstet Gynecol, 2000. 183(1): p. S1-S22.

15. The Netherlands Perinatal Registry. Bilthoven: NPR-foundation. Available at: http://www.perinatreg.n;/. Retrieved September 18, 2009.

16. Lo H.M., Lin J.L., Lin F.Y., Tseng Y.Z., Characteristic $P$ wave morphology in patients undergoing the atrial compartment operation for chronic atrial fibrillation with mitral valve disease. Pacing Clin Electrophysiol, 2003. 26(9): $p$. 1864-72.

17. Abreu-Lima C., Marques de Sa J.P., Coelho G., Almeida J., Silva-Carvalho F., Hernandez C., Frontal-plane QRS axis revisited: accuracy of current approximations and reappraisal of their merit in the diagnosis of right ventricular hypertrophy. J Electrocardiol, 1988. 21(4): p. 369-75.

18. Prajapat L., Ariyarajah V., Frisella M.E., Apiyasawat S., Spodick D.H., Association of P-wave duration, dispersion, and terminal force in relation to P-wave axis among outpatients. Ann Noninvasive Electrocardiol, 2007. 12(3): p. 210-5.

19. Priori S.G., Schwartz P.J., Napolitano C., Bloise R., Ronchetti E., Grillo M., et al., Risk stratification in the long-QT syndrome. N Engl J Med, 2003. 348(19): p. 1866-74.

20. Antikainen R.L., Grodzicki T., Palmer A.J., Beevers D.G., Webster J., Bulpitt C.J., Left ventricular hypertrophy determined by Sokolow-Lyon criteria: a different predictor in women than in men? J Hum Hypertens, 2006. 20(6): p. 451-9.

21. Tsao C.W., Josephson M.E., Hauser T.H., O'Halloran T.D., Agarwal A., Manning W.J., et al., Accuracy of electrocardiographic criteria for atrial enlargement: validation with cardiovascular magnetic resonance. J Cardiovasc Magn Reson, 2008. 10(1): p. 7.

22. Department of Epidemiolgy and Community Health, University of Minnesota [homepage on the internet]. Available at: http://www.epi.umn.edu/ecg/mncode.pdf. Retrieved October 19, 2009.

23. De Bacquer D., De Backer G., Kornitzer M., Prevalences of ECG findings in large population based samples of men and women. Heart, 2000. 84(6): p. 625-33.

24. Jonsdottir L.S., Arngrimsson R., Geirsson R.T., Sigvaldason H., Sigfusson N., Death rates from ischemic heart disease in women with a history of hypertension in pregnancy. Acta Obstet Gynecol Scand, 1995. 74(10): p. 772-6.

25. Sibai B., Dekker G., Kupferminc M., Pre-eclampsia. Lancet, 2005. 365(9461): p. 785-99.

26. Fagard R.H., Staessen J.A., Thijs L., Relationships between changes in left ventricular mass and in clinic and ambulatory blood pressure in response to antihypertensive therapy. J Hypertens, 1997. 15(12 Pt 1): p. 1493-502. 
27. Engblom H., Hedstrom E., Palmer J., Wagner G.S., Arheden H., Determination of the left ventricular long-axis orientation from a single short-axis MR image: relation to BMI and age. Clin Physiol Funct Imaging, 2004. 24(5): p. 310-5.

28. Fraley M.A., Birchem J.A., Senkottaiyan N., Alpert M.A., Obesity and the electrocardiogram. Obes Rev, 2005. 6(4): p. 275-81.

29. Pontiroli A.E., Pizzocri P., Saibene A., Girola A., Koprivec D., Fragasso G., Left ventricular hypertrophy and QT interval in obesity and in hypertension: effects of weight loss and of normalisation of blood pressure. Int J Obes Relat Metab Disord, 2004. 28(9): p. 1118-23.

30. Mirvis D.M., Goldberger A.L., Electrocardiography, in Braunwald's Heart Disease. 8th edition. Philidelphia (PA): Saunders Elsevier; 2008. p. 149-194.

31. Kors J.A., de Bruyne M.C., Hoes A.W., van Herpen G., Hofman A., van Bemmel J.H., et al., T axis as an indicator of risk of cardiac events in elderly people. Lancet, 1998. 352(9128): p. 601-5. 


\section{Part II}

Early-pregnancy adaptation 



\section{CHAPTER 7}

\section{Early-pregnancy}

adaptation of the

maternal lipid profile in recurrent preeclampsia

Simone Sep, Carmen Rijvers, Luc Smits, Marc van Bilsen, Otto Bekers, Louis Peeters 


\section{Abstract}

Objective: To evaluate early-pregnancy changes in lipid profile in women who did or did not develop recurrent preeclampsia.

Methods: Design: Retrospective, longitudinal, observational study. Setting: Tertiary referral centre. Population: Women with a history of early-onset preeclampsia. Fasting blood samples were obtained before pregnancy and at 12 and 16 weeks amenorrhea and analyzed for triglycerides (TG), total-cholesterol (TC), high density (HDL-C) and low density lipoproteins cholesterol (LDL-C). Using mixed design repeated measurements ANCOVA we compared the longitudinal patterns of lipid substrates in women who experienced preeclampsia $(n=12)$ with those who did not develop recurrent preeclampsia $(n=26)$. Main outcome measure: Recurrent preeclampsia.

Results: Women who did not develop recurrent preeclampsia showed a transient decline in LDL-C by 12 weeks, which was absent in women who did develop recurrent disease. The increase in HDL-C in the first 16 weeks tended to be limited in women with recurrent preeclampsia as compared to their counterparts without recurrent disease. Finally, serum TG rose comparably over the first 16 weeks of pregnancy in both subgroups.

Conclusion: These new insights indicate that an abnormal early adaptation of the lipid metabolism to pregnancy precedes the clinical manifestation of (recurrent) preeclampsia, which may be of pathophysiologic importance and could contribute to the development of prediction strategies. 


\section{Introduction}

Pregnancy-induced changes in lipid metabolism promote the accumulation of maternal fat stores in the first half of pregnancy and enhance fat mobilization in late gestation. In the early stages, increased estrogen, progesterone, and insulin levels favor lipid deposition and inhibit lipolysis. ${ }^{1}$ After an initial decrease during the first trimester, cholesterol and lipoproteins increase steadily throughout gestation. ${ }^{2,3}$ In preeclampsia, plasma lipids have been reported to reach levels substantially above those seen in normal pregnancy. ${ }^{4-7}$ However, in most studies, blood samples were collected after diagnosis and, to our knowledge, they all were cross-sectional. The pathogenesis of preeclampsia originates in early pregnancy, presumably even during the first stages of placentation. ${ }^{8}$ Unlike normal early pregnancy, when apoptotic syncytiotrophoblast nuclei are packed into syncytial knots and released in the maternal circulation, ${ }^{9-11}$ in preeclampsia, impaired trophoblast differentiation is proposed to lead to mechanisms as necrosis and aponecrosis. ${ }^{12}$ Eventually, the latter may cause systemic alterations of the maternal endothelium and inflammatory system.

The question arises whether abnormal lipid metabolism and its maladaptation in preeclampsia can be detected early in pregnancy. If so, differences in longitudinal patterns could improve our understanding of the pathophysiology of preeclampsia and offer opportunities for prediction and/or counselling strategies. We aimed to study the longitudinal patterns of circulating lipid levels in early pregnancy in formerly preeclamptic women who did and those who did not develop recurrent disease. To this end, we compared the adaptional changes of the lipid profile to pregnancy in the two groups.

\section{Methods}

This is a longitudinal observational cohort study performed at Maastricht University Medical Centre in the Netherlands. All measurements reported originate from the usual care provided to high-risk obstetrical patients in our centre. In view of their increased risk of recurrent disease, pregnant women with a history of early-onset (diagnosis $\leq 34$ weeks and delivery $\leq 37$ weeks of gestational age) preeclampsia are being offered a longitudinal screening program to detect abnormalities in the adaptation to pregnancy, before clinical symptoms become manifest. The screening assessments take place in the non-pregnant condition at least six months after the first delivery and at 12, 16 and 20 weeks of the next pregnancy. High-risk obstetrical care in this format was initiated in 2002. Although observations had been collected prospectively, data collection was done retrospectively. All hospital data, including those on pregnancy outcome, were collected and entered in a database by a clinical 
research assistant who was not involved in the statistical analysis. Prior to analysis, data were anonymized. In the Netherlands, ethical approval of a study based on anonymous data originating from clinical care as usual is not required.

In this study, we included all women whose pregnancy outcome was known by February 2009 and who had completed at least two check-ups before and/or during this pregnancy. We excluded six women because their pregnancy was still ongoing and three because two of the three check-ups were missing. Furthermore, we excluded one woman with a twin pregnancy. Eventually, 38 women with a history of early-onset preeclampsia, who had participated in our follow-up program, completed a subsequent pregnancy and were included in the analysis.

We defined preeclampsia according to the guidelines of the National working group on High Blood Pressure in Pregnancy, ${ }^{13}$ as de novo hypertension (blood pressure > $140 / 90 \mathrm{mmHg}$, occurring after the $20^{\text {th }}$ week of pregnancy) accompanied by proteinuria ( $\geq 300 \mathrm{mg}$ in a 24-hour urine sample). Preeclampsia superimposed on chronic hypertension was defined as new-onset proteinuria after 20 weeks' gestation. We defined the HELLP syndrome as the concomitant occurrence of hemolysis (evidence on peripheral blood smear, serum LDH level $>600 \mathrm{IU} / \mathrm{L}$ ), elevated $(\geq 70$ IU/L) serum aspartate aminotransferase (ASAT) and/or alanine aminotransferase (ALAT) and a low platelet count $\left(<100 * 10^{9} / \mathrm{L}\right)$, as proposed by Sibai et al. ${ }^{14} \mathrm{~A}$ smallfor-gestational age (SGA) infant was defined as a child with a birth weight below the $10^{\text {th }}$ percentile, based on the most recent Dutch birth weight reference curves. ${ }^{15}$ Although longitudinal gestational screening data had been collected in our medical centre, the location of delivery could be in any of Dutch hospitals, giving rise to variation in diagnostic methods for preeclampsia. For example, the diagnosis of proteinuria was based on a 24-hours urine collection in some hospitals and on the ratio protein to creatinine in others. In the database available for statistical analysis, women were coded as having had a next pregnancy complicated by preeclampsia or not, according to the definition described above. Individual in-pregnancy laboratory values were not supplied.

Before conception, and again at 12 and 16 weeks pregnancy, venous blood was sampled after an overnight fast and - after centrifugation - stored at $-30{ }^{\circ} \mathrm{C}$. Serum concentrations of triglycerides (TG), total cholesterol (TC) and high-density lipoprotein cholesterol (HDL-C) were determined on a Beckman Coulter LX20 PRO Clinical Chemistry analyzer (Beckman Coulter, Fullerton, USA). We calculated low-density lipoprotein cholesterol (LDL-C) by the Friedewald equation. ${ }^{16}$ Pre-pregnant body length and weight were determined in a standardized fashion to calculate body mass index (BMI). Pre-pregnant fasting levels of glucose and insulin were assessed using standard laboratory techniques.

The statistical analysis was performed using SPSS version 15.0 for Windows. Missing values ( $17 \%$ of longitudinal data) were imputed using a single imputation regression procedure. ${ }^{17}$ In case of non-normality, we transformed the data logarithmically. To 
test differences between longitudinal patterns of lipid substrates during pregnancy we used mixed design analysis of covariance (ANCOVA) with a multivariate approach. Potential confounders were BMI, chronic hypertension, and circulating levels of fasting glucose and insulin. Bonferroni's adjustment for multiple comparisons was used in testing within-group differences. Data are presented as mean \pm standard error (SE), unless otherwise noted. The 95\%-confidence intervals presented in the figures were corrected for between-subject variability according to the methods of Loftus and Masson. ${ }^{18,19}$ All effects are reported as significant at $p<$ 0.05 .

\section{Results}

Table 1 summarizes the characteristics of the preceding complicated pregnancy. Mean gestational age at birth was 30.2 weeks and mean newborn weight $1151 \mathrm{~g}$. Ten (26\%) women gave birth to an SGA infant and 8 (21\%) women had an intrauterine fetal demise. In 24 (63\%) women, the HELLP syndrome complicated their previous early-onset preeclampsia. All women were Caucasian and primiparous. None of them had (gestational) diabetes.

Table 1: Obstetric history of 38 women with a history of early-onset preeclampsia. Data are presented as mean $\pm S E$ or $n(\%)$, unless otherwise noted.

$\begin{array}{ll}\text { HELLP syndrome } & 24(63 \%) \\ \text { Gestational age at } 1^{\text {st }} \text { birth (weeks) } & 30.2 \pm 0.5 \\ \text { Birth weight } 1^{\text {st }} \text { child (g) } & 1151 \pm 95 \\ \text { Intra-uterine demise } 1^{\text {st }} \text { pregnancy } & 8(21 \%) \\ 1^{\text {st }} \text { child SGA at birth }(<\mathrm{p} 10) & 10(26 \%) \\ \text { Time between } 1^{\text {st }} \text { birth and pregravid measurements (months) } & 9(6-22) \\ \text { Time between pregravid measurements and } 12 \text { weeks amenorrhea (months) } & 6(5-13)\end{array}$

Time intervals between $1^{\text {st }}$ birth and pregravid measurements and between pregravid measurements and 12 weeks amenorrhea are presented as median (interquartile range).

Table 2 lists the outcome of the next pregnancy. Preeclampsia recurred in 12 (32\%, 95\%-Cl: 17-46\%) women, with 3 early-onset cases, 6 cases with an SGA newborn, and 1 with an intra-uterine fetal demise. Eighteen (47\%) women did not develop maternal hypertensive disease in their next pregnancy, although one of them gave birth to an SGA infant.

Table 3 lists some pregravid clinical features of women with and without recurrent preeclampsia. The two subgroups did neither differ clinically nor statistically with respect to maternal age, prevalence of overweight, and lipid substrate concentrations. Although not statistically significant, the prevalence of obesity and chronic hypertension tended to be lower and that of hyperglycemia and -insulinemia higher in women with recurrent preeclampsia. 
Table 2: Maternal and fetal pregnancy outcome of second pregnancy in formerly preeclamptic women ( $\mathrm{N}$ = 38). Data are presented as $\mathrm{n}(\%)$.

\begin{tabular}{ll}
\hline Maternal outcome & \\
Early-onset preeclampsia/HELLP & $3(8 \%)$ \\
Late-onset preeclampsia/HELLP & $9(24 \%)$ \\
Pregnancy induced hypertension without proteinuria & $8(21 \%)$ \\
No hypertensive disease & $18(47 \%)$ \\
Fetal outcome & \\
Intra-uterine demise & $1(3 \%)^{\dagger}$ \\
Extremely preterm birth $(<32 \mathrm{wks})$ & $2(5 \%)$ \\
Small for gestational age $(<\mathrm{p} 10)$ & $11(32 \%)$
\end{tabular}

${ }^{\dagger}<32$ weeks amenorrhea, fetal weight $<1500 \mathrm{~g}(<\mathrm{p} 2.3)$, mother had preeclampsia. The two extremely preterm births were the result of early-onset preeclampsia. Seven of the pregnancies resulting in a small for gestational age infant were complicated by preeclampsia/HELLP.

Table 3: Prepregnancy clinical characteristics and lipid profile of women with recurrent preeclampsia (PE) and women without recurrent PE. Data are presented as mean \pm SE or $n(\%)$, unless otherwise noted.

\begin{tabular}{llll}
\hline & $\begin{array}{l}\mathrm{PE} \\
(\mathrm{n}=12)\end{array}$ & $\begin{array}{l}\text { No PE } \\
(\mathrm{n}=26)\end{array}$ & $\mathrm{P}$ \\
\hline Age $(\mathrm{y})$ & $31.6 \pm 0.7$ & $31.9 \pm 0.8$ & 0.86 \\
Overweight & $5(42 \%)$ & $13(50 \%)$ & 0.63 \\
Obesity & $1(8 \%)$ & $4(15 \%)$ & 0.55 \\
Hyperglycemia & $2(17 \%)$ & $1(4 \%)$ & 0.51 \\
Hyperinsulinemia & $4(33 \%)$ & $6(23 \%)$ & 0.71 \\
Chronic hypertension & $1(8 \%)$ & $4(15 \%)$ & 0.55 \\
Total cholesterol (mmol/L) & $4.4 \pm 0.2$ & $4.7 \pm 0.2$ & 0.33 \\
Triglycerides (mmol/L) & $0.88(0.59-1.41)$ & $0.79(0.60-1.16)$ & 0.84 \\
HDL-cholesterol (mmol/L) & $1.19 \pm 0.09$ & $1.19 \pm 0.06$ & 0.95 \\
LDL-cholesterol (mmol) & $2.8 \pm 0.1$ & $3.0 \pm 0.1$ & 0.36 \\
\hline
\end{tabular}

Hyperglycemia: fasting glucose level $>5.6 \mathrm{mmol} / \mathrm{L}$; Hyperinsulinemia: fasting insulin level $>15.0 \mathrm{mmol} / \mathrm{L}$. Maternal age at 12 weeks amenorrhea. Circulating level of triglycerides are presented as median (interquartile range). Statistical tests: independent samples t-test, Mann-Whitney test, and chi $^{2}$-test.

Figures $1 \mathrm{~A}$ to $1 \mathrm{D}$ display the changes in lipid parameters with pregnancy. No significant differences were observed between groups in the altering circulating levels of TC (figure $1 \mathrm{~A}$ ). LDL-C decreased by $12 \%$ relative to the pregravid level in the first 12 weeks of pregnancy in women who did not develop preeclampsia (mean decrease $0.5 \pm 0.1 \mathrm{mmol} / \mathrm{L}, \mathrm{p}<0.01$ ), to increase again in the period until 16 weeks (figure 1B). This transient dip in LDL-C was absent in women destined to develop recurrent disease $(p>0.99)$, the pattern being significantly different from women without recurrent disease $(p=0.01)$. HDL-C had increased similarly in both subgroups, with no statistically significant differences in patterns of change ( $p$ for interaction term $=$ 0.36) (figure $1 \mathrm{C}$ ). However, the increase tended to be larger and was statistically significant only in the subgroup of women without recurrent preeclampsia (mean increase by the $16^{\text {th }}$ week $0.32 \pm 0.07 \mathrm{mmol} / \mathrm{L}, \mathrm{p}<0.01$ ). In women destined to de- 
velop recurrent preeclampsia the increase in $\mathrm{HDL}-\mathrm{C}$ in 16 weeks was small $(0.16 \pm$ $0.05 \mathrm{mmol} / \mathrm{L})$ and not statistically significant $(p=0.22)$. Finally, starting at the same pregravid level, the increase in serum TG over the first 16 weeks of pregnancy was similar in both subgroups, with a median rise of approximately $25 \%(p<0.05$ in both subgroups) (Figure 1D).

\section{Discussion}

Our results indicate that an initial transient decline in LDL-C was absent in women who developed recurrent preeclampsia. Moreover, the increase in HDL-C tended to be less strong during the first 16 weeks as compared to women who did not develop recurrent disease. On the other hand, the pre-pregnant circulating levels of cholesterol and triglycerides were comparable between women with and without recurrent preeclampsia and, throughout the first weeks of pregnancy, triglycerides increased in both groups.

Although partly overcome by evaluating repeated measurements within patients, a limitation of the present study is its small sample size. The statistical power to detect a within group alteration in cholesterol or triglycerides over time of 0.2 $\mathrm{mmol} / \mathrm{L}$ with a standard deviation of $0.3 \mathrm{mmol} / \mathrm{L}$ was $90 \%$ in women without $(\mathrm{n}=$ $26)$ and $54 \%$ in women with recurrent preeclampsia $(n=12)$. However, we also tested between-group differences in longitudinal patterns (e.g. statistical interaction between the presence of recurrent preeclampsia and gestational age) by means of a multivariate approach.

We believe that our observations are important, since they address the initial adaptation of the lipid profile during the sub-clinical stage of preeclampsia. We aimed to evaluate whether these adaptive changes differ between formerly preeclamptic women destined to develop recurrent preeclampsia and their counterparts who are not. For this reason, we did not include 'normal' pregnant women or define a control group of women without any complications, but compared women who developed preeclampsia in their second pregnancy with those who did not. To the best of our knowledge, early-pregnancy alterations of serum lipid levels in preeclampsia with a preconception level as a starting point- have not been reported previously. The initial fall in LDL-C observed in women who did not develop recurrent preeclampsia is in line with previous observations in normal pregnancy and is believed to result from placental uptake of cholesterol for the synthesis of steroid hormones. ${ }^{1-3,20}$ Although results are contradictory, oestrogen concentrations have repeatedly shown to be reduced relative to levels in uncomplicated pregnancies. ${ }^{21,22}$ Since oestrogen is produced by syncytiotrophoblast, the latter could be the result of increased aponecrosis of syncytiotrophoblasts in preeclampsia. As we did not measure the circulating levels of oestrogen in these women, we can only further 
speculate that the absence of a decline in LDL-C in women with recurrent preeclampsia in our cohort is due to a lower placental steroid production. In a subanalysis, in which we defined a third subgroup $(n=5)$ of women without preeclampsia who gave birth to an SGA infant, the initial fall in LDL-C was absent as well, providing additional support for reduced placental steroid production to be involved. If this hypothesis is to be accepted, the absent decline in LDL-C can be considered a marker for recurrent preeclampsia rather than a predisposing factor in its pathological pathway.
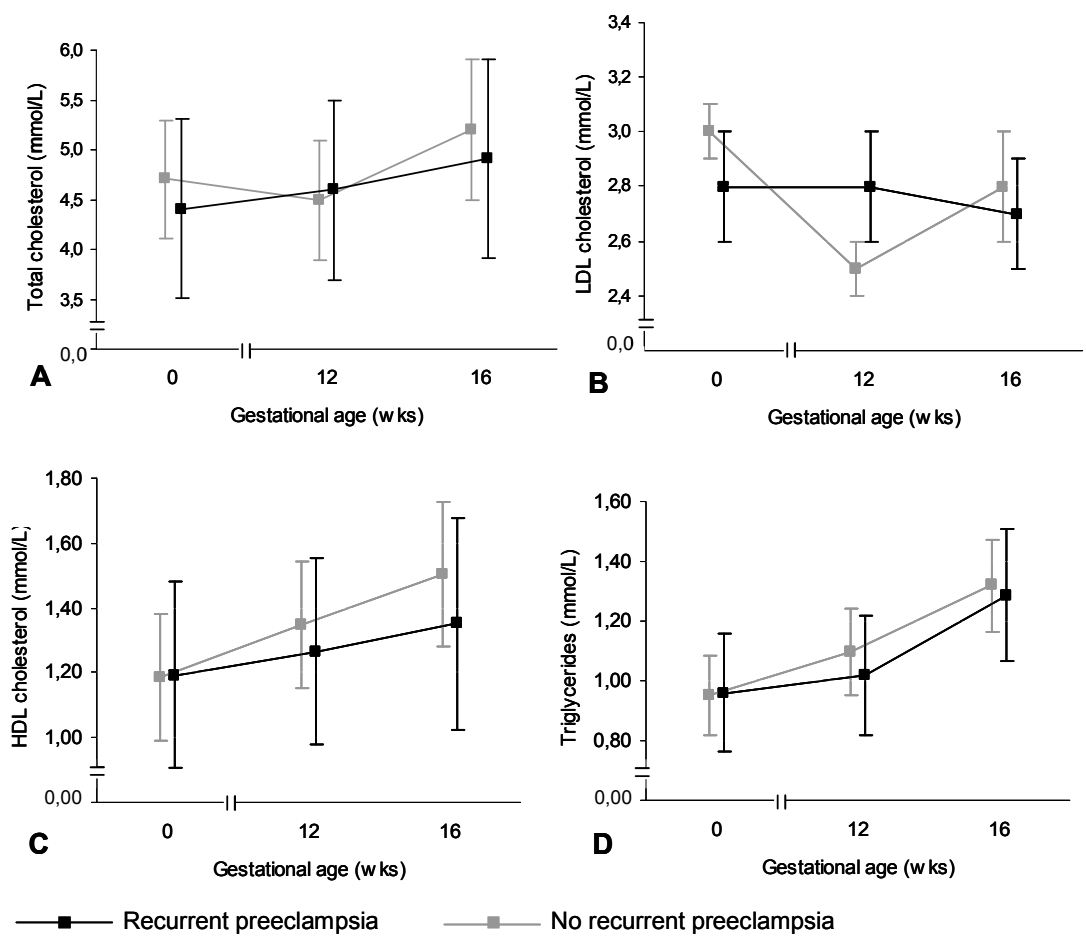

Figure 1: Circulating levels of: A) total cholesterol, B) LDL-cholesterol, C) HDL-cholesterol, and D) triglycerides, before pregnancy and at 12 and 16 weeks amenorrhea in women with and without recurrent preeclampsia. Data are presented as mean with $95 \%-\mathrm{Cl}$ (adjusted for between-subject variability).

Previously, we found cholesterol parameters to be predictive for recurrent earlyonset preeclampsia, with the highest predictive values for HDL-C. ${ }^{23}$ Due to discrepancy in outcome measures (the present study is not restricted to recurrent earlyonset preeclampsia), pre-pregnant HDL-C levels were comparable between groups. However, the mean level of pre-pregnant HDL-C was lower in women with recurrent early-onset preeclampsia $(n=3)$ as compared to women without early-onset disease $(n=35)(p<0.01)$. 
Because of the small number of women with this outcome, we did not treat them as a separate group in our main analysis. HDL-C is characterized by antiinflammatory and endothelium-protective properties. ${ }^{24}$ In the perspective of preexisting low levels of HDL-C, it seems plausible that in affecting endothelial cells or the inflammatory system, overkill is facilitated of the mechanisms that dispose released apoptotic trophoblast fragments. In turn, this can induce systemic activation and damage to endothelial cells, which may eventually result in preeclampsia. In later pregnancy, circulating levels of HDL-C have repeatedly been proven to be reduced in preeclamptic as compared to normotensive women. ${ }^{25,26}$ In our study, we observed a tendency towards an absent increase in the first 16 weeks of pregnancy in women who later on developed recurrent preeclampsia as compared to their counterparts without recurrent disease.

Note that the generalisability of our results to nulliparous pregnant women may be limited. To test the hypothesis generated, future research with a larger sample size, assessment of steroid hormones and distinguishing early- and late-onset disease is needed.

\section{Conclusion}

The results let us to postulate that the absence of the, for normal pregnancy typical, initial decline in LDL-C, observed in women with recurrent preeclampsia, is due to a lower placental steroid production in these women. In addition, our data indicate that the increase in HDL-C during the first 16 weeks of pregnancy tended to be lower in women who later-on developed preeclampsia, possibly heading the reduced levels that have been reported later in preeclamptic pregnancy. These new insights suggest that an abnormal early adaptation of the lipid metabolism to pregnancy precedes the clinical manifestation of (recurrent) preeclampsia, which can be of pathophysiologic importance and could contribute to the development of prediction strategies.

\section{Acknowledgements}

We thank T Ekhart for the collection and entry of the data. 


\section{References}

1. Butte NF. Carbohydrate and lipid metabolism in pregnancy: normal compared with gestational diabetes mellitus. Am J Clin Nutr 2000;71(5 Suppl):1256S-61S.

2. Fahraeus L, Larsson-Cohn U, Wallentin L. Plasma lipoproteins including high density lipoprotein subfractions during normal pregnancy. Obstet Gynecol 1985;66(4):468-72.

3. Darmady JM, Postle AD. Lipid metabolism in pregnancy. Br J Obstet Gynaecol 1982;89(3):211-5.

4. Hubel CA, McLaughlin MK, Evans RW, Hauth BA, Sims CJ, Roberts JM. Fasting serum triglycerides, free fatty acids, and malondialdehyde are increased in preeclampsia, are positively correlated, and decrease within 48 hours post partum. Am J Obstet Gynecol 1996;174(3):975-82.

5. Ogura K, Miyatake T, Fukui O, Nakamura T, Kameda T, Yoshino G. Low-density lipoprotein particle diameter in normal pregnancy and preeclampsia. J Atheroscler Thromb 2002;9(1):42-7.

6. Franz $\mathrm{H}$, Wendler D. A controlled study of maternal serum concentrations of lipoproteins in pregnancy-induced hypertension. Arch Gynecol Obstet 1992;252(2):81-6.

7. Sattar N, Gaw A, Packard CJ, Greer IA. Potential pathogenic roles of aberrant lipoprotein and fatty acid metabolism in pre-eclampsia. Br J Obstet Gynaecol 1996;103(7):614-20.

8. Roberts JM, Hubel CA. The two stage model of preeclampsia: variations on the theme. Placenta 2009;30 Suppl A:S32-7.

9. Huppertz B, Kingdom JC. Apoptosis in the trophoblast--role of apoptosis in placental morphogenesis. J Soc Gynecol Investig 2004;11(6):353-62.

10. Huppertz B, Frank HG, Kingdom JC, Reister F, Kaufmann P. Villous cytotrophoblast regulation of the syncytial apoptotic cascade in the human placenta. Histochem Cell Biol 1998;110(5):495-508.

11. Mayhew TM. A stereological perspective on placental morphology in normal and complicated pregnancies. J Anat 2008.

12. Formigli L, Papucci L, Tani A, Schiavone N, Tempestini A, Orlandini GE, et al. Aponecrosis: morphological and biochemical exploration of a syncretic process of cell death sharing apoptosis and necrosis. J Cell Physiol 2000;182(1):41-9.

13. Report of the National High Blood Pressure Education Program. Working group report on high blood pressure in pregnancy. Am J Obstet Gynecol 2000;183:S1-S22.

14. Sibai BM. Diagnosis, controversies, and management of the syndrome of hemolysis, elevated liver enzymes, and low platelet count. Obstet Gynecol 2004;103(5 Pt 1):981-91.

15. The Netherlands Perinatal Registry [homepage on the internet]. Bilthoven: NPR-foundation; [cited April 2009]. Available from: http://www. perinatreg.nl/.

16. Friedewald WT, Levy RI, Fredrickson DS. Estimation of the concentration of low-density lipoprotein cholesterol in plasma, without use of the preparative ultracentrifuge. Clin Chem 1972;18(6):499-502.

17. Longford N. Single Imputation and Related Methods. In: Missing data and small-area estimation. London: Springer; 2005. p. 37-58.

18. Loftus G, Masson M. Using confidence intervals in within-subject designs. Psychonomic Bulletin and Review. 1994;1:476-490.

19. Atkinson G. Analysis of repeated measurements in physical therapy research: multiple comparisons amongst level means and multi-factorial designs. Physical Therapy in Sport 2002;3(4):191-203.

20. Di Cianni G, Miccoli R, Volpe L, Lencioni C, Del Prato S. Intermediate metabolism in normal pregnancy and in gestational diabetes. Diabetes Metab Res Rev 2003;19(4):259-70.

21. Innes KE, Byers TE. Preeclampsia and breast cancer risk. Epidemiology 1999;10(6):722-32.

22. Zeisler $H$, Jirecek $S$, Hohlagschwandtner $M$, Knofler M, Tempfer $C$, Livingston JC. Concentrations of estrogens in patients with preeclampsia. Wien Klin Wochenschr 2002;114(12):458-61.

23. Sep SJ, Smits L, Prins MH, Spaanderman ME, Peeters LL. Simple prepregnant prediction rule for recurrent earlyonset hypertensive disease in pregnancy. Reprod Sci 2009;16(1):80-7.

24. Norata GD, Catapano AL. Molecular mechanisms responsible for the antiinflammatory and protective effect of HDL on the endothelium. Vasc Health Risk Manag 2005;1(2):119-29.

25. Ware-Jauregui S, Sanchez SE, Zhang C, Laraburre G, King IB, Williams MA. Plasma lipid concentrations in preeclamptic and normotensive Peruvian women. Int J Gynaecol Obstet 1999;67(3):147-55.

26. Williams MA, Woelk GB, King IB, Jenkins L, Mahomed K. Plasma carotenoids, retinol, tocopherols, and lipoproteins in preeclamptic and normotensive pregnant Zimbabwean women. Am J Hypertens 2003;16(8):665-72. 


\section{CHAPTER 8}

\section{Early cardiac adaptation}

to pregnancy in women with recurrent preeclampsia

Simone Sep, Malou Schreurs, Sebastiaan Bekkers, Arnold-Jan Kruse, Luc Smits, Louis Peeters 


\section{Abstract}

Objective: To compare the adaptation of the cardiac diastolic function to pregnancy between formerly preeclamptics with (RECUR) and without (NORECUR) recurrent preeclampsia.

Methods: Retrospective observational cohort study, in which the peak mitral filling velocity in early diastole $(E)$ and that at atrial contraction $(A)$ and the $E / A$ ratio were assessed before and at 12, 16 and 20 weeks of the next pregnancy in 34 women with a history of early-onset preeclampsia.

Results: In 10 (29\%) women preeclampsia recurred. By 12 weeks pregnancy, the E/A ratio had increased in RECUR, but not in NORECUR $(p<0.01)$. Moreover, from 16 weeks onwards, RECUR had a lower cardiac output and higher systemic vascular resistance as compared to NORECUR ( $p<0.05)$.

Conclusion: Our results suggest that formerly preeclamptics destined to develop recurrent preeclampsia differ from their counterparts who do not develop recurrent preeclampsia by impaired first-trimester adaptation of cardiac diastolic function. 


\section{Introduction}

In normal pregnancy, systemic vascular adaptation starts in the fifth week with a fall in vascular tone, resulting in an approximately $30 \%$ decline in systemic vascular resistance. ${ }^{1-3}$ As the latter tends to decrease cardiac pre- and afterload, the sympathetic contribution to the autonomic control of the circulation increases. 4 The fall in systemic vascular tone also activates the volume regulatory system giving rise to accelerated volume retention. ${ }^{4}$ These compensations, which raise cardiac output and plasma volume, are paralleled by renal hyperfiltration, hemodilution and activation of the renin-angiotensin-aldosterone system, eventually resulting in the institution of a high flow and low resistance circulation. ${ }^{1}$

Data on the concomitant changes in cardiac function are scarce. Pregnancy-induced higher tidal volumes modify cardiac pre - and afterload by the concomitant magnified negative intrathoracic pressures. ${ }^{5}$ Early-onset preeclampsia has been shown to be preceded by impaired early-pregnancy hemodynamic and cardiac adaptation. ${ }^{6}$ However, it is currently unknown whether maladaptation of the cardiac diastolic function to pregnancy is involved in its pathophysiology. In their next pregnancy, these women have an increased risk of recurrence of preeclampsia. ${ }^{7}$

Our objective was to evaluate whether the adaptation of the cardiac diastolic function to pregnancy differs between women who develop recurrent preeclampsia and those who do not. If true, this phenomenon may eventually offer opportunities for future prediction or counseling purposes. We observed a cohort of 34 women with a history of early-onset preeclampsia and compared the adaptation of the cardiac diastolic function to the next pregnancy between those who did and those who did not develop recurrent preeclampsia. Diastolic function parameters had been assessed before the second pregnancy and at 12,16 and 20 weeks gestation.

\section{Methods}

This is a longitudinal observational cohort study performed at Maastricht University Medical Centre in the Netherlands. All measurements reported originate from the usual care provided to high-risk obstetrical patients. It follows that, although observations were collected prospectively, data collection was done retrospectively. All hospital data, including those on pregnancy outcome, were collected and entered in a database by a research assistant who was not involved in the statistical analysis. Prior to analysis, data were anonymized, making ethical approval superfluous.

Because of their increased risk for recurrent disease, pregnant women with a history of early-onset (diagnosis $\leq 34$ weeks and delivery $\leq 37$ weeks of gestational age) preeclampsia receive high-risk obstetrical care in our hospital, which consists of a thorough medical check-up at 12, 16 and 20 weeks pregnancy. Combined with a 
preconceptional check-up (at least 6 months after first delivery), these measurements serve to detect abnormalities in the adaptation to pregnancy before clinical signs become manifest. High-risk obstetrical care in this format was initiated in 2002.

In this study, we included all women whose pregnancy outcome was known by December 2008 and who had completed at least three check-ups. We excluded four women because their pregnancy was still ongoing and two because two or more check-ups were missing. Furthermore, we excluded one woman with a twin pregnancy and one because of chronic renal failure. Eventually, 34 women with a history of early-onset preeclampsia, who had participated in our in-pregnancy follow-up program, completed a subsequent pregnancy, and were included in the analysis.

Although screening data were collected in our medical centre, the location of delivery in the next pregnancy could be in any of Dutch hospitals. Diagnostic methods for preeclampsia varied between hospitals. For example, the diagnosis of proteinuria was based on a 24-hours urine collection in some hospitals and on the ratio protein to creatinine in others. Preeclampsia was defined according to the guidelines of the National working group on High Blood Pressure in Pregnancy, as de novo hypertension (blood pressure $>140 / 90 \mathrm{mmHg}$, occurring after the 20th week of pregnancy) accompanied by proteinuria ( $>300 \mathrm{mg} / 24 \mathrm{~h}$ or $>30 \mathrm{mg} / \mathrm{mmol}$ creatinine). ${ }^{8}$ Preeclampsia superimposed on chronic hypertension was defined as newonset proteinuria after 20 weeks' gestation. In the database available for statistical analysis, women were coded as having had a next pregnancy complicated by preeclampsia or not. Individual in-pregnancy laboratory values were not supplied. A birth weight below the 10th percentile, based on the most recent Dutch birth weight reference curves, ${ }^{9}$ was used to diagnose fetal growth restriction in the preceding pregnancy.

Echocardiography was performed with the patient in the left-lateral position, after 5 minutes of rest, with an S5-1 (bandwidth 5-1 MHz) phased array transducer interfaced with a Philips IE33 system (Philips Medical Systems, Best, The Netherlands). Pulsed wave (PW) Doppler-derived transmitral velocities were obtained the mitral leaflet tips according to the guidelines of the American Society of Echocardiography. ${ }^{10}$ From the parasternal long axis view we performed the following measurements: left ventricular end-diastolic diameter (LVEDD), left ventricular end systolic diameter (LVESD), interventricular septal end diastolic wall thickness, posterior wall end diastolic wall thickness and left atrial diameter (LAD) according to criteria of the American Society of Echocardiography. ${ }^{11}$ The diameter of the inferior caval vein was measured from a substernal M-Mode recording. Left ventricular mass was calculated by the Devereux formula. ${ }^{12}$ Left atrial volume was measured in the apical four- and two chamber view at mitral valve closure using the biplane method of discs. ${ }^{13}$ In the apical 4 chamber view, right atrial volume was estimated using the area-length formula. ${ }^{11}$ Cardiac dimensions were indexed to body surface 
area. All data were stored digitally and calculations were performed offline using dedicated software (Excelera, Philips, The Netherlands) by a single observer, who was blinded to the clinical data.

LV function was assessed using Teicholz formula applied to ventricular diameters measured parasternally, resulting in LV ejection fraction. ${ }^{14}$ Cardiac output (CO, $\mathrm{L} / \mathrm{min}$ ) was obtained by multiplying stroke volume (SV) with heart rate (HR). The HR was obtained by taking the reciprocal of the mean of 3-5 consecutive R-R intervals on the electrocardiogram. From an apical approach, aortic flow across the aortic valve was measured using continuous wave (CW) Doppler. SV was calculated by multiplying aortic velocity time integral (VTI) with the cross-sectional area measured at the level of the aortic annulus in the parasternal long axis view. The mean VTI, used to calculate SV, was measured by averaging the outer edge tracings of 3-5 consecutive CW Doppler registrations.

Diastolic function was measured using PW Doppler echocardiography to obtain transmitral flow determined from the apical 4-chamber view. The PW Doppler sample volume $(5 \mathrm{~mm})$ was carefully positioned at the tip of the mitral valve leaflets. The sweep rate was set at $50 \mathrm{~mm} / \mathrm{s}$. We defined E/A ratio as the ratio of peak mitral flow velocity in early diastole $(E)$ and that during atrial contraction (A). In addition, the E-wave deceleration time was measured. ${ }^{15}$ Doppler derived indices were averaged from 3-5 consecutive cardiac cycles.

We recorded blood pressure in standardized environmental conditions with external disturbances kept to a minimum and the subject laying on her back. Participants did not eat for at least 10 hours prior to the measurement. We registered blood pressure every three minutes, using a semiautomatic oscillometric device (Dinamap Vital Signs Monitor 1846; Critikon, Tampa, Florida, USA), during 30 minutes.

SPSS package version 15.0.0 was used for statistical analysis. We transformed nonnormally distributed data logarithmically. To evaluate the response of the cardiac diastolic function to pregnancy and differences in this response between groups we used mixed design analysis of covariance (ANCOVA). Missing values were imputed using a single imputation regression procedure to avoid listwise deletion. ${ }^{16}$ In order to control for regression to the mean, we adjusted for baseline (prepregnancy) values in all between groups comparisons of patterns. ${ }^{17}$ Pregravid body mass index (BMI), mean arterial pressure and gestational age at previous delivery as a measure for disease onset were considered potential confounders and therefore were added to the model as well.

The $p$-values reported for interaction resulted after adjustment for these confounders. In the mixed design ANCOVA analysis, statistically significant interaction indicates different longitudinal patterns in women with recurrent preeclampsia as compared to those without recurrence. Bonferroni's adjustment for multiple comparisons was used in testing within-group differences. Data are presented as mean \pm SD, unless otherwise stated. The $95 \%$-confidence intervals presented in the fig- 
ures are corrected for between-subject variability according to the methods of Loftus and Masson. ${ }^{18}$ All effects are reported as significant at $p<0.05$.

\section{Results}

Ten (29\%, 95\% Cl: $13-42 \%$ ) of the 34 formerly preeclamptic women developed recurrent preeclampsia (RECUR) in their next pregnancy. The remaining 24 women had no recurrent event in their next pregnancy (NORECUR), although five of them developed gestational hypertension.

\begin{tabular}{|c|c|c|}
\hline Variable & $\begin{array}{l}\text { RECUR } \\
(n=10)\end{array}$ & $\begin{array}{l}\text { NORECUR } \\
(n=24)\end{array}$ \\
\hline Maternal age (y) & $30 \pm 5$ & $33 \pm 5$ \\
\hline $\mathrm{BMI}\left(\mathrm{kg} / \mathrm{m}^{2}\right)$ & $24.5 \pm 3.5$ & $27.0 \pm 5.2$ \\
\hline Height (cm) & $164 \pm 4$ & $169 \pm 6$ \\
\hline Mean arterial pressure $(\mathrm{mmHg})$ & $96 \pm 7$ & $94 \pm 15$ \\
\hline Chronic hypertension & $3(30 \%)$ & $6(25 \%)$ \\
\hline Smoking & $1(10 \%)$ & $1(4 \%)$ \\
\hline Multiparity & $1(10 \%)$ & $1(4 \%)$ \\
\hline Gestational age previous birth (wks) & $29.6 \pm 2.9$ & $30.6 \pm 3.8$ \\
\hline Very preterm birth (<32 wks) & $8(80 \%)$ & $15(63 \%)$ \\
\hline Birth weight of previous child (g) & $890(599-1348)$ & $990(615-1680)$ \\
\hline Very low birth weight $(<1500 \mathrm{~g}$ ) & $8(80 \%)$ & $17(71 \%)$ \\
\hline Previous SGA newborn (<p10) & $4(40 \%)$ & $10(42 \%)$ \\
\hline IUFD in previous gestation & $3(30 \%)$ & $7(29 \%)$ \\
\hline
\end{tabular}

Maternal age at 12 weeks pregnancy. Birth weight is presented as median (inter-quartile range). BMI: body mass index; IUFD: intra-uterine fetal demise.

Table 1 lists pregravid demographic, clinical and obstetric characteristics of the women in both subgroups (leaving statistical significance of the differences aside). The groups did not differ from one another with respect to mean arterial pressure, chronic hypertension, smoking status and parity. None of the women had diabetes mellitus. Mean maternal age, BMI and height were lower in the RECUR group. Moreover, duration of previous pregnancy in RECUR was on average one week shorter with a higher frequency of very preterm births (<32 weeks), and with median birth weight being $100 \mathrm{~g}$ lower as compared to NORECUR. Furthermore, frequencies of very low-birth-weight infants (<1500 g), small-for-gestational-age (SGA) infants and intra-uterine fetal demise did not differ between groups. Tables 2 and 3 list the mean prepregnancy values for cardiac dimensions and cardiac function va- 
riables. None of these variables differed appreciably between RECUR and NORECUR.

Table 2: Pregravid cardiac dimensions in 10 formerly preeclamptic women, who developed recurrent preeclampsia in their subsequent pregnancy (RECUR) and 24 formerly preeclamptics who did not (NORECUR). Data are presented as mean \pm SD.

\begin{tabular}{llll}
\hline Variable & $\begin{array}{l}\text { RECUR } \\
(\mathrm{n}=10)\end{array}$ & $\begin{array}{l}\text { NORECUR } \\
(\mathrm{n}=24)\end{array}$ & $P$ \\
\hline Left atrium diameter $(\mathrm{mm})$ & $2.0 \pm 0.2$ & $1.8 \pm 0.1$ & 0.12 \\
Left atrium volume $(\mathrm{mL})$ & $30.9 \pm 7.52$ & $30.4 \pm 5.8$ & 0.82 \\
Left ventricular mass $(\mathrm{g})$ & $74.3 \pm 12.4$ & $77.2 \pm 11.0$ & 0.51 \\
Left ventricular end-diastolic diameter $(\mathrm{mm})$ & $26.1 \pm 2.5$ & $25.1 \pm 2.2$ & 0.22 \\
Left ventricular end-systolic diameter $(\mathrm{mm})$ & $16.8 \pm 1.8$ & $16.7 \pm 1.7$ & 0.79 \\
Vena cava diameter $(\mathrm{mm})$ & $7.9 \pm 1.8$ & $9.3 \pm 2.3$ & 0.10 \\
\hline
\end{tabular}

The independent t-test was used. All cardiac dimensions were indexed to body surface area $\left(\mathrm{m}^{2}\right)$.

Table 3: Pregravid cardiac function variables in 10 formerly preeclamptic women who developed recurrent preeclampsia in their subsequent pregnancy (RECUR) and 24 formerly preeclamptics who did not (NORECUR). Data are presented as mean \pm SD.

\begin{tabular}{llll}
\hline Variable & $\begin{array}{l}\text { RECUR } \\
(\mathrm{n}=10)\end{array}$ & $\begin{array}{l}\text { NORECUR } \\
(\mathrm{n}=24)\end{array}$ & $\mathrm{P}$ \\
\hline Peak E-wave velocity $(\mathrm{cm} / \mathrm{s})$ & $80.5 \pm 13.6$ & $85.4 \pm 12.7$ & 0.32 \\
Peak A-wave velocity $(\mathrm{cm} / \mathrm{s})$ & $58.8 \pm 10.9$ & $58.4 \pm 9.1$ & 0.91 \\
E/A ratio & $1.4 \pm 0.3$ & $1.5 \pm 0.3$ & 0.60 \\
E deceleration time $(\mathrm{s})$ & $0.15 \pm 0.3$ & $0.17 \pm 0.04$ & 0.27 \\
Cardiac output $(\mathrm{mL})$ & $5.12 \pm 0.78$ & $5.25 \pm 0.88$ & 0.68 \\
Stroke volume $(\mathrm{mL})$ & $68.3 \pm 11.2$ & $73.7 \pm 12.8$ & 0.26 \\
Heart rate $(\mathrm{bpm})$ & $76.2 \pm 16.6$ & $72.5 \pm 14.0$ & 0.51 \\
TPVR $\left(\right.$ dynes $\left.\cdot \mathrm{s} \cdot \mathrm{cm}^{-5}\right)$ & $1532 \pm 249$ & $1477 \pm 325$ & 0.64 \\
\hline
\end{tabular}

The independent t-test was used. TPVR: total peripheral vascular resistance.

Overall, $4 \%$ of the longitudinal data were imputed because of missing values. The pregnancy-induced changes in E/A ratio are displayed in figure 1 . As opposed to no appreciable first-trimester change in E/A ratio in NORECUR, we observed a consistent rise in this ratio in RECUR ( $p<0.01$ for interaction). The latter resulted from a trend towards a steeper rise in E-wave velocity relative to NORECUR ( $p=0.33$ for interaction), along with a fall in A-wave velocity ( $p=0.02$ for interaction). In contrast, in NORECUR, pregnancy had induced a consistent rise in the A-wave velocity, on average by $4.9 \pm 1.8 \mathrm{~cm} / \mathrm{sec}(p=0.05)$ (fig. 1). An increase in E/A ratio of more than $7 \%$ by 12 weeks pregnancy (difference score, cut-off was estimated by receiver operating characteristic curve) was associated with an increased risk for recurrent preeclampsia, the relative risk being 4.80 (95\%-Cl: 1.86-12.37). The responses of the E deceleration time and left atrial diameters and volumes to pregnancy did not differ between both groups. 
Figures 2 and 3 show the changes in cardiac output and total peripheral vascular resistance in the first 20 weeks of gestation. From 16 weeks onwards, cardiac output was lower and systemic vascular resistance higher in RECUR as compared to NORECUR $(p<0.05)$.

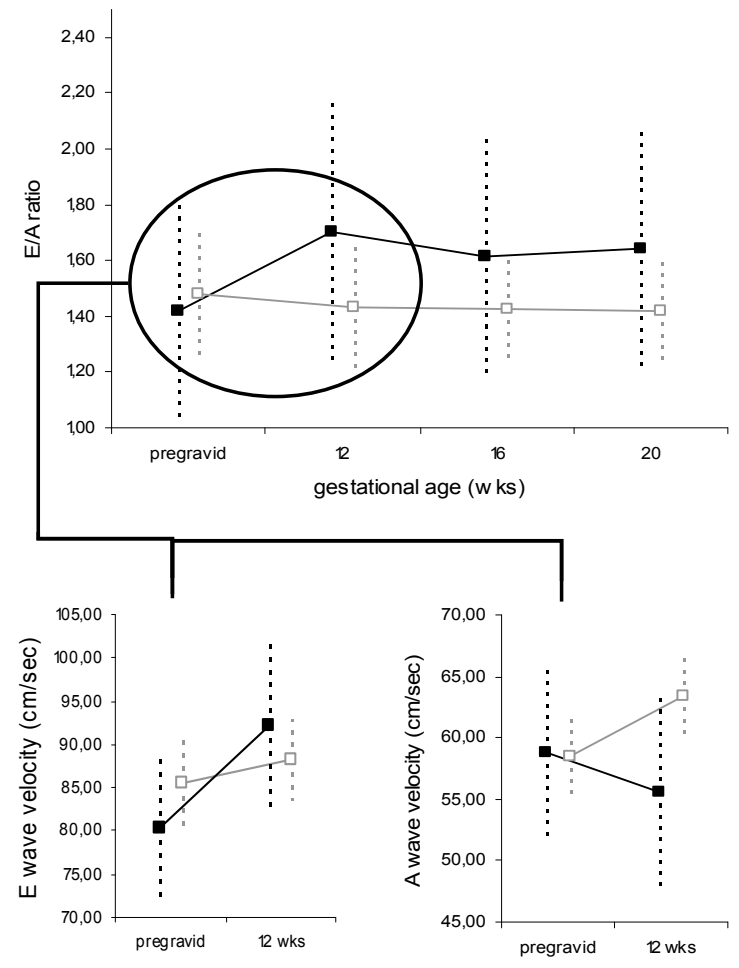

Figure 1: Mean and 95\% confidence intervals (corrected for between-subjects variability) of the E/A ratio in the first 20 weeks and the $E$ and $A$ wave velocity in the first 12 weeks of pregnancy in women who developed recurrent preeclampsia (black squares) and those who did not (gray squares).

\section{Comment}

Our results indicate that formerly preeclamptic women destined to develop recurrent disease in their next pregnancy differed from their counterparts with no recurrent disease by a rise in E/A ratio in the first trimester, together with a lower cardiac output and higher peripheral vascular resistance between 16 and 20 weeks. In the recurrence group, the first-trimester increase in E/A ratio resulted from an increasing trend in the E-wave velocity along with a decrease in A-wave velocity. In con- 
trast, in women without recurrent disease both $\mathrm{E}$ - and A-wave velocity had increased in response to pregnancy, resulting in an absent initial change in E/A ratio. This study is limited to a small sample size. Nevertheless, we believe that our observations are important, as they address the initial changes in cardiac function in the period of pregnancy when they are expected to be largest. We wanted to find out whether these adaptive changes differ between formerly preeclamptic women who do and do not develop recurrent preeclampsia in their next pregnancy. For this reason, we did not include 'normal' pregnant women or define a control group of women without any complications, but compared RECUR with NORECUR. The noninvasive assessment of cardiac diastolic function by echocardiography is complex. Besides the basic parameters reported in this study, more sophisticated methods exist to determine left ventricular diastolic function, based on complex analysis of transmitral flow, pulmonary vein flow, color M-mode velocity propagation and tissue Doppler imaging.

Nine women in the NORECUR subgroup had gestational hypertension without proteinuria and/or gave birth to a growth-restricted infant. To verify that these women had not distorted our findings we performed a sub-analysis in which they were considered a third subgroup. The response in these women was similar to the remainder of the women in NORECUR with respect to the main variables evaluated. In a previous study, early cardiac adaptation to pregnancy was found to differ between formerly preeclamptic women with subnormal ( $\leq 48 \mathrm{~mL} / \mathrm{kg}$ lean body mass) and normal plasma volume. ${ }^{1}$ In the present study, the proportions of women with subnormal plasma volume were similar in RECUR and NORECUR $60 \%$ vs. $55 \%$, respectively), indicating that plasma volume had not influenced the effects observed.

It is well established that the mitral E-wave velocity primarily reflects the pressure gradient between the left atrium (LA) and left ventricle (LV) during early diastole. The E-wave velocity is thus affected by both preload and alterations in LV relaxation. Meanwhile, the mitral A-wave velocity reflects the LA-LV pressure gradient during late diastole, affected by LV compliance and LA contractile function. During normal pregnancy, there is a reversible shift in transmitral flow velocities from early to late filling leading to a decreased E/A ratio in late pregnancy. This is strongly related to physiologic changes in HR, preload, LV compliance and contractility, as well as to gestational age. ${ }^{19}$ The increase in A-wave velocity observed in NORECUR is in line with previous findings, ${ }^{20}$ but in contrast with others, ${ }^{21,22}$ and is consistent with enhanced LA contraction in the face of the pregnancy-induced increase in LA preload and LV compliance. $^{3}$

In diastolic dysfunction, atrial contribution to LV filling is reduced due to impaired left ventricular relaxation and increased LV end-diastolic filling pressures. ${ }^{24,25}$ Although a parallel with preeclampsia should be drawn with caution, we believe the steeper increase in E-wave velocity observed in the RECUR group during early pregnancy, together with a trend in A-wave velocity to decline, reflects impaired relaxa- 
tion and higher LV end-diastolic filling pressures due to increased LV stiffness in these women. Future studies including more detailed assessment of pregnancyinduced response of the cardiac diastolic function (even in normal pregnancy), are needed to prove the importance of this phenomenon. The results of this study may provide a starting point to further explore the possibilities of this phenomenon for early counseling and predictive purposes.
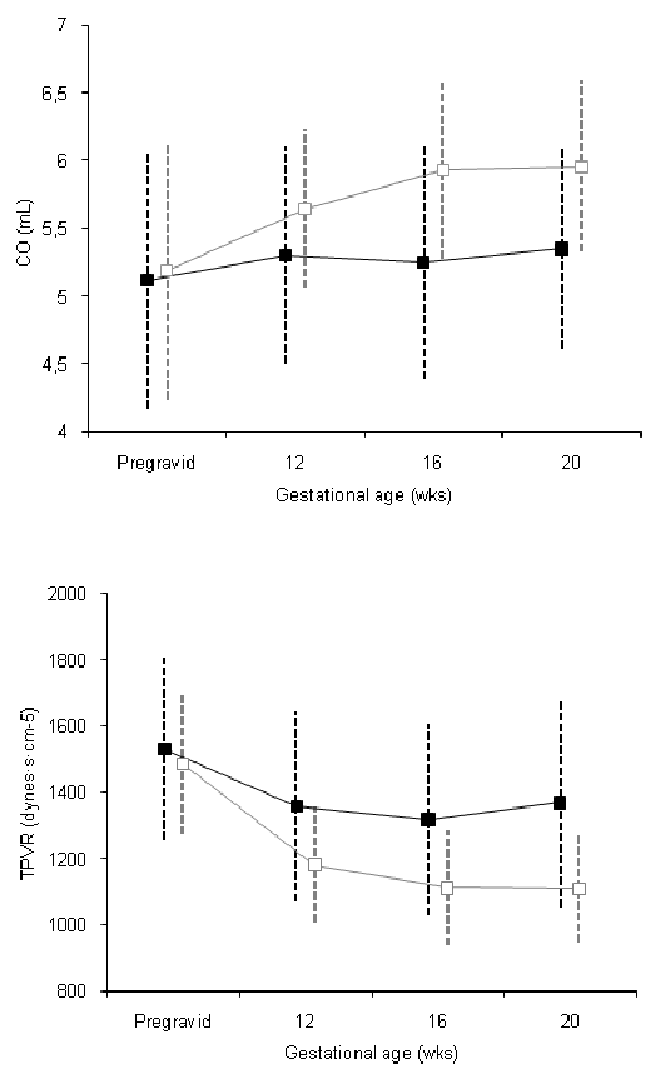

Figure 2: Mean and 95\% confidence intervals (corrected for between-subjects variability) of cardiac output (CO) and total peripheral vascular resistance (TPVR) in the first 20 weeks of pregnancy in women who developed recurrent preeclampsia (black squares) and those who did not (gray squares).

In summary, we found that formerly preeclamptic women, who developed recurrent preeclampsia in their next pregnancy differed from their counterparts who did not. Formerly preeclamptic women showed an initial rise in E/A ratio, which is consistent with an initially impaired adaptation of the cardiac diastolic function. In the recurrence group this phenomenon was followed by a lack of increase in cardiac output in concert with a rise in systemic vascular resistance, providing indirect evi- 
dence for a higher sympathetic contribution to the autonomic control of the circulation in the second trimester. The latter supports the view that impaired adaptation of the cardiac diastolic function might be an important contributor to the subnormal cardiovascular adaptation to pregnancy preceding overt preeclampsia.

\section{Acknowledgements}

We thank T Ekhart for the collection and entry of the data. 


\section{References}

1. Andrietti S, Kruse AJ, Bekkers SC, Sep S, Spaanderman M, Peeters LL. Cardiac adaptation to pregnancy in women with a history of preeclampsia and a subnormal plasma volume. Reprod Sci 2008;15(10):1059-65.

2. Aardenburg R, Spaanderman ME, van Eijndhoven HW, de Leeuw PW, Peeters LL. A low plasma volume in formerly preeclamptic women predisposes to the recurrence of hypertensive complications in the next pregnancy. J Soc Gynecol Investig 2006;13(8):598-603.

3. Carbillon L, Uzan M, Uzan S. Pregnancy, vascular tone, and maternal hemodynamics: a crucial adaptation. Obstet Gynecol Surv 2000;55(9):574-81.

4. Guarracino F, Lapolla F, Danella A, Stefani M, Volpe ML, Gemignani R. Reduced compliance of left ventricle. Minerva Anestesiol 2004;70(4):225-8.

5. Courtar DA, Spaanderman ME, Aardenburg R, Janssen BJ, Peeters LL. Low plasma volume coincides with sympathetic hyperactivity and reduced baroreflex sensitivity in formerly preeclamptic patients. J Soc Gynecol Investig 2006;13(1):48-52.

6. Yamamoto K, Redfield MM, Nishimura RA. Analysis of left ventricular diastolic function. Heart 1996;75(6 Suppl 2):27-35.

7. Barton JR, Sibai BM. Prediction and prevention of recurrent preeclampsia. Obstet Gynecol 2008;112(2):359-72.

8. Report of the National High Blood Pressure Education Program. Working group report on high blood pressure in pregnancy. Am J Obstet Gynecol 2000;183:S1-S22.

9. The Netherlands Perinatal Registry [homepage on the internet]. Bilthoven: NPR-foundation; [cited April 2009]. Available from: http://www. perinatreg.nl/.

10. Quinones MA, Otto CM, Stoddard M, Waggoner A, Zoghbi WA. Recommendations for quantification of Doppler echocardiography: a report from the Doppler Quantification Task Force of the Nomenclature and Standards Committee of the American Society of Echocardiography. J Am Soc Echocardiogr 2002;15(2):167-84.

11. Lang RM, Bierig M, Devereux RB, Flachskampf FA, Foster E, Pellikka PA, et al. Recommendations for Chamber Quantification: A Report from the American Society of Echocardiography's Guidelines and Standards Committee and the Chamber Quantification Writing Group, Developed in Conjunction with the European Association of Echocardiography, a Branch of the European Society of Cardiology. J Am Soc Echocardiogr 2005;18(12):1440-1463.

12. Devereux RB, Casale PN, Kligfield P, Eisenberg RR, Miller D, Campo E, et al. Performance of primary and derived Mmode echocardiographic measurements for detection of left ventricular hypertrophy in necropsied subjects and in patients with systemic hypertension, mitral regurgitation and dilated cardiomyopathy. Am J Cardiol 1986;57(15):1388-93.

13. Lester SJ, Ryan EW, Schiller NB, Foster E. Best method in clinical practice and in research studies to determine left atrial size. Am J Cardiol 1999;84(7):829-32.

14. Teichholz LE, Kreulen T, Herman MV, Gorlin R. Problems in echocardiographic volume determinations: echocardiographic-angiographic correlations in the presence of absence of asynergy. Am J Cardiol 1976;37(1):7-11.

15. Appleton CP, Hatle LK, Popp RL. Relation of transmitral flow velocity patterns to left ventricular diastolic function: new insights from a combined hemodynamic and Doppler echocardiographic study. J Am Coll Cardiol 1988;12(2):426-40.

16. Longford N. Single Imputation and Related Methods. In: Missing data and small-area estimation. London: Springer; 2005. p. 37-58.

17. Barnett AG, van der Pols JC, Dobson AJ. Regression to the mean: what it is and how to deal with it. Int J Epidemiol 2005;34(1):215-20.

18. Loftus G, Masson M. Using confidence intervals in within-subject designs. PB\&R. 1994;1:476-490.

19. Moran AM, Colan SD, Mauer MB, Geva T. Adaptive mechanisms of left ventricular diastolic function to the physiologic load of pregnancy. Clin Cardiol 2002;25(3):124-31.

20. Bamfo JE, Kametas NA, Nicolaides KH, Chambers JB. Maternal left ventricular diastolic and systolic long-axis function during normal pregnancy. Eur J Echocardiogr 2007;8(5):360-8.

21. Mesa A, Jessurun C, Hernandez A, Adam K, Brown D, Vaughn WK, et al. Left ventricular diastolic function in normal human pregnancy. Circulation 1999;99(4):511-7.

22. Schannwell CM, Schneppenheim M, Perings SM, Zimmermann T, Plehn G, Strauer BE. Alterations of left ventricular function in women with insulin-dependent diabetes mellitus during pregnancy. Diabetologia 2003;46(2):267-75.

23. Poppas A, Shroff SG, Korcarz CE, Hibbard JU, Berger DS, Lindheimer MD, et al. Serial assessment of the cardiovascular system in normal pregnancy. Role of arterial compliance and pulsatile arterial load. Circulation 1997;95(10):2407-15.

24. Gorelik O, Almoznino-Sarafian D, Shteinshnaider M, Alon I, Tzur I, Sokolsky I, et al. Clinical variables affecting survival in patients with decompensated diastolic versus systolic heart failure. Clin Res Cardiol 2009;98(4):224-32.

25. De Conti F, Da Corta R, Del Monte D, Catena V, Berton G, Mormino P, et al. Left ventricular diastolic function in pregnancy-induced hypertension. Ital Heart J 2003;4(4):246-51. 


\section{Part III}

Methodological challenges in predicting reproductive outcomes 



\section{CHAPTER 9}

\section{Collider bias in}

recurrence risk research:

Example of obesity and recurrence of preeclampsia

Simone Sep, Sander van Kuijk, Martin Prins, Louis Peeters, Luc Smits

Submitted 


\section{Abstract}

Studies of recurrent abnormal pregnancy outcome are becoming increasingly important for the development of evidence-based guidelines in clinical management. Therefore, it is important to emphasize that these studies may be subject to a relatively unknown type of bias, the so-called "collider bias". This type of bias may lead to seriously distorted, even inverted association estimates. In this report, we illustrate the concept of collider bias using a quantitative example of recurrent adverse pregnancy outcome and discuss scientific and clinical implications of this methodological problem. Collider bias may, however, distort associations in any study on the influence of factors on recurrence risk. 


\section{Introduction}

Women with a certain pregnancy complication or adverse pregnancy outcome usually have an increased risk of that outcome in a next pregnancy. Data gathered from women with a history of a certain adverse pregnancy outcome may provide clues about causation and can be used for the development of prediction models or the evaluation of risk factors for recurrent disease. ${ }^{1}$ This may help care providers in their future clinical management of high-risk women.

In this report, we will focus on a relatively unknown type of bias that may affect studies of recurrence risk. The bias, referred to as collider bias, ${ }^{2,3}$ is introduced when a study population is restricted to persons who previously experienced the outcome under study, a strategy commonly employed in reproductive recurrence studies. Specifically, the bias affects strength and sometimes direction of estimates of association between risk factors and recurrence. We will illustrate the phenomenon of collider bias using a fictitious example of obesity as a risk factor for preeclampsia in both the first and second pregnancy. Furthermore, we discuss general scientific and clinical impact of the bias and provide some recommendations to deal with it.

Prior pregnancy outcome as a collider in studies on reproductive recurrence risk A collider is a factor that is affected by two or more other variables in a causal diagram. ${ }^{2,3}$ An example is low birth weight, being affected by - among others - smoking and genetic factors. Within strata of a collider, associations among its causal factors are different than they are without stratification; associations may even arise that were non-existent before stratification. ${ }^{2,3}$ Smoking women delivering a low birth weight child may have a lower probability of carrying certain genetic factors leading to low birth weight than non-smokers with small infants, even when the occurrence of these genetic factors and smoking are unrelated in the unselected population. In studies on recurrence risk of a certain adverse reproductive outcome, restriction to women with that outcome in a previous pregnancy is a common procedure. Because of the resulting association (either introduced or altered) between potential risk factors of the outcome, their crude individual effects on recurrence risk will be biased.

Figure 1 schematically depicts the introduction of an association between two risk factors, $A$ and $B$, through restriction to previous pregnancy outcome. Consequently, the crude association between factor $A$ and recurrence of the pregnancy outcome is distorted by factor B (or vice versa). All recurrence-risk studies with prior occurrence of the outcome as an inclusion criterion may in theory be affected by collider bias, with the involvement of a wide range of causal factors. 


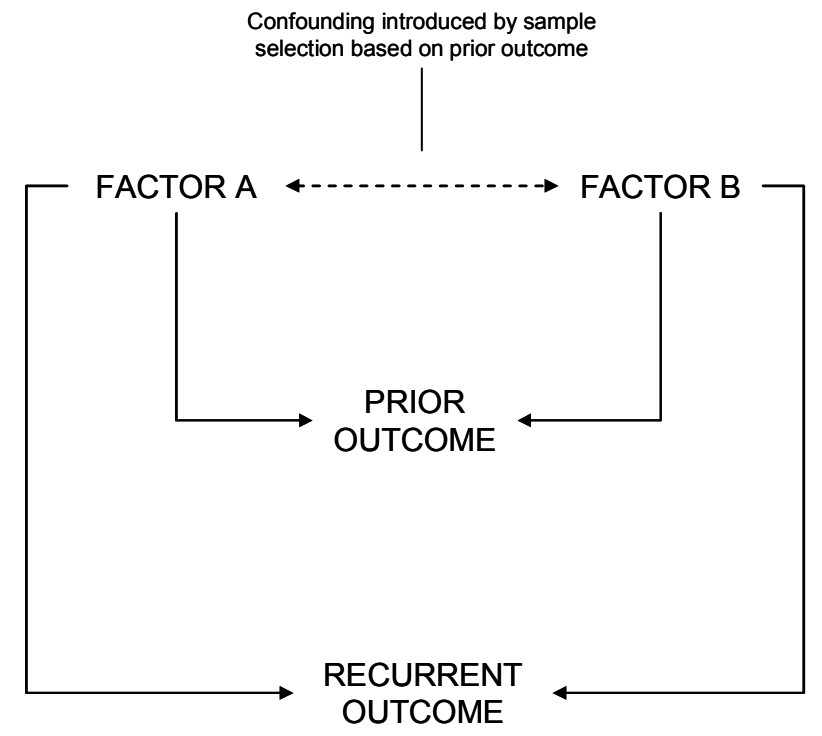

Figure 1: Possible relations among risk factors $A$ and $B$, prior pregnancy outcome and recurrent outcome in a next pregnancy.

\section{Obesity and recurrent preeclampsia, a quantitative example}

Preeclampsia is a hypertensive disorder of pregnancy with potentially serious consequences for mother and child. Women with a history of preeclampsia are at increased risk of developing the disease in a next pregnancy. ${ }^{4}$ The magnitude of this risk depends, among others, on maternal preexisting medical disorders or constitutional genetic factors. One of the objectives of counseling former patients is to minimize the impact of these risk factors before a next conception. ${ }^{4}$

Contrary to expectation, but in line with the methodological problem described above, some risk factors for preeclampsia in primigravid women remain unidentified as such in women with a history of preeclampsia. An example is a high maternal body mass index (BMI). Being a generally accepted risk factor for preeclampsia in unselected women, ${ }^{5}$ with a BMI of 21 as a reference, the risk of preeclampsia doubles at a BMI of 26 (odds ratio 2.1), triples at a BMI of 30 (odds ratio 2.9) and increases further with severe obesity (odds ratio 3.5), its association with recurrent preeclampsia has been reported to be weaker (relative risk $=1.27(95 \%-\mathrm{Cl}: 1.07$ 1.50) for BMI $25.0-29.9 \mathrm{~kg} / \mathrm{m} 2$ and 1.68 (95\%-Cl: $1.45-1.95)$ for $\mathrm{BMI} \geq 30 \mathrm{~kg} / \mathrm{m} 2$ ), ${ }^{6}$ absent (relative risk $=1.07$ (95\%-Cl: 0.46-2.46) for $\mathrm{BMI}>25 \mathrm{~kg} / \mathrm{m} 2){ }^{7}$ or even inverse (hazard ratio $=0.9$ (95\%-Cl: $0.8-1.0$ ) for $\mathrm{BMI}$ as a continuous factor). ${ }^{8}$ Although an absent or even protective effect of high $\mathrm{BMI}$ on the recurrence risk of preeclampsia 
does not seem plausible, an explanation for this paradoxical finding has not been provided so far. Using a quantitative example, in which obesity is evaluated as a risk factor for both preeclampsia in the first pregnancy and recurrent preeclampsia in the second pregnancy, we will try to show that collider bias is a possible explanation for this finding.

We assumed a population of 100,000 nulliparous women who eventually completed two consecutive pregnancies. These women each had a combination of two characteristics: obesity $(\mathrm{OB})$ or not, and another (non-specified) risk factor of preeclampsia (OTHER) or not. We set the prevalence of OB at $20 \%$ and that of OTHER at $5 \%$, and stipulated marginal independence between the two variables (i.e. the probability of having one risk factor is independent of having the other or not). During the women's first pregnancy, the risk of preeclampsia was assumed to be $10 \%$ in the presence of $\mathrm{OB}$ and $50 \%$ in the presence of OTHER. Furthermore, the combined effect of the presence of $O B$ and OTHER was assumed to be $60 \%$. We set the risk of preeclampsia in the absence of both factors at only $1 \%$, implying that OB and OTHER are responsible for the great majority of cases of preeclampsia. Finally, all women had a second pregnancy with the risk of developing preeclampsia being the same as in the first pregnancy, given each woman's individual combination of risk factors. We thus assumed that these risk factors did not change across pregnancies.

Tables 1 and 2 list the results of the quantitative example in this cohort of women. As shown, 4660 (5\%) women developed preeclampsia in their first pregnancy (table 2). Obesity was a risk factor for preeclampsia in this first pregnancy, with a crude relative risk of 3.0. The absolute risk of preeclampsia was $10 \%$ in obese and $3.3 \%$ in non-obese women. Among women with preeclampsia in their first pregnancy, the probability of having OB, given that OTHER was present, was $24 \%$, and given that OTHER was absent, $64 \%$ (in the total population this figure was $20 \%$ for both combinations).

\begin{tabular}{|c|c|c|c|c|}
\hline \multicolumn{5}{|c|}{$\begin{array}{l}\text { Cross-table: Occurrence of preeclampsia (expressed as proportion of total in each cell) in 100,000 nul- } \\
\text { liparous women. }\end{array}$} \\
\hline & OTHER+ & OTHER- & Total & \\
\hline $\mathrm{OB}+$ & $600 / 1,000$ & $1,400 / 19,000$ & $2,000 / 20,000$ & \\
\hline OB- & $1,900 / 4,000$ & $760 / 7,6000$ & $2,660 / 80,000$ & \\
\hline Total & $2,500 / 5,000$ & $2,160 / 95,000$ & $4,660 / 100,000$ & \\
\hline \multicolumn{5}{|c|}{ Risk of preeclampsia: } \\
\hline $\mathrm{OB}+$ & $10 \%$ & & & \\
\hline OB- & $3 \%$ & & & \\
\hline Overall & $5 \%$ & & & \\
\hline \multicolumn{4}{|c|}{ Crude relative risk (RR) of preeclampsia ( $\mathrm{OB}+/ \mathrm{OB}-)$ : } & 3.0 \\
\hline \multicolumn{4}{|c|}{ Stratum specific RR of preeclampsia (OB+/OB-) if OTHER+: } & 1.3 \\
\hline \multicolumn{4}{|c|}{ Stratum specific RR of preeclampsia (OB+/OB-) if OTHER-: } & 7.4 \\
\hline
\end{tabular}




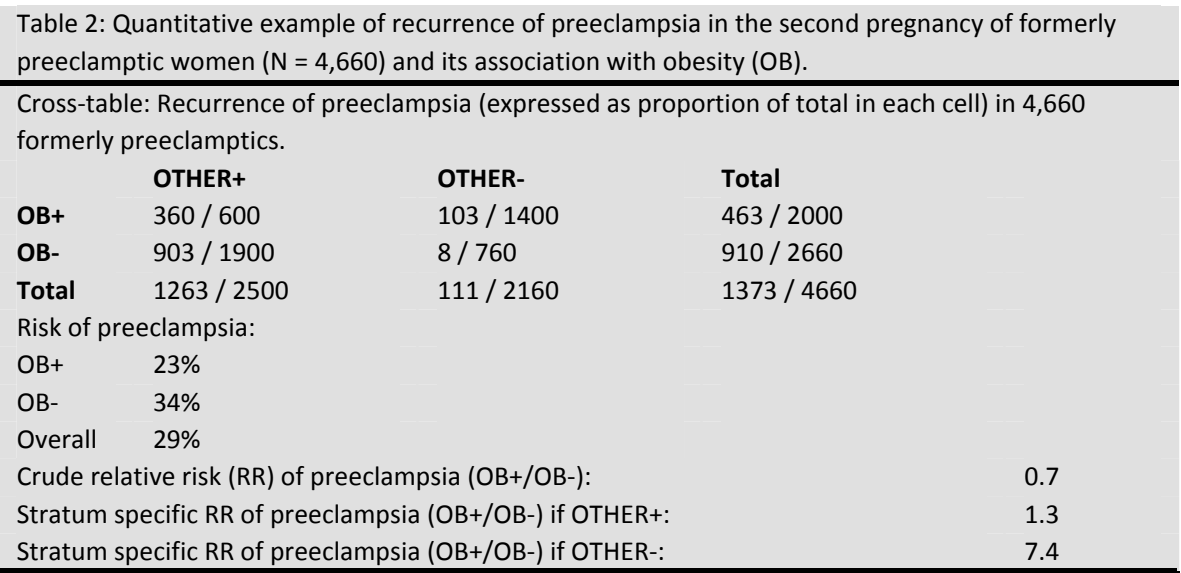

In their next pregnancy, preeclampsia recurred in $29 \%$ of formerly preeclamptics (table 2). The crude relative risk of recurrent preeclampsia in obese versus nonobese women was 0.7 , whereas the relative risk was 3.0 in the first pregnancy. However, the relative risks of recurrent preeclampsia in each stratum of OTHER were identical to those in the first pregnancy (table 2).

OTHER distorted the crude association between $\mathrm{OB}$ and recurrence of preeclampsia in the second pregnancy in such a way that the crude RR points to a protective effect of $O B$, while in facts it was as strong a risk factor for recurrent disease as it was for preeclampsia in the first pregnancy. Although, in this example, the bias could be removed through stratification on OTHER, this maneuver is seldom feasible in practice because of incomplete knowledge of the relevant other factors.

\section{Implications for studies on recurrence risk}

Collider bias can occur in any recurrence risk study in which sample selection is based on prior occurrence of the disorder studied. The bias has different implications for etiologic and prediction studies. In etiologic studies, this kind of confounding may distort the crude association between a factor and recurrence, leading to false conclusions with respect to disease etiology. In prediction studies, potential predictors for recurrence of an event are usually selected on the basis of knowledge of prognostic factors for the initial event. As a consequence of collider-stratification bias and corresponding confounding, these factors may lose their predictive value in the selected population.

Possibly, collider bias is also a source of heterogeneity across study populations selected on the basis of a previous event. In the example of $O B$ and recurrent preeclampsia described above, the factor OTHER may in fact refer to a collection of several maternal conditions predisposing to preeclampsia. We have seen that sample 
selection based on the collider 'prior preeclampsia' can introduce confounding bias; meanwhile, also the prevalence of maternal conditions predisposing to preeclampsia may differ between populations and with it the strength of confounding. In etiologic studies, this may result in heterogeneous association estimates with sometimes inconsistent or even contradictory results across studies. In prediction studies, variations in the magnitude of the bias can affect external validity of prediction tools in independent populations.

In our example, we assumed the risk of preeclampsia in the second pregnancy for the different combinations of $O B$ and OTHER to be the same as in the first pregnancy. However, the uterine environment in the next pregnancy may be different, due to aging, a different interaction with a new fetal genome, and ongoing exposure to only partly known environmental stressors. Obviously, our numerical example merely serves to demonstrate the possibility of collider bias when a study population is selected based on prior pregnancy outcome. In empirical recurrence risk studies, other than methodological explanations for paradoxical associations are also possible.

The finding that prior pregnancy outcome can be a collider in the causal diagram leading to recurrence of a pregnancy outcome has been described before in the light of adjusting for reproductive history in analytic models. ${ }^{9,10}$ Controversy exists whether it is appropriate to adjust for reproductive history, when the objective is to obtain an unbiased estimate of the effect of a certain variable on recurrent disease or outcome. ${ }^{9-11}$

Recently, collider-stratification bias was subject of debate in the field of reproductive medicine in conjunction with paradoxical findings of the effect of partner change on preeclampsia risk and that of birth weight on infant-mortality. ${ }^{12,13}$ Not reproductive history, but exposure variables were identified as colliders in these studies. The type of collider bias presented in the present paper, has, to our knowledge, not been reported before.

\section{Clinical implications}

Pregnancy is an attractive condition for studying recurrence risk. The effects of having had a certain complication in the first pregnancy often carry over into a next pregnancy, either through changes in health, changes in clinical management, or through stress and anxiety. ${ }^{14}$ Research on recurrent pregnancy complications is essential for the provision of clinicians with information for counseling and improvement of management plans for patients with a history of adverse outcomes. ${ }^{14}$ Most pregnancy complications tend to recur in a next pregnancy. ${ }^{14}$ It has become clear that these conditions have a complex mix of risk factors and etiologies. This 
heterogeneity in particular makes it challenging to study and quantify recurrence risk.

Much of the quantitative assessment of recurrence risk of adverse pregnancy outcomes is based on epidemiological data. Assessing associations between a particular risk factor and a recurrent outcome may provide important clues to both etiology and clinical care. Awareness of the phenomenon of collider bias is crucial, as in risk factor studies these estimations can become distorted. This is also true for prediction studies. Coefficients in prediction models should always be interpreted with caution as these models are not designed to estimate associations. In addition, collider bias may lead to coefficients in the model suggesting a protective effect of a (potential risk) factor. Therefore, absent or invert associations of factors known to be strong risk factors for the initial occurrence of a certain complication or pregnancy outcome, should be interpreted with caution as they are likely to be biased by sample selection. Nevertheless, predicted risks themselves are not expected to be subject to collider bias.

\section{Recommendations}

The possibility of collider bias should be taken into account in the design stage of a study on recurrent pregnancy outcome. In recurrence risk studies, an observational cohort design is commonly applied. In such a design, women with an index pregnancy are followed longitudinally over time and outcomes are observed in the next pregnancy. Including all women with an index pregnancy in this cohort, rather than limiting the cohort to women with prior adverse outcome only, enables analysis of the two strata (with or without prior outcome) both combined and separately.

In theory, completely removing the bias caused by sample selection is only possible by means of adjustment for all causal factors in the pathological pathway of the recurrent disease or outcome. Unfortunately, this solution is elusive as many causal factors are still unknown. In reproductive medicine, often three sources of causation (mother, father, and child) are involved, hampering appropriate correction even further. However, adjustment for as many maternal, paternal and fetal conditions as possible may reduce the confounding effects, its success rate depending largely on the quantity of causes.

\section{Acknowledgements}

We thank our colleagues of the prognostic methodology research group of the department of Epidemiology at Maastricht University Medical Centre for sharing their knowledge during the research meetings. 


\section{References}

1. Wilcox AJ. The analysis of recurrence risk as an epidemiological tool. Paediatr Perinat Epidemiol 2007;21 Suppl 1:47.

2. Rothman K, Greenland S, Lash T. Modern Epidemiology. 3th ed: Lippincott Williams \& Wilkins; 2008.

3. Greenland S. Quantifying biases in causal models: classical confounding vs collider-stratification bias. Epidemiology 2003;14(3):300-6.

4. Barton JR, Sibai BM. Prediction and prevention of recurrent preeclampsia. Obstet Gynecol 2008;112(2):359-72.

5. Walsh SW. Obesity: a risk factor for preeclampsia. Trends Endocrinol Metab 2007;18(10):365-70.

6. Mostello D, Kallogjeri D, Tungsiripat R, Leet T. Recurrence of preeclampsia: effects of gestational age at delivery of the first pregnancy, body mass index, paternity, and interval between births. Am J Obstet Gynecol 2008;199(1):55 e1-7.

7. Makkonen N, Heinonen S, Kirkinen P. Obstetric prognosis in second pregnancy after preeclampsia in first pregnancy. Hypertens Pregnancy 2000;19(2):173-81.

8. van Rijn $B B$, Hoeks $L B$, Bots ML, Franx A, Bruinse HW. Outcomes of subsequent pregnancy after first pregnancy with early-onset preeclampsia. Am J Obstet Gynecol 2006;195(3):723-8.

9. Nurminen T. On adjusting for the outcome of previous pregnancies in epidemiologic reproductive studies. Epidemiology 1995;6(1):84-6.

10. Howards PP, Schisterman EF, Heagerty PJ. Potential confounding by exposure history and prior outcomes: an example from perinatal epidemiology. Epidemiology 2007;18(5):544-51.

11. Wein P, Dong ZG, Beischer NA, Sheedy MT. Factors predictive of recurrent gestational diabetes diagnosed before 24 weeks' gestation. Am J Perinatol 1995;12(5):352-6.

12. Zhang J, Christianson RE, Torfs CP. Fetal trisomy 21 and maternal preeclampsia. Epidemiology 2004;15(2):195-201.

13. Whitcomb BW, Schisterman EF, Perkins NJ, Platt RW. Quantification of collider-stratification bias and the birthweight paradox. Paediatr Perinat Epidemiol 2009;23(5):394-402.

14. Smulian JC. Research on recurrent pregnancy complications: a clinician's perspective. Paediatr Perinat Epidemiol 2007;21 Suppl 1:19-23. 



\section{CHAPTER 10}

\section{How long do}

preconception risk prediction models hold? Influence of selective fertility on model performance

Sander van Kuijk, Simone Sep, Patty Nelemans, Luc Smits

Submitted 


\section{Abstract}

Risk estimates derived from preconception prediction models can be used to counsel women with regard to any future pregnancies. Women with a high predicted risk of an adverse pregnancy outcome may decide more often not to try for another pregnancy again than women with a low predicted risk. This prediction guided selective fertility can cause a change in the composition of the pregnant population with respect to those parameters that are comprised in the prediction model. The question can be raised whether such a change in composition could influence performance parameters of the prediction model, such as sensitivity, specificity, positive- and negative predictive values and discriminative ability, when evaluating risks in the new population and whether it could compromise the longevity of the model. Using a hypothetical example, we show that the original sensitivity and specificity estimates of a preconception prediction model for an adverse pregnancy outcome do not hold anymore when the model is applied in a population affected by modelbased selective fertility: sensitivity decreases, while specificity increases. However, individual patient risk estimates remained unbiased, and discriminative ability, expressed as the area under the receiver operating characteristic (ROC) curve, remain unaffected. In diagnostic research, several types of bias with similar mechanisms have been described. 


\section{Introduction}

Multivariable models for the prediction of individual risks of adverse health outcomes are increasingly being developed and used within a wide range of clinical disciplines. In gynecology, models have been developed for the prediction of, among others, fertility after in vitro insemination, ${ }^{1}$ small-for-gestational-age fetuses, ${ }^{2}$ preeclampsia, ${ }^{3}$ and recurrence of preeclampsia. ${ }^{4}$ Some models estimate risks of adverse reproductive outcome on the basis of preconception factors only, while others (additionally) take parameters into account that are measured during the target pregnancy.

Individual risk estimates derived from preconception prediction models may be used for counseling purposes and the optimization of preconception and antepartum care. In this way, the result of preconception prediction models may influence women's choices whether or not to try for a subsequent pregnancy. Such influence could be regarded as a variant of selective fertility, a phenomenon earlier defined as the tendency to adjust reproduction after the outcome of previous pregnancies. ${ }^{5}$ Women with a high predicted risk of an adverse pregnancy outcome may decide more often not to get pregnant again than women with a low predicted risk, and vice versa. This prediction-guided type of selective fertility may thus cause changes in the composition of the population of pregnant women with respect to those parameters that are comprised in the prediction model. The question can be raised whether such a change in composition can have implications for the future predictive ability of the model.

In this paper, using a hypothetical example with simulated data, we will show that predictive sensitivity and specificity at different cutoff points of predicted probabilities can change under the influence of selective fertility, while the discriminative ability of the model as well as individual risk predictions remain unaffected.

\section{Methods}

\section{Measures of model performance}

Predicted probabilities, derived from the prediction model, that exceed a prespecified cutoff point are usually defined as a positive test result, while values below the pre-specified cutoff point are considered a negative test result. Frequently used measures of prediction model performance are predictive sensitivity and specificity. Sensitivity is the number of subjects with a positive test result who develop the outcome, divided by the total number of subjects who develop the outcome. Specificity, on the other hand, is the number of subjects with a negative test who do not develop the outcome, divided by the total number of subjects who do not de- 
velop the outcome. Sensitivity and specificity are inversely related, and if both parameters are computed for several cutoff values, a receiver operating characteristic (ROC) curve can be plotted. The area under the ROC curve (AUC), or the concordance statistic (c-statistic), is a measure of the discriminative ability of the model. The AUC represents the chance that a randomly selected subject who develops the outcome has a higher test score than a randomly selected subject who doesn't develop the outcome.

Two performance measures that are often more relevant to clinical practice are the positive and negative predictive value of a test. The positive predictive value is the number of subjects with a positive test result who develop the outcome, divided by the total number of subjects with a positive test result. The negative predictive value is the proportion of subjects with a negative test who do not develop the outcome, divided by the total number of subjects with a negative test result. The positive and negative predictive values thus denote the chance of developing the disease (or its complement), giving the outcome of the test.

\section{Illustration}

Consider the hypothetical data of 5000 women who experienced severe preeclampsia in their first pregnancy. We emphasize that all following assumptions are made for simulation purposes. We assumed that, although all women in the population wished to get pregnant again, 20 percent of them refrained from trying because of fear of recurrent disease. Not having been exposed to the future prediction rule, these women represented a random selection of the population.

In order to keep the illustration straightforward, we further assumed that all women who tried to get pregnant, succeeded in achieving an ongoing pregnancy, so that consecutive pregnancy outcomes are known for all of the remaining 4000 women. This population will henceforth be referred to as the derivation population (table 1). Suppose a simple prediction model was developed using recorded data of the derivation population, in which individual risk estimates of recurrent preeclampsia were determined by the presence or absence of one or more of a total of 4 risk factors. Extremely simplified, the mean risk of recurrence among women with no risk factors present was set at 5\%, and 10,15, 20 and 25\% among women with 1, 2, 3 and 4 risk factors present, respectively. In order to achieve a high sensitivity, women with a predicted risk $>5 \%$ were set to test positive. For this specific cut-off point, sensitivity, specificity, positive predictive value and negative predictive value were computed. Using estimates of sensitivity and specificity for all predefined cut-off points, the ROC curve was plotted and the area under curve was estimated. After development, this prediction model was proven valid in an independent population, and it was decided to apply the model in routine clinical practice. 
Next, consider the population in which the prediction model is applied (henceforth referred to as the application population). In this population of 5000 women, which is in essence the same as the true underlying population we obtained the derivation population from, the choice to try to get pregnant again is not random, but it is now influenced by prediction model outcome (i.e. high risk or low risk). In this scenario, we stipulated that $40 \%$ of all high risk women decide not to get pregnant again, while all low risk women are reassured and try (and succeed in) getting pregnant. Thus, only a subset of the application population chooses to get pregnant again, conditional on prediction model outcome. Using data of this selection $(\mathrm{N}=4000)$ of the application population, performance parameters of the prediction model were again estimated, and compared to values obtained in the derivation population.

\section{Results}

Since the aim is to illustrate bias as a result of selective fertility, only point estimates are reported, without any confidence intervals. Table 1 shows the data of the 4000 women used to derive the prediction model from. Lower risks of recurrent preeclampsia are more prevalent than higher risks. Of these women, $1200(30 \%)$ had no risk factors, corresponding to a low risk of recurrent preeclampsia, and thus a negative test result; 2800 (70\%) women had one or more risk factors, corresponding to a high risk of recurrence and a positive test result. In total, 500 women (12.5\%) developed recurrent preeclampsia.

\begin{tabular}{|c|c|c|c|}
\hline $\begin{array}{l}\text { No. of risk factors } \\
\text { present }\end{array}$ & $\begin{array}{l}\text { True underlying population } \\
\mathrm{n}(\%)\end{array}$ & $\begin{array}{l}\text { Derivation population } \\
\mathrm{n} \text { (total of true under- } \\
\text { lying pop.) }\end{array}$ & $\begin{array}{l}\text { Recurrent preeclampsia } \\
\mathrm{n} \text { (\% of derivation pop.) }\end{array}$ \\
\hline 4 & $500(10 \%)$ & $400(80 \%)$ & $25(25 \%)$ \\
\hline 3 & 750 (15\%) & 600 (80\%) & $30(20 \%)$ \\
\hline 2 & $1000(20 \%)$ & $800(80 \%)$ & 30 (15\%) \\
\hline 1 & $1250(25 \%)$ & $1000(80 \%)$ & $25(10 \%)$ \\
\hline 0 & $1500(30 \%)$ & $1200(80 \%)$ & $15(5 \%)$ \\
\hline Total & 5000 & 4000 & 500 \\
\hline
\end{tabular}

Table 2 shows the cross tabulation of predicted outcomes (positive and negative test result) and the observed recurrence of preeclampsia, based on the risk cutoff point of $>5 \%$ for a positive test result. Of all women who developed recurrent preeclampsia, 440 had a positive test result, corresponding to a sensitivity of $88 \%$. Specificity was only $33 \%$, because only 1140 of 3500 women who did not develop recurrent preeclampsia, had a negative test result. Of all 2800 women with a posi- 
tive test result, only 440 developed recurrent preeclampsia (positive predictive value was $16 \%$ ), and 1140 of 1200 women with a negative test result did not develop recurrent preeclampsia (negative predictive value was 95\%). The discriminative ability of the model in the derivation population, quantified by the area under the ROC curve, was approximately 0.67 (Figure 1, black graph).

Table 2. Cross tabulation of predicted outcomes (positive or negative test result) and observed recurrence of preeclampsia in the derivation population $(N=4000)$ and corresponding test characteristics. $A$ positive test result refers to the presence of at least one risk factor.

\begin{tabular}{|c|c|c|c|}
\hline & $\begin{array}{l}\text { Recurrent } \\
\text { preeclampsia }\end{array}$ & $\begin{array}{l}\text { No recurrent } \\
\text { preeclampsia }\end{array}$ & Total \\
\hline Positive test & 440 & 2360 & 2800 \\
\hline Negative test & 60 & 1140 & 1200 \\
\hline Total & 500 & 3500 & 4000 \\
\hline $\begin{array}{l}\text { sensitivity }=(4 \\
\text { specificity }=(1 \\
\text { positive predic } \\
\text { negative predi }\end{array}$ & $\begin{array}{l}0 \%=88 \% \\
100 \%=33 \% \\
=(440 / 2800) * 1 \\
=(1140 / 1200)\end{array}$ & & \\
\hline
\end{tabular}

Data of the women of the application population who chose to try for a subsequent pregnancy $(\mathrm{N}=2900)$ are shown in table 3 . The composition of this population, with respect to the presence of the risk factors, was considerably different than that of the derivation population, because of selective fertility. In this case only 1400 (48\%) of women had 1 or more risk factors present, 1500 (52\%) had no risk factors present. Of all women, 295 (10\%) developed recurrent preeclampsia.

\begin{tabular}{|c|c|c|c|}
\hline $\begin{array}{l}\text { No. of risk } \\
\text { factors present }\end{array}$ & $\begin{array}{l}\text { Application } \\
\text { population } \\
\mathrm{N} \text { (\% of total) }\end{array}$ & $\begin{array}{l}\text { Subset } \\
\text { who try for next pregnancy } \\
\mathrm{N} \text { (\% of application pop.) }\end{array}$ & $\begin{array}{l}\text { Recurrent } \\
\text { preeclampsia } \\
\mathrm{N} \text { (\% of subset) }\end{array}$ \\
\hline 4 & $500(10 \%)$ & $200(40 \%)$ & $50(25 \%)$ \\
\hline 3 & 750 (15\%) & 300 (40\%) & $60(20 \%)$ \\
\hline 2 & $1000(20 \%)$ & $400(40 \%)$ & 60 (15\%) \\
\hline 1 & $1250(25 \%)$ & 500 (40\%) & $50(10 \%)$ \\
\hline 0 & $1500(30 \%)$ & $1500(100 \%)$ & 75 (5\%) \\
\hline Total & 5000 & 2900 & 295 \\
\hline
\end{tabular}

The cross tabulation of predicted outcomes and observed recurrent preeclampsia for women from the application population who tried for a subsequent pregnancy shows the number of patients with true positive and true negative test results and false positive and false negative test results (Table 4). Sensitivity of the prediction model in these data was $75 \%$, only 220 of 295 women who developed a subsequent pregnancy had a positive test result. Of 2605 women who did not develop recurrent 
preeclampsia, 1425 had a negative test result, corresponding to a specificity of $55 \%$. Positive and negative predictive values were the same as in the derivation population, 16\% (220/1180) and 95\% (1425/1500) respectively. The ROC curve of the model is depicted in figure 1 (grey graph); the area under the curve was approximately 0.67 .

Table 4. Cross tabulation of predicted outcomes (positive or negative test result) and observed recurrence of preeclampsia in the application population $(N=2900)$ and corresponding test characteristics. A positive test result refers to the presence of at least one risk factor.

\begin{tabular}{llll}
\hline & Recurrent preeclamp- & No recurrent preeclamp- & Total \\
\hline sia & sia & 1400 \\
Positive test & 220 & 1180 & 1500 \\
Nogative test & 75 & 1425 & 2900 \\
\hline Sotal & 295 & 2605 & \\
sensitivity $=(220 / 295) * 100 \%=75 \%$ & & \\
posificity $=(1425 / 2605) * 100 \%=55 \%$ & & \\
negative predictive value $=(220 / 1180) * 100 \%=16 \%$ & & \\
\hline
\end{tabular}

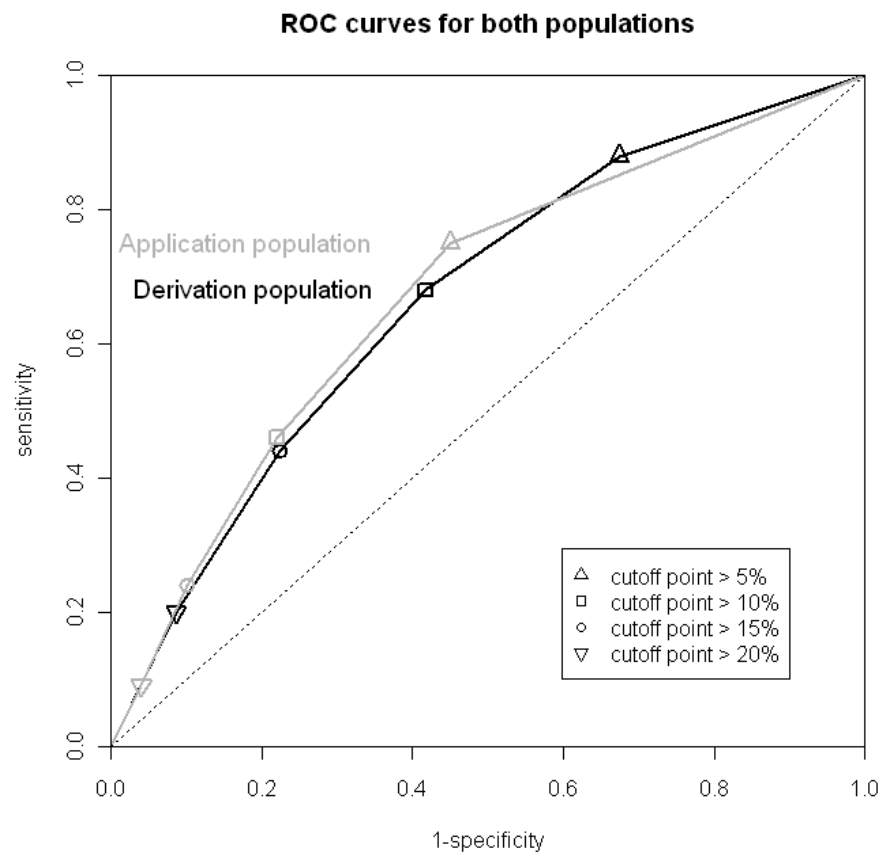

Figure 1. ROC curves of the prediction model in the derivation population and in the subset of the application population who tried for subsequent pregnancy. Points in the graph correspond to the different predefined risk-cutoff points of the prediction model result. 


\section{Discussion}

We have illustrated how exposure of women to the results of a preconception risk prediction model can change performance parameters of the model. In our example, women with a high predicted risk of recurrent disease were less likely to try for subsequent pregnancy. We saw a decrease in sensitivity from $88 \%$ to $75 \%$ when the model was evaluated in the subset of the application population of whom next pregnancy outcomes were available, whereas specificity increased from $33 \%$ to $55 \%$. Individual risk predictions remained unaffected; in the application population both positive and negative predictive values remained the same as in the derivation population. Furthermore, the discriminative ability of the model, as quantified by the area under the ROC curve, was the same in both populations. Even though the area remains virtually unchanged, the different cutoff points in the ROC curve migrate to the lower left corner, a phenomenon described earlier in another context (6). This is because of the decrease in sensitivity (cutoff point moves down on the $y$ axis) combined with an increase in specificity (cutoff point moves left on the $x$-axis). Sensitivity and specificity are of less clinical relevance than predictive values, but are still popular measures of performance in prognostic and diagnostic research, because of the false belief that they are fixed properties of a test. It is often stated that, when introducing a test in a different population, only the positive and negative predictive values are subject to change. In our simulation we have shown that because of selective fertility, and thus a selection conditional on test result, sensitivity and specificity change while, remarkably, the predictive values seem fixed. This might seem a strange phenomenon, even more because the change in our population is merely a change in mean risk $(12.5 \%$ in the derivation population versus $10 \%$ in the subset of the application population who tried for subsequent pregnancy). However, the explanation is quite straightforward. Because of the selection conditional on test result instead of selection conditional on disease status, in our cross tabulations (tables 2 and 4), only the ratios between numbers of women with positive and negative test results (different rows) change rather than those between numbers of women with or without recurrent preeclampsia (different columns).

Although this selective fertility-related form of bias has not been described yet in prognostic research, in diagnostic research, however, biases with similar mechanisms have been identified. These biases are referred to as work-up bias, ${ }^{7}$ verification bias, ${ }^{8}$ or referral bias. ${ }^{6}$ The mechanisms of these biases are in essence similar to one another. Patients with a positive test result tend to be referred more often for verification by the gold standard than patients with a negative test result (selection conditional on test result). Thus, the probability of verification of disease is higher in subjects with a positive test result. As a result, sensitivity is overestimated and specificity underestimated. In the present example from prognostic research, it is the other way around. 
Our example is undoubtedly a simplified version of the truth. In the true underlying population, we assumed that the choice to try for a subsequent pregnancy was random over the risk groups. However, this assumption may not hold. In a more realistic scenario, it is likely that the choice to try for a next pregnancy, without knowing an individual risk estimate, is amongst other factors guided by the severity of the first occurrence of preeclampsia. Severity of the first occurrence of preeclampsia is most likely related to the risk of recurrent preeclampsia (despite it was not comprised in our prediction model), and therefore selection might not be random with respect to the risk groups. This may imply that in our example the strength of the bias was overestimated. On the other hand, perinatal loss is associated with severity of preeclampsia and thus associated with a risk of recurrence, yet reproduction is increased after a perinatal loss. ${ }^{9}$

Our scenario of a preconception prediction model estimating the risk of an adverse pregnancy outcome is probably the only scenario this phenomenon can occur. Patients altering their risk profile (e.g. lifestyle changes) after risk estimation or counseling can be observed in many disciplines, yet the choice to be 'at risk' or have an absolute risk of zero is unique to pregnancy-related outcomes (i.e. women who do not get pregnant again will never develop an adverse pregnancy outcome). This makes it hard to generalize this bias to other clinical disciplines.

In summary, using a simulated example, we have shown that the original sensitivity and specificity estimates of a preconception prediction model for an adverse pregnancy outcome can become biased when the model is applied in practice. However, positive and negative predictive values, as well as the discriminative ability of the model, remain unbiased. Therefore, the prediction model still yields valid individual risk estimates, and can still be used to evaluate risks and counsel these women accordingly. 


\section{References}

1. Lintsen AM, Eijkemans MJ, Hunault CC, Bouwmans CA, Hakkaart L, Habbema JD, et al. Predicting ongoing pregnancy chances after IVF and ICSI: a national prospective study. Hum Reprod. 2007 Sep;22(9):2455-62.

2. Pihl K, Larsen T, Krebs L, Christiansen M. First trimester maternal serum PAPP-A, beta-hCG and ADAM12 in prediction of small-for-gestational-age fetuses. Prenat Diagn. 2008 Dec;28(12):1131-5.

3. Herraiz I, Arbues J, Camano I, Gomez-Montes E, Graneras A, Galindo A. Application of a first-trimester prediction model for pre-eclampsia based on uterine arteries and maternal history in high-risk pregnancies. Prenat Diagn. 2009 Oct 7.

4. Sep SJ, Smits L, Prins MH, Spaanderman ME, Peeters LL. Simple prepregnant prediction rule for recurrent earlyonset hypertensive disease in pregnancy. Reprod Sci. 2009 Jan;16(1):80-7.

5. Skjærven R, Melve KK. Selective fertility - the examples of perinatal death and preeclampsia. Norsk Epidemiologi. $2007 ; 17(2): 175-80$.

6. Knottnerus JA, Leffers P. The influence of referral patterns on the characteristics of diagnostic tests. J Clin Epidemiol. 1992 Oct;45(10):1143-54.

7. Begg CB. Biases in the assessment of diagnostic tests. Stat Med. 1987 Jun;6(4):411-23.

8. Ransohoff DF, Feinstein AR. Problems of spectrum and bias in evaluating the efficacy of diagnostic tests. N Engl J Med. 1978 Oct 26;299(17):926-30.

9. Skjaerven R, Wilcox AJ, Lie RT, Irgens LM. Selective fertility and the distortion of perinatal mortality. Am J Epidemiol. 1988 Dec;128(6):1352-63. 
CHAPTER 11

General Discussion 


\section{General discussion}

Preeclampsia is a relatively common pregnancy disorder with not only short-term complications, such as the HELLP syndrome and eclampsia, but also long-term consequences, such as an increased risk of developing hypertension, ischemic heart disease, stroke and thromboembolic disease. ${ }^{1}$ Perinatal risks include impaired growth and complications associated with elective preterm birth. Although fortunately preeclampsia has a favorable outcome in many cases, from a public health perspective, it is an important cause of maternal and perinatal morbidity and mortality worldwide. In the Netherlands, it even is the number one cause of maternal death. ${ }^{2}$ Moreover, from a health economic perspective, preeclampsia accounts for an estimated $20 \%$ of antenatal admissions, $33 \%$ of referrals to day-care assessment units and $25 \%$ of obstetric admissions to intensive care units. ${ }^{3-5}$

Although prevention of preeclampsia seems illusive, there is indirect evidence for the concept that the onset of preeclampsia can be postponed and the severity of its clinical presentation alleviated by the timely institution of tailored preventive measures. As repeatedly stated in this thesis, formerly preeclamptic women are at increased risk of developing recurrent preeclampsia in their next pregnancy. Therefore, the management of these women will benefit from the prepregnancy identification of underlying disorders and their adequate treatment. Consequently, tailored preventive measures can be instituted prior to and in the first trimester of the next pregnancy. An important part of antenatal care in this next pregnancy consists of the earliest possible detection of imminent recurrent disease. However, in the Netherlands, guidelines for screening, early detection and management of preeclampsia, and a generally accepted threshold for disease severity for referral are lacking.

Approximately 5 to $8 \%$ of all pregnant women develop preeclampsia. Risk factors for preeclampsia include medical conditions such as chronic hypertension, diabetes, multiple pregnancies, and previous preeclampsia. ${ }^{6}$ About one out of four women with a history of early-onset preeclampsia develops recurrent preeclampsia in the next pregnancy. ${ }^{7}$ Therefore, prediction of and counseling for preeclampsia is particularly relevant for these women.

\section{Prediction of recurrent preeclampsia, implications for future studies}

As outlined in chapters 2 and 3 of this thesis, the ability to predict the risk of recurrent preeclampsia has several advantages. Clinicians would have the possibility to better identify women who require closer surveillance and would benefit from timely referral to specialized treatment. Conversely, it would also enable the identi- 
fication of low-risk women who then could be reassured and offered the appropriate regular low-risk care.

Important in prediction issues in general is the level of accuracy required to allow the systematic application of a test. 8 Ideally, one would aim for a test with perfect accuracy; that is to say, $100 \%$ sensitivity and $100 \%$ specificity. Such a test would have a zero false-negative and false-positive rate. Unfortunately, this is unreal in clinical practice. Usually, we are dealing with a test characterized by a certain error rate of false positives and false negatives. There is a trade-off between these two; reducing false positives may lead to an increase in false negatives and vice versa, which corresponds with the reciprocal relation between sensitivity and specificity. Understanding the balance of benefit and harm between false positives and false negatives is critical to define the level of accuracy a predictive test for preeclampsia should achieve. False positive test results refer to women falsely identified as destined to develop preeclampsia. Consequently, their management may include superfluous close surveillance along with unnecessary prophylactic measures. This is inconvenient for the mother, but is unlikely to lead to relevant adverse health sequels, as the surveillance is generally non-invasive and preventive measures such as low-dose aspirin are not associated with serious side effects. In contrast, counseling of women with a false negative test result implies that they receive unjustified reassurance about having a low risk of recurrent preeclampsia in their next or current pregnancy. Close surveillance and preventive measures will be erroneously withheld from these women. Therefore, in preeclampsia, the negative impact of a false negative test result is larger than that of a false positive test result. ${ }^{9}$ High sensitivity is thus preferred over high specificity in the prediction of preeclampsia. When the negative predictive value of a test reaches values that correspond with the risk in nulliparae, the care provided to these women could be adjusted to the level of regular low-risk care.

Preeclampsia is known to be preceded by a wide range of causes and pathophysiological pathways, which eventually culminate into a clinical presentation of the disorder that may vary widely in time of onset, severity of hypertension and proteinuria, and the concomitant presence or absence of the HELLP syndrome (chapter 5). Therefore, more emphasis should be put on the development of different prediction tests for homogeneous subpopulations. Moreover, it may be more appropriate to explore combinations of tests of different categories instead of a single predictor (chapter 3). Surprisingly, only one study evaluated the predictive performance of a multivariable prediction model for recurrent preeclampsia previously (chapter 2).

An interesting challenge for future research is to evaluate whether the combination of pre- and in-pregnancy tests can improve predictive capacity. A highly sensitive prediction test for recurrent preeclampsia, applied prior to or early in the next pregnancy, with adequate predictive specificity, has not proven achievable so far. At 
preferred high levels of sensitivity, corresponding specificity levels of the prediction rule presented in chapter 3 of this thesis were relatively poor. This implies that a rather large proportion of tested women would receive unnecessarily intensive surveillance. Hypothetically, a model like this may benefit from the concept of hierarchical testing. That is to say, the application of more than one consecutive prediction tests for recurrent preeclampsia between 6 months post-preeclampsia and the 20th week of the next pregnancy. This approach is likely to reduce the falsepositive rate without raising the false-negative rate. According to this concept, a pre-pregnancy prediction rule could reassure women with a (very) low risk of developing recurrent preeclampsia, while the women with a positive test outcome are retested in the first half of the next pregnancy. This second stage of testing may, for example, involve longitudinal patterns to identify abnormal hemodynamic and metabolic adaptations to the next pregnancy, as proposed in chapters 7 and 8 of this thesis, respectively. The rationale is that women with constitutional risk factors who adapt normally to the next pregnancy are more likely to have normal initial placental development and therefore, are less likely to develop the prodromes of dysfunctional endothelium in preeclampsia, which include an increased inflammatory response, excessive circulation of anti-angiogenetic factors and accelerated platelet turnover.

Common methodological problems inherent to developing a clinically useful prediction model concern, among others, the management of missing values, selection of potential predictors, the model-building approach itself and occasionally, setting justified cut-off values of the predicted probability. Before being applied in clinical practice, validation analyses are required for which a wide range of methodological options are available. Relatively unknown is the phenomenon of collider-bias, as described and illustrated in chapter 9 of this thesis. It can affect various stages of the development of a prediction model for recurrent adverse pregnancy outcome. Due to this type of bias, clues on potentially relevant variables derived from previous reports can be misleading, resulting in incorrect selection of candidate predictors. Furthermore, inter-population variation in the prevalence of risk factors may potentially lead to different effects of confounding. Although this is not likely to influence the individual risk prediction, it could affect model performance on a population level with implications for external validation and updating. Also important in this stage is the phenomenon of selective fertility that may occur after application of a prepregnancy prediction model for a certain reproductive outcome (chapter 10). Prediction test results may influence women and their partners in their decision whether or not to choose for a next pregnancy. In formerly preeclamptic patients, this may imply that women refrain from a new pregnancy after being informed about their high risk of recurrence in a next pregnancy. In theory, this would change the composition of the pregnant population with respect to the predictors in the model. Although this concept proved to have a modest effect on 
the sensitivity and specificity of the prediction model (chapter 10), individual risk estimates, positive and negative predictive values and the c-statistic are not affected.

\section{Counseling for recurrent preeclampsia, clinical implications}

The potential recurrence of preeclampsia is a matter of serious concern for patients, their families, and healthcare providers, especially after having experienced early-onset preeclampsia. The latter is related to an increased risk of adverse maternal and perinatal outcome and predisposes to severe co-morbidity. Fortunately, the outcome of a next pregnancy is generally favorable. ${ }^{7,9}$ Although the recurrence risk of preeclampsia in women with a history of early-onset disease is high, the risk of developing recurrent early-onset preeclampsia is only 5-9\%, as described in several chapters of this thesis and reported by others. ${ }^{7}$

The ability to predict the individual risk of recurrent (early-onset) preeclampsia would be a valuable tool in preconception counseling of formerly preeclamptic women. As outlined in chapter 2 of this thesis, accurate clinically useful prediction tests for recurrent preeclampsia are lacking. Chapter 3 of this thesis delineates that preconception prediction can be achieved by a combination of relatively simple maternal parameters. For clinical prediction rules to be widely used in practice, it is essential that clinicians know how to take advantage of the incremental predictive value provided. ${ }^{10}$ Underlying the development of prediction rules is the unproven assumption that better predictions will have a positive effect on subsequent management. However, at present, coupling of the predicted risk of recurrent preeclampsia and clinical management decisions remains vague. It is not realistic to expect even the most accurate predictions to contribute to the post-testing clinical management of a patient. Nevertheless, impact analyses are important to determine whether the application of a prediction test and adjustment of clinical management to the outcome of the test is beneficial for pregnancy (and health) outcome. This is one of the aims of the PreCare study, a follow-up study that evaluates the cost-effectiveness of recurrence-risk guided care (i.e. based on the outcome of a prediction tool) of pregnant former preeclamptic or HELLP patients. ${ }^{11}$ For practical reasons, the prediction tool applied in this multicenter study differs from that presented in chapter 3 . At any rate, in order to strive for optimal clinical strategies, the final test result of a prediction model for recurrent preeclampsia should be available at the latest by the end of the first half of pregnancy. Only the latter warrants adjustment of the intensity of care to the test result.

Influenceable risk factors, such as lifestyle-related factors, are of particular importance in counseling for recurrent preeclampsia, since they are modifiable with potential beneficial effects on the recurrence risk of preeclampsia. An explicit example 
is the metabolic syndrome. ${ }^{12}$ The presence of metabolic abnormalities contributing to this syndrome proved associated with recurrent preeclampsia, even in the absence of obesity (chapter 4). Besides, the recognition of these abnormalities identifies women with potentially increased risk of cardiovascular disease later in life. ${ }^{13,14}$ This will allow for early intervention, either primarily by modifying risk factors or secondarily by instituting specific prophylaxis. ${ }^{15}$ However, follow-up of women with a recent history of preeclampsia is currently insufficient and undeveloped in primary care in the Netherlands. ${ }^{16}$

\section{Concluding remarks}

\section{Part I - Preconception prediction of and counseling for recurrent preeclampsia}

Until recently, no multivariable preconception prediction model had been available for recurrent preeclampsia (chapter 2).

We developed a prediction model based on easily obtainable preconception maternal parameters with moderate to good predictive accuracy (chapter 3). Potentially, combining this model with early-pregnancy prediction tests will improve its predictive potential.

Metabolic abnormalities are important indicators for increased risk of recurrent preeclampsia, regardless the woman's body mass index (chapter 4). Therefore, the efficacy of lifestyle changes in the reduction of preeclampsia recurrence risk is an interesting topic for future study.

In HELLP syndrome, these metabolic abnormalities proved to be less important and so did thrombophilic abnormalities (chapter 5).

The relatively high prevalence of metabolic abnormalities and the presumably related increased risk of cardiovascular disease later in life were not reflected in more frequent abnormal electrocardiograms (ECGs) shortly after preeclampsia (chapter 6). Therefore, the postpartum ECG assessment in women with a recent history of preeclampsia seems superfluous.

\section{Part II - Early-pregnancy adaptation}

Early-pregnancy adaptation of the lipid profile and diastolic function tended to differ between formerly preeclamptic women destined to develop recurrent disease later in pregnancy as compared to their counterparts who are not (chapters 7 and 8).

These findings may be of pathophysiologic importance and could contribute to the development of prediction strategies. Future studies are needed to test the hypotheses generated about the observed dissimilarities in early-pregnancy adaptation. 


\section{Part III - Methodological challenges in predicting reproductive outcomes}

Studies on recurrence risk may be affected by collider bias, which can seriously distort and even invert association estimates (chapter 9).

Collider bias may occur in any recurrence risk study in which sample selection is based on prior occurrence of the disorder studied.

Collider bias may affect correlation coefficients in a prediction model to such an extent that they suggest a protective effect of a potential risk factor. Therefore, unexpected absent or invert associations of factors with recurrent outcome should be interpreted with extra caution as they are likely to be biased by sample selection. Prediction-based selective fertility may arise when prediction test results influence the women and their partners in their decision to choose for a next pregnancy, which in turn affects the composition of the pregnant population with respect to the predictors in the model (chapter 10).

After application, predictive sensitivity and specificity of preconception prediction models for adverse pregnancy outcome may be different when evaluated in the new pregnant population, as a result of prediction-based selective fertility. 


\section{References}

1. Bellamy L, Casas JP, Hingorani AD, Williams DJ. Pre-eclampsia and risk of cardiovascular disease and cancer in later life: systematic review and meta-analysis. Bmj 2007;335(7627):974.

2. Schutte JM, Steegers EA, Schuitemaker NW, Santema JG, de Boer K, Pel M, et al. Rise in maternal mortality in the Netherlands. Bjog 2009.

3. Rosenberg K, Twaddle S. Screening and surveillance of pregnancy hypertension--an economic approach to the use of daycare. Baillieres Clin Obstet Gynaecol 1990;4(1):89-107.

4. Anthony J. Improving antenatal care: the role of an antenatal assessment unit. Health Trends 1992;24(4):123-5.

5. Bouvier-Colle MH, Salanave B, Ancel PY, Varnoux N, Fernandez H, Papiernik E, et al. Obstetric patients treated in intensive care units and maternal mortality. Regional Teams for the Survey. Eur J Obstet Gynecol Reprod Biol 1996;65(1):121-5.

6. Duckitt K, Harrington D. Risk factors for pre-eclampsia at antenatal booking: systematic review of controlled studies. BMJ 2005;330(7491):565.

7. van Rijn BB, Hoeks LB, Bots ML, Franx A, Bruinse HW. Outcomes of subsequent pregnancy after first pregnancy with early-onset preeclampsia. Am J Obstet Gynecol 2006;195(3):723-8.

8. Cnossen JS, ter Riet G, Mol BW, van der Post JA, Leeflang MM, Meads CA, et al. Are tests for predicting preeclampsia good enough to make screening viable? A review of reviews and critical appraisal. Acta Obstet Gynecol Scand 2009;88(7):758-65.

9. McDonald SD, Best C, Lam K. The recurrence risk of severe de novo pre-eclampsia in singleton pregnancies: a population-based cohort. Bjog 2009;116(12):1578-84.

10. Liao L, Mark DB. Clinical prediction models: are we building better mousetraps? Journal of the American College of Cardiology 2003;42(5):851-853.

11 The PreCare Study [homepage on the internet]. Amsterdam: Consortium for women's health and reproductivity studies; [cited December 2009]. Available from: http://www.studies-obsgyn.nl/precare.

12. Perk J. Risk factor management: a practice guide. Eur J Cardiovasc Prev Rehabil 2009;16 Suppl 2:S24-8.

13. Rodie VA, Freeman DJ, Sattar N, Greer IA. Pre-eclampsia and cardiovascular disease: metabolic syndrome of pregnancy? Atherosclerosis 2004;175(2):189-202.

14. Sattar N. Do pregnancy complications and CVD share common antecedents? Atheroscler Suppl 2004;5(2):3-7.

15. Lykke JA, Langhoff-Roos J, Sibai BM, Funai EF, Triche EW, Paidas MJ. Hypertensive pregnancy disorders and subsequent cardiovascular morbidity and type 2 diabetes mellitus in the mother. Hypertension 2009;53(6):944-51.

16. Nijdam ME, Timmerman MR, Franx A, Bruinse HW, Numans ME, Grobbee DE, et al. Cardiovascular risk factor assessment after pre-eclampsia in primary care. BMC Fam Pract 2009;10(1):77. 


\section{Samenvatting}


In hoofdstuk 1 van dit proefschrift worden de zwangerschapsaandoening preëclampsie, het ontstaansmechanisme, het herhalingsrisico in een volgende zwangerschap en de mogelijkheden tot counseling (adviesgeving) kort geïntroduceerd. Preëclampsie omvat de ontwikkeling van hypertensie (verhoogde bloeddruk) en proteïnurie (verhoogde eiwituitscheiding in de urine) na 20 weken zwangerschap. Het syndroom compliceert 5-8 procent van alle zwangerschappen en is een belangrijke oorzaak van morbiditeit en mortaliteit bij zowel moeder als kind. Hoewel nog steeds geen open boek, is de laatste 20 tot 30 jaar meer bekend geworden over de oorzaken van preëclampsie. Tegenwoordig beschrijft men het ontstaan van preëclampsie als een tweefasen model, waarbij afwijkende ontwikkeling van de bloedvaten in de baarmoederwand in de eerste fase resulteert in een verslechterde doorbloeding van de placenta (de moederkoek). Hierdoor komen factoren vrij in de moederlijke bloedsomloop die een stress reactie veroorzaken, welke uiteindelijk kan leiden tot de klinische symptomen. Vrouwen die eenmaal preëclampsie hebben doorgemaakt, hebben een verhoogde kans op herhaling in de volgende zwangerschap. Het is dan ook belangrijk hen counseling te bieden voorafgaand aan een volgende zwangerschap. Daarbij kan ondermeer worden ingegaan op aanwezige risicofactoren en mogelijke strategieën om het herhalingsrisico te verlagen.

Het eerste deel van dit proefschrift beslaat mogelijkheden tot predictie (voorspelling) van het herhalingsrisico op preëclampsie en daaraan gekoppeld mogelijkheden tot counseling van voormalige patiënten, voorafgaand aan de volgende zwangerschap. Hoofdstuk 2 biedt een literatuuroverzicht van beschikbare predictoren (voorspellers) voor het herhalingsrisico op preëclampsie. Hierbij wordt ingegaan op de mate waarin de testen hiertoe in staat zijn en hun toepasbaarheid in de klinische praktijk. In 33 artikelen werden 24 verschillende predictoren geïdentificeerd. Daarvan waren het plasma volume, de stroomsnelheid van het bloed in de baarmoederslagaders en een combinatie van herhaaldelijk in de zwangerschap gemeten variabelen het meest veelbelovend. Deze voorspellers kennen echter ook praktische bezwaren, zoals een laat moment van toepassing. Tevens was de vastgestelde voorspellende capaciteit in veel gevallen onbetrouwbaar. Preëclampsie is een heterogene aandoening. Daarom wordt verondersteld dat een combinatie van verschillende typen voorspellers tot een betere voorspelling van de kans op herhaling kan leiden.

Hoofdstuk 3 presenteert een predictiemodel voor het herhalingsrisico op preëclampsie vroeg in de zwangerschap, waarin meerdere predictoren gecombineerd worden. Deze predictoren zijn ten minste zes maanden na de eerste en nog voor de volgende zwangerschap bepaald. De combinatie van HDLcholesterol (het "goede" cholesterol) en de hoeveelheid eiwit dat in de urine wordt 
uitgescheiden binnen 24 uur in één model bleek de beste voorspelling van het risico op te leveren. Dit model bleek in staat om $94 \%$ van de vrouwen die in de volgende zwangerschap opnieuw een vroege preëclampsie ontwikkelen te identificeren. Bijna $50 \%$ van de vrouwen kunnen zo gerustgesteld worden dat het risico op herhaling zeer laag is $(<1 \%)$.

In hoofdstuk 4 wordt obesitas (zwaarlijvigheid) als risicofactor voor preëclampsie tegen het licht gehouden. Obesitas is geassocieerd met andere aan preëclampsie gelinkte factoren, zoals hypertensie, chronische ontsteking en afwijkingen in de stofwisseling. Het is dan ook denkbaar dat obesitas niet zozeer direct, maar eerder indirect effect heeft op het ontstaan van preëclampsie. De bevindingen in hoofdstuk 4 bevestigen deze stelling. Het risico op preëclampsie na de aandoening te hebben doorgemaakt in een vorige zwangerschap was weliswaar verhoogd bij obese vrouwen in vergelijking tot vrouwen zonder obesitas, maar indien metabole afwijkingen in ogenschouw werden genomen was de associatie verdwenen. Bovendien bleek de aanwezigheid van metabole afwijkingen, onafhankelijk van de aan- of afwezigheid van obesitas, een risicofactor voor preëclampsie. Het advies luidt dan ook de aandacht bij het counselen van voormalige preëclampten minder specifiek op obesitas te richten en meer op metabole factoren in het algemeen, ongeacht de lichaamsomvang.

In hoofdstuk 5 worden de verschillen tussen preëclampsie en het HELLP syndroom (gekenmerkt door hemolyse, verhoogde leverenzymen en verlaagde bloedplaatjes) geëvalueerd. De ontstaanswijze en symptomen van het HELLP syndroom overlappen deels met die van preëclampsie. Dit heeft geleid tot vergelijkbare behandelmethoden van beide syndromen. Omdat de syndromen wel degelijk twee afzonderlijke ziektebeelden zijn valt te betwijfelen of dit wel terecht is. In hoofdstuk 5 wordt duidelijk dat het HELLP syndroom verschilt van preëclampsie op enkele belangrijke punten, waaronder het frequenter voorkomen van eclampsie (stuipen) tijdens de zwangerschap en het minder vaak voorkomen van hypertensie, proteinurie, verhoogde stollingsneiging, obesitas, verhoogde bloedsuikerspiegel, verhoogde triglyceriden, en verhoogd homocysteine in de nietzwangere conditie.

In hoofdstuk 6 wordt het voorkomen van electrocardiografische afwijkingen (afwijkingen op het ECG, ook wel hartfilmpje) beschreven bij voormalige preëclampsie patiënten. Bovendien worden de ECG dimensies vergeleken tussen vrouwen die in de volgende zwangerschap preëclampsie ontwikkelen en vrouwen waarbij dat niet gebeurd. Voormalige preëclampsie patiënten hebben een verhoogd risico op hart- en vaatziekten op latere leeftijd. Of zich dit recent na het doormaken van preëclampsie uit in het vaker voorkomen van ECG afwijkingen is onduidelijk, evenals de vraag of vrouwen met herhaaldelijke preëclampsie vaker afwijkingen hebben dan vrouwen met eenmalige preëclampsie. De prevalentie (frequentie) van 
ECG afwijkingen bleek bij expreëclampten niet hoger te zijn dan in de algemene populatie vrouwen van vruchtbare leeftijd. Vrouwen met herhaaldelijke preëclampsie vertoonden verschillen in elektrische hartas (een middeling van alle ontladingen in het hart) en QT-interval (geleidingstijd), maar dit bleek met name veroorzaakt te worden door verschillen in bloeddruk.

Het tweede deel van dit proefschrift gaat in op de vroege aanpassingen aan de zwangerschap bij voormalige preëclampten. Hoofdstuk 7 behandelt de veranderingen in het lipidenprofiel. Hoewel bekend is dat bij preëclampsie de hoeveelheid lipiden (vetten) in het bloed hogere waarden bereikt dan bij gezonde zwangerschap, is het onduidelijk of deze verschillen al vroeg in de zwangerschap detecteerbaar zijn. De bevindingen in hoofdstuk 7 zijn afgeleid van metingen voor de zwangerschap en 8 en 16 weken tijdens de zwangerschap. Wat bleek is dat bij vrouwen die opnieuw preëclampsie ontwikkelen de gebruikelijke tijdelijke daling in LDL-cholesterol na het eerste trimester niet waarneembaar is. Mogelijk wordt dit veroorzaakt door een lagere productie van steroïde hormonen door de placenta. Bovendien was de stijging in HDL-cholesterol bij deze groep minder sterk, vermoedelijk voorafgaand aan de verlaagde waarden die eerder zijn waargenomen bij reeds gediagnosticeerde preëclampsie. Geen verschillen in aanpassing van de concentratie triglyceriden werden waargenomen.

In hoofdstuk 8 ligt de focus op de aanpassingen van de diastolische hartfunctie aan de zwangerschap. Preëclampsie vroeg in de zwangerschap blijkt te worden voorafgegaan door verminderde adaptatie van het hart- en bloedvaten systeem. Hoeverre maladaptatie van de diastolische hartfunctie hierbij betrokken is, is onbekend. In hoofdstuk 8 worden verschillende diastolische functie parameters geëvalueerd voor de zwangerschap en bij 12, 16 en 20 weken tijdens de zwangerschap bij voormalige preëclampsie patiënten. Bij 12 weken bleek de E/A ratio (een parameter voor diastolische functie) sterker te zijn toegenomen bij vrouwen die later in de zwangerschap preëclampsie ontwikkelen ten opzichte van vrouwen die dit niet doen. Bovendien was het hart-minuut volume lager en de systemische vaatweerstand hoger. Indirect zou dit kunnen betekenen dat het sympatische aandeel van de autonome controle van de bloedsomloop in het tweede trimester groter is onder vrouwen die opnieuw preëclampsie ontwikkelen. Dit laatste ondersteunt dan weer de gedachte dat verminderde adaptatie van de diastolische hartfunctie bijdraagt aan de abnormale adaptatie van hart en bloedvaten aan de zwangerschap bij preëclampsie.

Het derde en laatste deel van dit proefschrift heeft betrekking op twee methodologische uitdagingen waar men in onderzoek naar recidiverende (herhalende) zwangerschapsgerelateerde uitkomsten tegenaan kan lopen. In 
hoofdstuk 9 betreft dit het fenomeen collider bias. Met de term collider wordt in dit verband een factor bedoeld die in een causale (oorzakelijke) keten beïnvloed wordt door twee andere factoren. Wanneer op basis van de collider wordt gestratificeerd (gecorrigeerd) ontstaat een associatie tussen die twee factoren, waardoor confounding wordt geintroduceerd. Schattingen van de associatie tussen dergelijke factoren en herhaling van een bepaalde uitkomst kunnen daardoor ernstig vertekend raken en in extreme gevallen zelfs een andere richting aannemen. Dit kan verstrekkende klinische gevolgen hebben. Het is dus belangrijk deze vorm van bias op zijn minst te herkennen. Collider bias is reeds eerder beschreven, maar vrij nieuw in deze context is de bevinding dat, in studies naar recidiverende uitkomsten, selectie van de onderzoekspopulatie op basis van het voorkomen van die uitkomst in het verleden ook collider bias kan veroorzaken. Het al dan niet eerder hebben gehad van de uitkomst is in dit geval de collider. We illustreren dit principe aan de hand van een denkbeeldig getallenvoorbeeld waarin obesitas als risicofactor voor recidiverende preëclampsie wordt geëvalueerd. In hoofdstuk 10 wordt ingegaan op de invloed van risicopredictie-gerelateerde keuze voor een nieuwe zwangerschap op de prestatie van predictiemodellen. In feite betreft het een variant op een fenomeen wat we kennen als selectieve fertiliteit; de neiging om reproductie (voortplanting) aan te passen op basis van de uitkomsten van eerdere zwangerschap(pen). Dit kan bij de toepassing van predictiemodellen in de praktijk een rol gaan spelen. Individuele risicoschattingen aan de hand van predictiemodellen kunnen gebruikt worden voor counseling doeleinden. Dientengevolge is het denkbaar dat vrouwen met een hoog voorspeld risico van een ongewenste uitkomst besluiten niet zwanger te worden. Deze risicopredictiegerelateerde selectieve fertiliteit kan veranderingen teweegbrengen in de samenstelling van de populatie zwangeren met betrekking tot de predictoren in het predictiemodel. Aan de hand van een hypothetisch voorbeeld met gesimuleerde data illustreren we dat dit invloed kan hebben op de sensitiviteit en specificiteit van een predictiemodel, maar dat de c-statistic (een maat voor het onderscheidend vermogen) en de individuele risicoschattingen onaangedaan blijven.

Hoofdstuk 11 levert ten slotte een algemene discussie over de onderwerpen aangesneden in dit proefschrift. Benadrukt wordt de ernst van de aandoening en het ontbreken van goede richtlijnen voor screening op verhoogd risico, vroege detectie en behandeling van vrouwen met een verhoogd risico op preëclampsie. Een belangrijk aandachtsgebied voor toekomstig onderzoek is het verder exploreren van combinaties van testen, met toepassingen zowel voor als tijdens de volgende zwangerschap. Voor de clinicus is het belangrijk in te zien op welke manier voordeel te halen valt uit de predictieve waarde van een predictie test voor het risico op herhaling van preëclampsie. Op dit moment is de koppeling tussen 
risicovoorspellingen, klinisch handelen en te behalen successen met betrekking tot gezondheidsuitkomsten nog vaag. Impact analyses moeten hierover meer duidelijkheid verschaffen. 


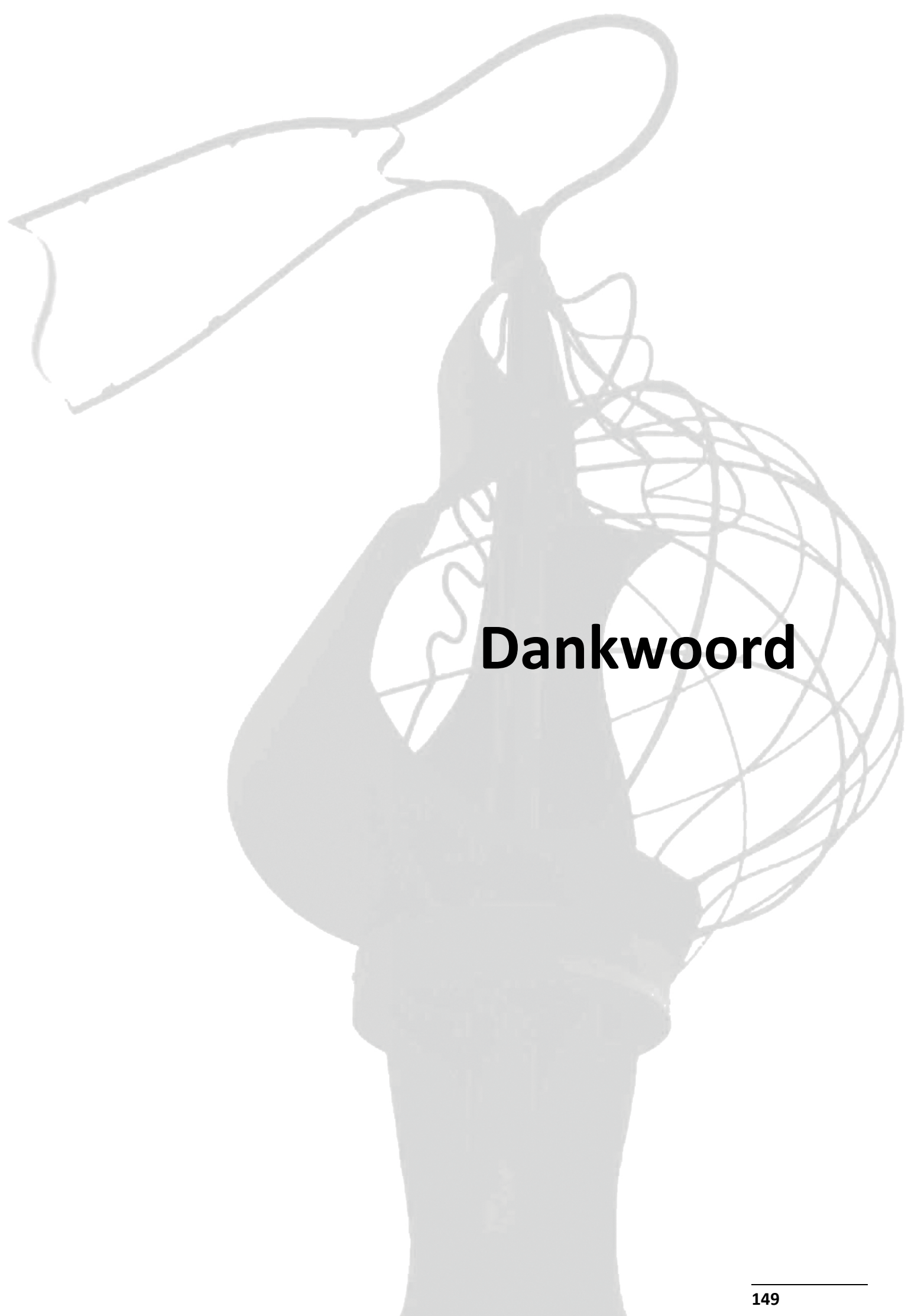




\section{Dankwoord}

Beste Louis, al vanaf het eerste kennismakingsgesprek voor aanvang van mijn afstudeerstage binnen de opleiding Gezondheidswetenschappen werkte uw enthousiasme, impulsiviteit, veelzijdigheid aan ideeën en geweldige kennis van hypertensieve aandoeningen in de zwangerschap aanstekelijk. Dit eerste gesprek was tegelijk mijn eerste kennismaking met preëclampsie. Na een half jaar was ik volledig overtuigd van de noodzaak van onderzoek naar dit onderwerp, hetgeen met recht uw passionele levenswerk genoemd mag worden. Ik ben dan ook dankbaar dat we uiteindelijk, samen met Martin Prins, een promotie project hebben kunnen starten. De wekelijkse bijeenkomsten samen met Luc heb ik als stimulerend, verhelderend, indien nodig verlichtend en uiterst leerzaam ervaren. Achteraf stel ik vast dat niet in de laatste plaats de interessante combinatie van klinisch inzicht en epidemiologische kunde hieraan ten grondslag ligt. Juist de botsingen en dilemma's die de welbekende 'fishing expeditions' en 'het leegknijpen van de spons' soms met zich meebrachten, heeft mij als onderzoeker gesterkt in mijn inzichten. Onuitputtelijk is de vraag naar nieuwe onderzoekstalenten uwerzijds. ledere arts in spé die zijn onderzoekershart voelt kloppen, zou ik een gesprek met dr. Peeters willen aanraden. Want hoewel we dat van de longitudinale data uit de follow-up niet kunnen zeggen, zijn er onderzoeksvragen in overvloed.

Beste Luc, al vrij snel na de start van mijn promotieproject kwam jij het begeleiderteam versterken. Jouw bijdrage aan dit proefschrift was onmisbaar. Ik heb veel gehad aan jouw verhelderende inzichten. Je hebt een talent om complexer wordende problemen terug te brengen naar het eenvoudige noodzakelijke en de focus te bewaren. Deze laatste vaardigheid heb je (misschien wel) tot vermoeiends toe mogen toepassen gaande het project, maar hopelijk heb je gemerkt dat ik er ook wat sterker in ben geworden. Fijn hoe na een week wikken en wegen gevolgd door een 5-minuten gesprek met jou resulteert in de conclusie: "Nee inderdaad, dat is ook zo. Bedankt.". Jouw deur stond, net als die van Louis, altijd voor me open. Alleen al het idee is een grote steun geweest. Excuses voor het feit dat ik ook na vier jaar nog de afstand tussen UNS 50 en Deb 1 weet te onderschatten heb ik al zo vaak gemaakt. Het is een geaccepteerd feit geworden. Dank voor de input, kennisoverdracht en zeer betrokken support!

Martin, promotor van het eerste uur. $U$ was reeds mijn begeleider tijdens de afstudeerstage en ik ben blij dat het mogelijk is gebleken hier vervolg aan te geven middels een promotieproject. Vanaf het begin uitte $u$ een rotsvast vertrouwen in mijn kunnen. Dat heeft mij enorm gesterkt. Ook toen de publicaties nog op zich lieten wachten, bleef $\mathrm{u}$ immer positief over de te behalen doelen. Net wat ik nodig had, zo bleek, want binnen vier jaar lag het manuscript van dit proefschrift bij de 
beoordelingscommissie. De dagelijkse begeleiding werd overgedragen en terecht toevertrouwd aan Luc, maar, voor zover de agenda dat toeliet, weet ik dat ik altijd bij $u$ terecht kon met vragen of andere kwesties. Bewonderenswaardig vond ik het dan hoe snel de draad weer opgepakt kon worden om over (voor mij) complexe problemen te discussiëren.

Via deze weg wil ik ook Prof. Nijhuis bedanken. Hoewel we minder direct hebben samen gewerkt ben ik vereerd dat hij mijn promotor wil zijn.

De onderzoeksgroep bij Obstetrie en Gynaecologie, het warme nest dat PeRIM heet. De collegialiteit die ik bij jullie heb mogen ervaren was een heerlijkheid, evenals de zeer frequente uitstapjes en de niet te missen jaarlijkse BBQ. Teambuilding staat bij PeRIM hoog in het vaandel, liefst onder extreme weersomstandigheden. Inez en Timo, jullie vormen de spil van de afdeling. Zonder jullie verbluffende inzet waren de promovendi en WESPers nergens. De combinatie organisatietalent (Inez) en creativiteit (Timo) komt perfect uit de verf. Henny, met de Mestreechter geis waait sinds jouw komst 'e fris windsje' (al dan niet afkomstig van de wapperende witte jas, die je, toegegeven, goed staat). Mooi hoe het jou binnen korte tijd gelukt is een stevige brug te slaan tussen onderzoek en kliniek. Rob de computerbouwer, bedankt voor de ondersteuning. De inzet, het doorzettingsvermogen en de gezelligheid van alle (WESP) stagiaires die in de afgelopen jaren werkzaam zijn geweest bij PeRIM waren van toegevoegde waarde. In het bijzonder wil ik Jef, Philippe, Robijn en Malou bedanken voor hun directe en onmisbare bijdrage aan de totstandkoming van dit proefschrift. Malou, ik denk met plezier terug aan 'onze nachten samen' in Glasgow en Edinburgh. Hoewel reeds uitgevlogen voor mijn komst wil ik de oudPeRIM-leden Olivier, Robert, Dorette (nu lange afstandslid) en Hugo, danken voor hun inspirerende werk. Eline, mijn eerste roommate op de uni. Ik heb genoten van de tijd dat wij collega's waren en denk nog vaak terug aan onze dinertjes c.q. roddelsessies. Het Amerika-avontuur was er een om nooit te vergeten. De tip dat Market Street in San Francisco niet de meest veilige plek is om 's nachts de Mc te bezoeken heb ik wijd verspreid (dat Twin Peaks net na zonsopgang met een jetlag juist wel is aan te raden trouwens ook). Bedankt voor de warme vriendschap die ook na jouw vertrek naar Brussel standhield. Carmen R. en Julia, mijn onvergetelijke paranimfen. Blij was ik toen ik niet langer de enige promovendus was en jullie als fijne collega's (en meer dan dat) het team kwamen versterken. Naast het feit dat ik vereerd ben dat jullie mijn paranimfen willen zijn, hebben jullie ook direct een onmisbare bijdrage geleverd aan de totstandkoming van dit proefschrift. Mijn dank is groot!

Een woord van dank gaat ook uit naar het ondersteunend personeel van de afdeling obstetrie en gynaecologie. Manon en Trudy, jullie zagen me alweer aankomen met 
de lege cartridge in de hand. Manon wil ik in het bijzonder bedanken voor de verzorging van de correspondentie rondom dit proefschrift. Annemie, de heerlijke Franse wijn is goed gevallen (of bevallen om in de termen van dit proefschrift te spreken) na de bbq in Scharn in september. Gelukkig hebben we de foto's nog. Artsen en assistenten, ik heb veel opgestoken van jullie interessante discussies over voor mij vaak onbekende onderwerpen tijdens de journal clubs en high-risk besprekingen.

Verder wil ik de meiden van Sapienza University of Rome bedanken, the Italian girls: Silvia, Sara, Angela and Claudia. Thanks a lot for the good company, support, Italian lessons and delicious food! Silvia, we met three years ago and despite the long distance we have been friends ever since. Your hospitality is amazing. I enjoyed our stay in Rome and felt honored to be part of your wedding in Abruzzo. I would have liked to say that I will always remember the '11de van de 11de' we celebrated together, but I would lie. You know why. In 2009, you were back in Maastricht for another research project, which now is part of this thesis. Thank you for your contribution!

De ontwikkeling van een predictiemodel voor de herhalingskans op preëclampsie was een voedingsbodem voor nieuwe onderzoeksideeën. In 2009 ging de PreCare studie van start. Projectleiders Luc en Carmen D. wil ik bedanken voor de mogelijkheid om mee te denken en van de brainstormsessies te leren. De samenwerking met Utrecht ontsprong op de WEON van 2008 in Groningen. MarieElise, de match van onze onderwerpen bood inspiratie. We hadden grootse plannen voor een validatie studie met enorme patiënten aantallen. De praktijk bleek anders uit te pakken, maar de krachten zijn gebundeld! De promovendi van PreCare, Sander en Denise wil ik bedanken voor hun collegialiteit. Leuk dat we het onderwerp van studie gemeenschappelijk hebben. Sander, jouw eerlijke, kritische blik is er een om trots op te zijn. Jouw betrokkenheid bij de totstandkoming van dit proefschrift was van grote waarde. Ik weet zeker dat heel wat epidemiologen jouw dankbaar gaan zijn voor het veelbelovende gestoei met getallen.

Dit laatste brengt mij op de op prognostiek gerichte methodologische sessies bij de afdeling Epidemiologie, in het leven geroepen door Luc. De sessies zijn een waardevolle aanvulling op de niet altijd even gemakkelijk te interpreteren methodologische literatuur en vormen een bron van inspiratie. Dat er vele publicaties mogen volgen!! Luc, Martin, Pieter, Patty, Adri, Isabella, Arina, Sander, Audrey en Paul, dank voor de leerzame discussies.

Alle collega's bij Epidemiologie, bedankt voor jullie kunde, medeleven en interesse. Mijn werkplek was elders, maar ik heb mogen genieten van de collegialiteit die op de afdeling heerst. Verbazingwekkend hoe het ieder jaar weer lukt om de 
bestemming en invulling van het altijd geslaagde dagje-uit tot het moment suprème geheim te houden. Nathalie en Yvonne, bedankt voor de ondersteuning in de brede zin van het woord. John, bedankt voor het geduld wanneer ik weer eens in de laatste minuut mijn verlofregistratie in orde zat te maken. Jos en Harry, niet dat de server nu optimaal functioneert op mijn pc, maar hij is wel geïnstalleerd, dankzij jullie. Docenten van het CAT-onderwijs, over de perikelen hoef ik niemand bij de praten - de 'sensitiviteit' van 40 soloCAT's is feitelijk hoger dan die van 20 - maar laten we vooral de mooie methodiek niet vergeten. De interactie (ook wel effectmodificatie) met studenten was leerzaam en vormde (eerlijk is eerlijk) een welkome afwisseling op de SPSS analyses (waar dan weer geen uren voor stonden).

De groep uit Nijmegen: Marc, Prof. Lotgering, Ineke, Joris en Ralph, bedankt voor de prettige samenwerking en ontmoetingen op de SGI. Marc, zonder jou was het zogenaamde na-onderzoek in de huidige vorm er niet geweest en dit proefschrift dus ook niet. Dat realiseer ik me terdege. Jouw interesse in en kennis van de pathophysiologie van preëclampsie is ongekend. Ineke, onze hotelkamer in Reno was een oase van rust tussen de piepende en flitsende gokkasten. Jouw promotie vorig jaar, regelmatig als voorbeeld gesteld door Louis, was met recht een bekroning op je inspanningen.

Uiteraard wil ik alle nog niet genoemde co-auteurs van de in dit proefschrift opgenomen manuscripten hartelijk bedanken voor hun samenwerking, interesse, kunde, geduldige uitleg, input en inspiratie: Dr. Koek, Dr. Dassen, Dr. Gorgels, Dr. Bekkers, Dr. Kruse (Arnold), Dr. van Bilsen en Dr. Bekers.

(Schoon)familie en vrienden, ook jullie hebben bijgedragen aan de totstandkoming van dit proefschrift. De onuitputtelijke interesse en het medeleven waren hartverwarmend. Eindelijk kan ik de vraag: "Zeg, wanneer is nu dat feest?" beantwoorden. Ik zal bij dezen nog één keer uitleggen dat de titel "doctor" niet verward moet worden met "dokter". Hoewel ik nu heel wat afweet van de zwangerschap en alles wat daarbij komt kijken, heb ik nog steeds geen pasklare oplossing voor allerhande gezondheidsproblemen. Annemieke en Hilde, goede vriendinnen en oud-studiegenootjes, fijn dat ik altijd bij jullie terecht kon om in GWers taal over werkgerelateerde onderwerpen te praten. Uiteraard bespreken we andere aspecten ook, maar dat leek me hier minder relevant. Miek, Ik ben vereerd dat ik jouw paranimf mag zijn. Een week voor jouw eigen promotie heb ik je die rol bespaard, al beleef ik het hetzelfde. Bedankt voor alle steun. Esther, we leerden elkaar kennen toen ook jij met de preeclampsie groep aan de slag ging. Wat hebben we veel lief en (promotie)leed gedeeld. Na een dinertje samen, uit of thuis, zag ik de toekomst veel zonniger in (dan ie al was). Wees bovenalles trots op jouw prestaties. De hoeveelheid klussen die jij de afgelopen jaren geklaard hebt zijn niet te 
evenaren. Ik vind het ontzettend jammer dat je niet bij mijn promotie aanwezig kunt zijn, maar de stage in Amerika is een absolute topkans. We drinken op jouw feest een extra pilsje (of twee).

Pap en mam, bedankt voor het onvoorwaardelijke vertrouwen en de onovertreffelijke steun bij alles wat ik doe (en laat). Het was niet altijd eenvoudig uit te leggen waar ik me zoal mee bezig hield, maar de krantenknipsels over zwangerschapsvergiftiging getuigen van het juiste begrip. Pap, de rit naar Wijk aan Zee (en terug) was dubbel en dik de moeite waard. Ik ben erg blij met de foto's die zowel op de voor-, achter- als binnenkant van dit proefschrift prijken. Woorden schieten te kort om te beschrijven wat jullie voor me betekenen, maar met een stuk of vier kom ik toch een heel eind. lech haw vaan uuch! Gilbert, je moet me al heel wat jaren 'missen' in Neerbeek, maar met msn blijkt dat goed te verkroppen. Heel erg bedankt voor de layout van omslag en uitnodigingen. Je denkt je roeping nog niet te hebben gevonden, maar ik zou niet heel veel verder zoeken als ik jou was, toch Lindsay?

Bas, lieve Bas, je hebt wat gezellige avonden en weekenden aan je neus voorbij zien gaan door de perikelen rond dit proefschrift. Uit het feit dat je zelf op een blauwe maandag het promoveren overwoog, hoop ik echter af te leiden dat ik het binnen de perken heb weten te houden. Jouw simpele kijk op voor mij complexe dilemma's, vertrouwen in mijn kunnen en trots (over mij) waren en zijn een grote steun. Sinds vorige zomer wonen we in ons eerste echte eigen huis (ook dat was me het projectje wel) en ik vind het heerlijk, met jou. Ik hoop dat we de vele herinneringen die we de afgelopen tien jaar samen hebben opgedaan nog lang kunnen aanvullen (dus laat die mooie reizen maar komen). De gelukkigste mens is degene die het denkt te zijn. Heb ik geluk! 


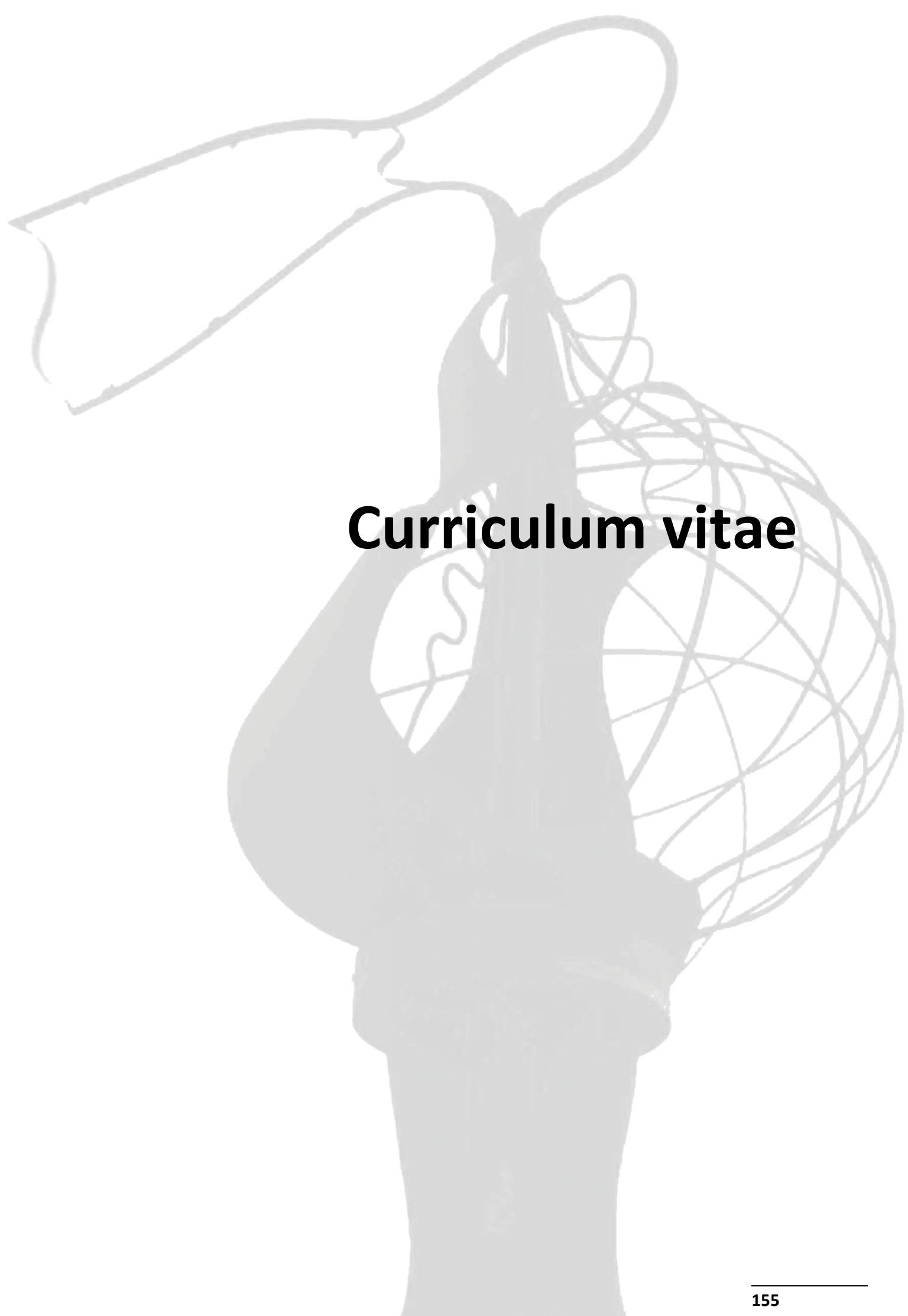





\section{Curriculum vitae}

Simone Sep werd op 2 januari 1983, net een uur na nieuwjaarsdag, geboren in het Sint Barbaraziekenhuis in Geleen. Ze groeide op in het kerkdorp Neerbeek. In 2001 slaagde ze voor het VWO aan het Graaf Huyn College (eerder: scholengemeenschap Sint Michiel) te Geleen. In datzelfde jaar startte ze met de opleiding Gezondheidswetenschappen aan de Universiteit Maastricht en al vrij snel verhuisde ze naar de Limburgse hoofdstad.

Binnen de doctoraalfase koos ze voor de studierichting Biologische Gezondheidkunde, om zich tijdens het keuzeonderwijs verder toe te spitsen op de Epidemiologie. Tijdens haar wetenschapsstage (onder begeleiding van Dr. Peeters en Prof.dr. Prins) bij de afdelingen Obstetrie \& Gynaecologie en Epidemiologie (MUMC+) nam de affiniteit met preëclampsie, toen ook al het onderwerp van studie, toe. In 2006 zette zij dan ook haar werk voort als promovenda bij deze afdelingen. Het onderzoek naar het herhalingsrisico op preëclampsie heeft geresulteerd in dit proefschrift.

Simone deelt het leven met haar jeugdliefde Bas Krekels. 
